Florida International University

FIU Digital Commons

FIU Electronic Theses and Dissertations

University Graduate School

1991

\title{
An evaluation of a curriculum response to the State of Florida mandate for computer literacy at a large comprehensive high school in Dade County, Florida
}

Beverly Arlene Broughton

Florida International University

DOI: $10.25148 /$ etd.FI14051851

Follow this and additional works at: https://digitalcommons.fiu.edu/etd

Part of the Curriculum and Instruction Commons

\section{Recommended Citation}

Broughton, Beverly Arlene, "An evaluation of a curriculum response to the State of Florida mandate for computer literacy at a large comprehensive high school in Dade County, Florida" (1991). FIU Electronic Theses and Dissertations. 1815.

https://digitalcommons.fiu.edu/etd/1815 


\title{
ABSTRACT OF THE DISSERTATION
}

An Evaluation of a Curriculum Response to the State of Florida Mandate for Computer Literacy at a Large Comprehensive High School in Dade County Florida

by

\author{
Beverly Arlene Broughton \\ Florida International University, 1991 \\ Miami, Florida \\ Professor Stephen Fain, Major Professor
}

Minimum Student Performance Standards in Computer Literacy and Science were passed by the Florida Legislature through the Educational Reform Act of 1983. This act mandated that all Florida high school graduates receive training in computer literacy. Schools and school systems were charged with the task of determining the best methods to deliver this instruction to their students.

The scope of this study is to evaluate one school's response to the state of Florida's computer literacy mandate. The study was conducted at Miami Palmetto Senior High School, located in Dade County, Florida. The administration of Miami Palmetto Senior High School chose 
to develop and implement a new program to comply with the state mandate - integrating computer literacy into the existing biology curriculum.

The study evaluated the curriculum to determine if computer literacy could be integrated successfully and meet both the biology and computer literacy objectives. The findings in this study showed that there were no significant differences between biology scores of the students taking the integrated curriculum and those taking a traditional curriculum of biology.

Student in the integrated curriculum not only met the biology objectives as well as those in the traditional curriculum, they also successfully completed the intended objectives for computer literacy. Two sets of objectives were successfully completed in the integrated classes in the same amount of time used to complete one set of objectives in the traditional biology classes. Therefore, integrated curriculum was the more efficient means of meeting the intended objectives of both biology and computer literacy. 
FLORIDA INTERNATIONAL UNIVERSITY

Miami, Florida

\begin{abstract}
AN EVALUATION OF A CURRICULUM RESPONSE TO THE STATE OF FLORIDA MANDATE FOR COMPUTER LITERACY AT A

LARGE COMPREHENSIVE HIGH SCHOOL IN

DADE COUNTY FLORIDA
\end{abstract}

\begin{abstract}
A dissertation submitted in partial satisfaction of the requirements for the degree of Doctor of Education in Curriculum and Instruction - Instructional Leadership
\end{abstract}

\title{
by
}

Beverly Arlene Broughton 
c Copyright by

Beverly Arlene Broughton

1991 
To Professors: Dr. Stephen M. Fain, Dr. Barry Greenberg, Dr. Janice Sandiford, and Mr. Peter Bucholtz.

This dissertation, having been approved in respect of form and mechanical execution, is referred to you for judgement upon its substantial merit.

Dean 1 . Ira Goldenberg College of Eduqation

The dissertation of Beverly Arlene Broughton is approved.

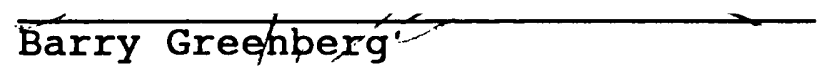

Janice Sandiford

Peter Bucholtz

Stephen M. Fith, Tajor Professor

Deah Rithard L. Campbell

Division of Graduate Studies

Florida International University, 1991 


\section{Dedication}

This dissertation is dedicated to:

$$
\text { Mrs . Emma R. Broughton - Mom }
$$

who has always been there for me through every high or low in my life. She has shared my joys, dried my tears, and helped calm my fears. Her inspiration has guided me throughout my education and taught me that giving up was never an option. 


\section{Acknowledgements}

The completion of this dissertation was made possible by the many contributions of committee members, professional colleagues, and friends. First and foremost, I would like to extend my most sincere expression of gratitude to Dr. Stephen Fain, committee chairman, for his guidance, encouragement, and assistance throughout this study. Dr. Fain's tutelage has opened to me a fascinating field of study - education. I would also like to extend my appreciation to Dr. Barry Greenberg, Dr. Janice Sandiford, and Mr. Peter Bucholtz for their willingness to serve as committee members and for their encouragement and guidance throughout this study.

A special expression of appreciation is extended to the faculty of Miami Palmetto Senior High School Science Department for their support and efforts needed to complete this study. Special mention is due to Jim Berty, Ann Davis, Lynn Fuscillo, and Foster Smith who implemented the curriculum in their Biology classes and collected the data for this study.

Most of all I would like to thank my family and friends, Bill, Jay, Cullen, Fred, Lynn, Foster, Jim, 
Karen, Diane, and Carl for their limitless source of encouragement, love, patience, and support throughout this research project. 
June 5, 1952

1971, B.A.

1979, B.S.; M.S.

$1979-1984$

1984

$1984-1991$

1987, SEd

1988-1989

1989

1990

1991

1991-1992
Born, Shelbyville, Kentucky

Bible, Home Economics

Kentucky Christian College

Grayson, Kentucky

Vocational Home Economics

Morehead State University

Morehead, Kentucky

Principal

Quail Roost Christian School Miami, Florida

Outstanding Young Women of America

Science Teacher

Palmetto Senior High School

Computer Education

Barry University

Miami, Florida

Computer Instructor

Palmetto Adult Education

Adjunct Instructor

Teaching Lab

F.I.U.

Distinguished Alumna Award Outstanding Achievement in Teacher Education

Kentucky Christian College

Adjunct Professor Computer Education

Barry University

Cadre Chairperson

SBM/SDM Executive Board

Palmetto Senior High School 
TABLE OF CONTENTS

Page

Dedication . . . . . . . . . . . . . . . ii

Acknowledge . . . . . . . . . . . . . . iii

Table of Contents . . . . . . . . . . . . . iv

List of Tables . . . . . . . . . . . . . viii

Chapter

I. INTRODUCTION . . . . . . . . . . . . . 1

Background of the Problem . . . . . . . . 3

Statement of the Problem . . . . . . . 8

Purpose of the Study . . . . . . . . . . 8

Statement of the Hypothesis . . . . . . . . 9

Definition of Terms . . . . . . . . . 11

Limitations of the Study . . . . . . . . . 14

Assumptions . . . . . . . . . . . . . 14

Organization of the Study . . . . . . . . 15

II. REVIEW OF THE IITERATURE . . . . . . . . . 17

What Constitutes Computer Literacy or Computer

Education? . . . . . . . . . . . . 17

Is There a Need for Computer Literacy in the

Schools? .................. 21

Gender Differences in Computer Education . . . 23

Curriculum Evaluation . . . . . . . . . 34 
Florida State Mandates Covering Computer

Literacy . . . . . . . . . . . . 36

Dade County Public School's Response to Florida

State Mandates Covering Computer Literacy . . . 42

What is Integrated Curriculum? . . . . . . 51

Integration of Microcomputers into Science

Curriculum . . . . . . . . . . . . 53

Computer Education at Miami Palmetto Senior High

School . . . . . . . . . . . . . . . 56

Summary of Findings in the Literature . . . . . 67

III. RESEARCH METHODOLOGY . . . . . . . . . 70

Selection of the Sample . . . . . . . 70

Instrumentation . . . . . . . . . 72

Historical Analysis . . . . . . . . . 72

Miami Palmetto Senior High School's Approach to

/Computer Literacy . . . . . . . . . . . 73

Procedures . . . . . . . . . . . 75

Basic Design and Analysis of Data . . . . . . 77

IV. ANALYSIS OF DATA . . . . . . . . . . 80

Initial Equivalence of the Groups . . . . . 80

Hypothesis \#1 . . . . . . . . . . . 82

Hypothesis \#2 . . . . . . . . . . . 83

Hypothesis \#3 . . . . . . . . . . . . 85

Summary . . . . . . . . . . . . 86

v. SUMMARY, CONCLUSION, AND RECOMMENDATIONS • • . 88 
Summary . . . . . . . . . . . . . 88

Results and Discussion . . . . . . . . 89

Conclusions . . . . . . . . . . . . 104

Implications . . . . . . . . . . 105

Recommendations . . . . . . . . . 107

BIBLIOGRAPHY . . . . . . . . . . . . . 110

APPENDIX

A. Computer Education Courses - Miami Palmetto

Senior High School . . . . . . . . 138

B. Graphs of MPSHS Computer Education

Enrollment .............. 148

C. Computer Literacy Pre/Post Test . . . . 149

D. Biology Pre/Post Test . . . . . . . 167

E. Raw Data . . . . . . . . . . . . 182

F. Letter of Approval from Dade County Public Schools ............... 191

G. Letter - Bill McCreary, Science Department Head, Miami Palmetto Senior High School • 193 


\section{LIST OF TABLES}

Table

Page

1. Chi-Square Test for Equivalence of the Groups for Sex................ 81

2. Chi-Square Test for Equivalence of Groups for Ethnic Group Membership . . . . . . . . 81

3. Chi-Square Test for Equivalence of Groups for Passing Grades . . . . . . . . . . . 82

4. Analysis of CoVariance . . . . . . . . 83

5. Comparison of Biology Pre/Post-test By Sex • . 84

6. History of Computer Education at MPSH . . . . 148

7. Biology / Computer Literacy Raw Data • . 182 - 190 


\section{CHAPTER I}

\section{INTRODUCTION}

Few innovations in education have fired the imaginations of classroom teachers as has the introduction of the microcomputer. The potential benefits of microcomputer applications for both instruction and teacher support were so evident to educators and their capability of changing educational methods seemed so great that their impact on education during the 1980's was spoken of as the 'Microcomputer Revolution.' (Roblyer, $1989)$.

The era when one or two isolated computer courses as a standard of many curricula is rapidly drawing to a close. The availability of microcomputer systems in the nation's schools has increased dramatically over the past several years. Computer systems were available to more than 67 percent of teachers nationally by 1984 (Ingersoll and Smith, 1984). That number has increased to over 90 percent of today's teachers and students (Dickey and Kherlopian, 1987) •

The first few years of the educational use of computers was a time for learning about the existence of 
small, affordable, desktop-sized computers and contemplating the possibilities they presented. In many ways these were exciting times because the usefulness of these machines seemed limited only by one's imagination and funds. The challenge was to think up new ways to use this powerful resource and find the money to carry out the plans (Roblyer, 1988). They were seen as an educational tool not as an unique part of the curriculum.

As more microcomputers came into the schools, they evolved from a means to help drill math facts to a possible solution to a growing need of society preparing our youth for the 'information age'. Computers are the tools that provide access to information in our world today (Molner, 1981). But the effective use of these tools requires knowledge, skill, and affective orientation. Since computers are not yet within the easy reach of every family, and since many parents feel incapable of guiding their children's learning through a medium with which they have had little experience, schools are widely seen as the most appropriate setting in which to prepare our students in computer literacy (Becker, 1984 ) •

The question facing educators was how to best go about preparing our students to enter a world that is 
rapidly becoming (if not already) a computer-dependent society. It is anticipated that the results of this research might provide valuable insight into one method of infusing the computer into an already crowded curriculum - the effective integration of computer technology into a previously traditional classroom.

\section{Background of the Problem}

More and more states, recognizing the societal impact computers are having on education and training are mandating computer literacy courses in teacher training programs and certification requirements (Lenkway, 1986). Certain computer literacy concepts are now included as part of the minimum student performance standards of all of the nation's youth.

Like many other states, the state of Florida has acknowledged the need to educate all of its students in computer literacy by developing and adopting minimum student performance standards in computer literacy. Minimum Student Performance Standards in Computer Literacy and Science were mandated by the Florida Legislature through The Educational Reform Act of 1983. These standards identify the minimum competencies expected of 
students not impaired by a mental or physical handicap. The Minimum Performance Standard in Computer Literacy for Florida's Schools are designed to ensure that all Floridians have the minimal competencies they need to deal with computers in their everyday lives. It is important to remember that these are minimum competencies, and that they do not reflect the higher standards that many school districts many expect of their student (Boulware, et. al., 1987). Neither do they mandate a means whereby the school systems were to insure that these standards were met.

"Revolutions have a way of mandating change while glossing over the logistical details of how to implement that change, and such has certainly been the case with the 'Microcomputer Revolution' in education. (Roblyer, Castine, and King, 1988). Adopting a set of standards for any curriculum area is only of value if the school systems provide the opportunity for the students to meet those standards.

The primary focus of computer education courses varies from school system to school system across the country. The Minimum Student Performance Standards for Florida Schools for secondary level, while containing some items on computer operations and program development, clearly place the emphasis on learning computer 
applications and computer uses in and impact on society (Roblyer, 1989). In most schools, computer education and/or computer literacy still seems to be an activity which goes on primarily in specially designated courses, rather than in the context of other content areas. Collis (1988) states that one reason for this is the fact that using computers effectively requires change in established teaching styles. She points out that 'teachers have preferred teaching styles, just as students have preferred learning styles, and that teachers have used primarily lecture/demonstration methods and directed seatwork for so many years that they are frequently reluctant to alter these familiar patterns. This tendency to use traditional methods is frequently reinforced in teachers' pre-service training, where traditional methods are used to teach them. Roblyer (1989) states that regardless of the reasons for the prevalence of traditional methods, it is clear that current methods are often ineffective in helping students learn, in preventing them from losing interest in school work, and in addressing some of the skills now being stressed in schools. Using computer applications seems an especially viable alternative to traditional methods when teaching 
students to use cooperative learning methods and inductive approaches to solving problems in real-life situations.

However, innovation proceeds slowly in education, and often with good reason. Experience has shown that largescale curricular revisions do not necessarily mean progress. Several recent national reports acknowledge that inadequacies currently exist in our curriculum and in our instructional methods (National Commission on Excellence in Education, 1983). Microcomputers are not miracle machines. The use of microcomputers in the classroom will not solve all the problems that are now perceived in education today. However, it is possible to promote higher-level 'thinking skills' and 'learning to learn' kinds of activities in the context of a structured, curriculum-based lesson (Mojkowski, 1987).

The evolution of the microcomputer movement in education is at a critical stage. Research results seem to indicate that many microcomputer applications do indeed have great potential for helping teachers raise the quality of instruction (Roblyer, Castine, and King, 1988). The problem at this stage is that many educators are unsure of how microcomputer applications should be integrated into the instructional activities they are already doing in order to enhance the overall 
instructional experience for instructional experience for the student.

Many teachers are willing to adapt their teaching methods and use computers in order to enhance their students' learning, however, they realize that using computers requires extra time for planning and handling logistics. They must be able to see the benefits which will make this time investment worthwhile to them (Collis, 1988). The decision to change from traditional methods to innovative ones is often difficult, but when there is a clear choice between old, ineffective methods and newer, more effective approaches, the likelihood is greater that teachers will make the transition (Roblyer, 1989). The major goal of this body of research is to show how one school used the integration of the microcomputer into the curriculum in order to not only improve the quality of instruction in content area, but also allows school to meet the state mandates in computer literacy without forcing another distinct course into an already overloaded curriculum. What this study in effect is calling for is the recognition that microcomputers are an effective instructional tool which can not only improves classroom learning, but also provides the student with the 
'computer literacy' skills necessary to function in a 'computer-dependent society.'

\section{Statement of the Problem}

The problem considered in this study is what specific changes occurred at one large suburban school, Miami Palmetto Senior High School, as a result of the Florida state mandate for computer literacy. A secondary problem to be examined is the effectiveness of this curriculum change to meet the Minimum Student Performance Standards in both Computer Literacy and in the content area effected, Biology.

\section{Purpose of the Study}

The purpose of this study was to examine one school's response to a state mandate for computer literacy. The State of Florida mandated that all Florida high school graduates be computer literate. In an attempt to comply with the state mandate teachers at Miami Palmetto Senior High School designed and implemented a program of integrating computer literacy skills into the existing Biology curriculum. Thus, the majority of students at 
Miami Palmetto Senior High School received computer literacy skills without being required to take an extra course.

The scope of this study did not include state and national comparative analysis. Instead, the comparative analysis was between two "kinds of sets of learning opportunities provided" (Saylor, Alexander, and Lewis, 1981). The two sets of learning opportunities provided are the traditional curriculum and the integrated curriculum. This study was conducted to determine the effectiveness of integrating the microcomputer into the content area curriculum as a viable solution to state mandates involving computer literacy.

It is projected that the results obtained from this study will provide insight into the process of accommodating external policy into local school curriculum. More directly the results will encourage more educators to take advantage of the microcomputer as an effective tool in improving instruction.

\section{Statement of the Hypothesis}

Upon review of the previous related studies, the following null hypothesis have been formulated: 
Null Hypothesis \#1: There will be no significant difference in the percentage students earning passing grades in Biology between those students taking the traditional biology curriculum and those taking the integrated curriculum of biology and computer Literacy.

Null Hypothesis \#2: There will be no significant difference on a Biology Posttest between students receiving the integrated curriculum of biology and computer literacy and those receiving Biology in a traditional classroom. Null Hypothesis \#3: Fewer than 808 of the students receiving the integrated curriculum of Biology and Computer Literacy will successfully meet the intended objectives for Computer Literacy as demonstrated by obtaining a passing grade in Computer Literacy for the semester. 


\section{Definition of Terms}

INTENDED OBJECTIVES: $\quad$ A curriculum objective is a purpose or end stated in specific, measurable terms. Curriculum planners wish students to accomplish it as a result to exposure to segments or all of a program of a particular school or school system." (Oliva, $1988)$ •

Objectives are formulated to organize content and learning experiences in behavioral terms; that is content and experiences are stated in such a way as to be observed and measured. Consequently, many objectives are also called behavioral objectives. Objectives are generally written at three levels of instruction: subject/grade level, unit plan level, and lesson plan level (Posner and Rudnitsky, 1986). According to Tyler (1949), the source of objectives most commonly used in typical schools and colleges is the suggestions about objectives from subject specialists. Courses of study prepared by school and college groups are usually worked out by subject specialists and represent their conception of objectives that the school should attempt to attain. 
The curriculum objectives, or intended objectives referred to in this paper have been prepared by subject specialists and classroom teachers in the Dade County Public School system. Once adopted by the school system these objectives are provided to each teacher of Biology and Computer Literacy. The expectation then is that unit plans and lesson plans prepared by the classroom teacher will be based upon these objectives. Dade County Public School Objectives for Computer Literacy and Biology can be found in the appendix of this paper. Curriculum Evaluation: "Instructional evaluation" is an assessment of (1) pupils' achievement, (2) the instructor's performance, and (3) the effectiveness of particular a approach or methodology. "Curriculum evaluation" includes instructional. Curriculum evaluation also goes well beyond the purposes of instructional evaluation into assessment of the program and related areas. "The primary purpose of curriculum evaluation is, of course, to determine whether the curriculum goals and objectives are being carried out" (Oliva, 1988).

There are many models which have been developed showing types of evaluation that schools should carry 
out and the processes they should follow. Evaluation models differ in detail and the points which their creators choose to include. For the purpose of this paper and this study, the Saylor, Alexander, and Lewis model (Saylor, Alexander, and Lewis, 1981) will be used as a guide.

Traditional Curriculum: The traditional curriculum as referred to in this paper is the Biology curriculum without the inclusion of Computer Literacy. The intended objectives for Biology are the same as those in the Integrated Curriculum, but only Biology is being taught. Traditional methods of instruction include lecture, discussion, group study, labs, and any other methods which do not include computer technology

\section{Integrated Curriculum: "By integration we mean the} blending, fusion, or unification of disciplines." (Oliva, 1988). The term integrated is used in this paper to describe Miami Palmetto Senior High School's curriculum program of combining the disciplines of Biology and Computer Literacy. 


\section{Limitation of the Study}

This study will be limited in scope to the degree that:

1. Only those students taking Biology and Honors Biology at Miami Palmetto Senior High School will participate in this study.

2. Only those student starting the semester and ending the semester with the same teacher will participate in this study.

3. Only teachers assigned to Biology and Honors Biology at Miami Palmetto Senior High School will participate in this study.

4. The results of this study may not have universal application to all schools due the to nature of Miami Palmetto Senior High School as a college prep oriented school with a repetition of being academically aggressive.

\section{Assumptions}

The basic assumptions of this study are that:

1. The students participating in this study are no different than of other students found in any large 
comprehensive high school which is academically oriented.

2. Teachers involved in this study are interested in working in an academically aggressive environment and have ownership in a college oriented curriculum.

\section{Organization of the Study}

This study was presented in five chapters. Chapter I stated the problem and purpose of the study, hypothesis, definition of terms, and limitations of the study. Chapter II was devoted to a review of related research and literature related to the problem of the study. This chapter also included a background for Florida state mandates covering computer literacy and Dade County Public School's response to society's need for computer literate students and Florida state mandates covering computer literacy. Finally, this chapter described Miami Palmetto Senior High School's interpretation and implementation of Florida state mandates covering computer literacy. Chapter III described the subjects, the treatment procedures, measuring instruments and tests, and the procedure employed to solve the problem. Chapter IV consisted of the presentation of the data along with 
statistical analysis of the data collected in the study. Chapter V presented the summary, conclusions, discussion, and recommendations for further research. 
CHAPTER II

REVIEW OF THE LITERATURE

What Constitutes Computer Literacy

or Computer Education?

The definition of computer literacy is constantly changing as people become more aware of the capabilities and usage of computers. An early definition simply states that "computer literacy is knowing about computers. What they are, how they work, and what they can and cannot do" (Laubacher, 1982). Watt (1980) defines computer literacy as a "cultural phenomenon which includes the full range of skills, knowledge, understandings, values and relations necessary to function effectively and comfortably as a citizen of a computer-based society." He feels that the mere knowledge of computer should be considered computer awareness.

Moursund (1975) has defined computer literacy as knowledge of the non-technical aspects of the capabilities and limitations of computers. He includes in his definition the need to know about the societal impact of computers and the potential for future development. 
Johnson, Anderson, Hansen, and Klassen (1980) came up with a similar definition which included an evaluation instrument that covered both cognitive and affective objectives based upon this definition. They called their instrument the Minnesota Computer Literacy and Awareness Assessment (MCLAA). The affective objectives relate to the degree of pleasure related to computers, level of stress attributed to computers, level of confidence exhibited in working with computers, and attitude toward the use of computers in schools. The cognitive objectives relate to a basic understanding of the major components of a computer (hardware), basic understanding of storage systems for programs and data (software), basic knowledge of how computers are used in society, and possible positive and negative effects of computer use.

Others (Luehrmann, 1984 Papert, 1980; Randhawa and Hunt, 1984; Self, 1983) feel the need to include computer programming as part of any definition of computer literacy. Randhawa and Hunt argue that unless computer literacy includes programming it is limited because it does not provide the user for the "freedom and autonomy that comes with an understanding of and the confidence to be able to manipulate the computer with which a person works." 
The National Science Board recommends that all students become familiar with a computer language so that they can use the computer to solve specific problems that arise in their schoolwork. Learning to program also helps student to develop skills in visualization and logical reasoning. Furthermore, students who learn programming also learn about the capabilities and limitations of the computer and how the computer processes information (Flake, McClintock, and Turner, 1985, p. 333).

Melmed (1985) argues against the need for programming in any definition of computer literacy stating that a computer literate person does not need to program a computer, but rather must effectively be able to use the computer. He compares using a computer to driving a car one does not need to know how a car works in order to drive one.

A review of the literature makes it apparent that there is no agreement as to what computer literacy is or should be, even among computer experts. A major problem faced by experts is the rapid change in the field of computers - what was needed to be computer literate in 1984 is not necessarily the same as what is needed to be computer literate in 1988. Anderson (1980) suggests that 
this need not be a problem, if one accepts the fact that "computer literacy is a matter of functioning effectively within a given role." Brumbaug (1980) further emphasizes that whatever the definition of computer literacy becomes, and whether or not programming is one of the requirements, the primary focus should be on individualization of instruction, with learner-based materials available to everyone, at all educational levels.

The definition of computer literacy used by the state of Florida in the 1983 revision of the Accountability Act includes the following six standards and will be used as the basis for this paper.

A. The student will operate a computer for an instructional purpose by loading and running programs.

B. The student will understand the function of the basic parts of a computer.

C. The student will understand the role and function of software and languages in computer technology.

D. The student will recognize the impact of computer technology in society and the need for its ethical use.

E. The student will understand the capabilities and applications of various computers and computer systems.

F. The student will understand the process of programming.

It was determined by the state of Florida that the ability to program in any language was not an appropriate requirement for all students (Lenkway, 1986). 
Is There a Need for Computer Literacy in the Schools?

At the turn of the century John Dewey (1915) took a long, hard look at American education and proclaimed that educators had yet to make the changes called for by the Industrial Revolution. Dewey specifically identified waste of human potential - waste related to the child's experience in school and to the child's ill-prepared future. Dewey pressed schools to adapt to the new industrial changes.

Dewey's example serves well as guidance for public education in the Information/Technological Revolution (Watson, Calvert, and Brinkley, 1987). It is generally agreed that computers are the dominant technological artifact of our time (Gordon, 1983; Grayson, 1984; Hannafin, Dalton, and Hooper, 1987; Murphy and Pardeck, 1985; Roblyer, 1989; Steier, 1987). Lepper (1985) states that we are currently on the edge of a revolution in technology that may eventually prove more sweeping and significant than any other technological advance in the last 200 years -- the revolution that is likely to occur as powerful microcomputers begin to infiltrate our lives. 
Masuda (1980) describes computer technology as fueling a transformation from an industrial society to an information society.

The United States has rapidly become a computerdependent society, as computers have proliferated and impacted every aspect of the nation's life. In addition to the more observable applications of recognizable computers ranging from supercomputers to minis and micros, computers-on-chips are becoming components in a wide variety of products and processes. Leading futurists such as John Naisbitt (1982) and Alvin Toffler (1980) have forecasted increasing numbers of computers and computer applications, the continued emergence of low-cost but powerful computers, and an expansion of the role computers will play through society.

The time for debate over if there is a need for the schools to respond to the "computer age" is past (Barnes and Hill, 1983; Luehrmann, 1985; Papert, 1980; Watson, Calvert, and Brinkley, 1987). Baumbach (1987) states that most jobs today are computer related and predicts that in the future almost everyone in the workforce will rely on computers in everyday life. Within an information society such as ours, citizens without relevant skills are at a serious disadvantage (Becker, 1984; Luehrmann, 1982; 
Molnar, 1978). Green (1985) states the belief that students who do not have a sufficient background in computer literacy are not only unprepared for the jobs of today, but are also experience "psychological obsolescence." Whatley (1984) argues that those who do not have such skills will be considered functionally illiterate. He argues that we owe it to our students to insure that they will not be functional illiterates and to provide training in those entry level skills that will give them the best chance at employment in today's and tomorrow's market.

\section{Gender Differences and Computer Education}

Historically, men and women have received different and unequal opportunities for professional development. Subtle gender biases pervade all of American education (Anderson, 1972). Distinctions in language and social conventions continue to differentiate men and women and to unnecessarily exaggerate gender differences. Fortunately, Americans are becoming more sensitive to distinctions made between the sexes, and some progress has been made toward a more equitable distribution of resources and opportunities between men and women. 
In a survey of research related to inequities in opportunities for computer literacy, Ondersn, Welch, and Harris (1984) found disparities in usage and access to computer training. These inequities related to wealth (rural/ghetto vs. urban/rich areas); community size (big, inner city/rural vs. small city/suburban); region (South vs. West, North, and Central); gender and race. Lack of access and opportunity for computer training would seem to imply attitudes that the poor, minorities, and females are less suited to training in computer usage than are middle and upper income, Caucasian males. These findings have been supported by other researchers (Becker and Sterling, 1987; Chambers and Clark, 1987; Reyes and Stanic, 1988; Schubert, 1986; Smith, 1987).

While computers flourished in our schools, certain groups of students are being bypassed by the computer revolution. Those students fall into four categories: minorities, female, economically disadvantaged students, and handicapped (Richman, 1988). What causes this inequality with regard to the computers in education is the subject of many studies by curriculum and computer specialists. The one group that has caused the most disagreement among the experts is that of gender differences. While most researchers agree that there is 
some difference between male and females in the computer classroom, they cannot agree on just what that difference is or what causes it.

Miura and Hess (1984) studied enrollment in computer camps and summer classes. They found that boys out numbered girls by about three to one, with 988 of enrollers being middle or upper income, and 918 described as Caucasian. Out of school opportunities in museums that house computer programs also report experiencing low female enrollments. A survey of 1,242 people by USA TODAY (Manning, 1984) found males to be the main users of home computers, with adult males accounting for about 438 of the use, followed by male children, 278 of whom were the main computer users in their household. Only 158 of female adults fell into this category, with female children (108) being least likely to be the main users of the computer. Other out-of-class opportunities where boys out number girls include both participants and observers in games arcades, entrants and winners of computer contests, and members of computer clubs (Chambers and Clark, 1987; Chen, 1986; Kiesler, et. al., 1984; Lockheed and Frakt, 1984; Parker and Widmer, 1984).

The causes of differences between the genders begins societal influences outside of school that send different 
messages to and about students of different race, sex, and socio-economic status regarding their aptitudes and the appropriateness of their achievement with computers (Reyes and Stanic, 1988). Examples of societal influences are the family, the community in which the child lives, religious institutions, the mass media, and the implicit messages that result from the pattern of prevailing occupational and other societal roles held by members of particular groups.

Ware and Stuck (1984) suggests that computer literature supports the belief that computer use is predominantly a male domain. Three mass market computer magazines dated October 1982, January 1983, and April 1983 were analyzed for (a) proportion of males and females represented, (b) settings in which they were portrayed, (c) roles they represented, and (d) ways males and females used the computer. The findings showed: men appeared twice as often as women; women were over-represented in stereotypic and traditional jobs such as clerical worker; men were over-represented as managers and computer experts; and women were depicted as passive computer users (Ware and Stuck, 1984). This perception of computers as a male domain is reflected in many ads for computers and in much of the software as well, underscoring the message for 
females that they have a secondary or peripheral role in the world of computing (Schubert, 1986).

Attitudes towards computers is not consistent across the genders when age is considered. In a study if 491 students from all grade levels, Smith (1987) found that sex related attitudes toward computers had both predictable and hopeful aspects. Elementary female students had the highest mean scores of all female students on a confidence scale. Female junior high students in this study had higher confidence levels than did the male students, While equality of opportunity may have resulted in responses showing younger females having more positive attitudes, older female students has less confident attitudes. Older female students showed a strong belief in the ability of both sexes to use computers or to have computer careers. Females' confidence in their computer skills appeared to decrease with age. Smith (1987) states that older females feel less competent because they have not "grown up" with computers. It also seems plausible that the sociocultural influences that are believed to influence sex related differences in older populations may not yet be present in younger, elementary children. 
These findings are supported by those of Swadener and Hannafin (1987). These researchers studied sixth-grade boys and girls and found that there was an absence of sexbiases toward computers at this age. However, they found that there was a pronounced bias among older learners, such as high school and college students.

A study of more than 1,800 eighth- and twelfth-grade students in two British Columbia school districts revealed gender differences in attitudes toward computers and found that these attitudes were established by the eighth grade. This study also revealed that females agreed that they have as much ability as males when learning to use computers. However, this confidence appears to be in the abstract because items assessing personal competency and self-confidence showed an absence of these abilities (Collis, 1985).

The results of the "Second National Survey of Instructional Uses of School Computers" (Becker and Sterling, 1987) support these studies. The overall computer use among $k-6$ schools was reported that a 50-50 split between boys and girls. By the high school years, a great many schools reported substantial male dominance.

The association between computers and traditionally male interests - e.g. math and machines -contribute to 
differential interests in computers (Sanders, 1984). There is evidence that sex-role stereotyping begins early in life (Boswell, 1979, Cohen and Cohen, 1984; Parsons, Kaczala and Meece, 1982). Mathematics and physical science are among the most strongly stereotyped areas of study; they are considered masculine and unfeminine (Cohen and Cohen, 1984; Kaczala, 1981). These stereotypes are carried over into computer related subjects. Even girls with a strong math and science aptitude traditionally drop out of the math/science/computer track by their junior year in high school. Parental and teacher expectations, peer pressure, and a narrow vision of future careers are some of the factors that can affect a girl's decision not to pursue high-level courses in math, science and computer science (Richman, 1988).

The question of gender difference in math and science has been studied by many researchers with sometimes conflicting results. During the preschool years, no important gender-related differences in mathematical ability appear. At the end of elementary school, boys begin to excel in mathematical reasoning, and the difference become greater in high school, college, and adulthood (Sherman 1980; Maccoby, 1966). New studies have shown no male dominance in mathematics (Fennema, 1982). 
New studies show that male dominance in mathematics may be related to the way mathematics is traditionally taught -as a competitive individual endeavor rather than a cooperative small-group learning activity. When basic mathematics is taught in cooperative small groups, girls do better than boys (Fennema and Peterson, 1987). Hyde (1981) estimated that if gender differences exists, these differences would account for only 1 percent of the variation in quantitative ability between girls and boys.

Regardless whether the difference is cognitive or something else, sciences and maths are not taken as much by girls as boys and this effects way girls perceive computers and computer careers. Many computer careers involve the completion of advance course work requiring higher mathematical achievement, spatial ability, or both. Girls' consistently lower performances in these areas are deterrents to their entering and succeeding in these careers (Klausmeir, 1985).

The trend continues through college, where females are less likely to earn degrees in computer science than are males. In 1981 females in the United States earned 32.58 of the bachelors' degrees and 238 of the masters' degrees in computer science (Vetter, 1983). At the University of California at Berkeley currently has about 
378 of the computer science majors are females. Thus, female participation at the college level in cognitively demanding computer learning environment corresponds to participation at lower grade levels (Linn, 1985).

Females participate more frequently in courses which are less likely to foster higher cognitive skills. Interest among females in using computers seems to heighten when females use the computer for word processing (Lockheed, 1985). Females enjoy creating stories (Schubert, 1984) and using programs for music and art (Sanders, 1984). Females are more positive than males on items related to pleasure in writing stories, essays, and compositions on the computer (Collis, 1985).

In a study in California (Linn. 1985), females constituted 428 of the 51,481 participants in high school instruction which involves computers, but they represented 868 of the students in word processing courses and only 378 of the students in programming courses. These results are supported by other studies (Becker, 1987; Chambers and Clarke, 1987; Fetler, 1985; Schubert, 1986; Swadener and Hannafin, 1987).

According to Fisher, the selection of software also tends to favor males. Symbols and images that may be more attractive to males, such as racing cars that display 
student scores and space images that reinforce correct responses, suggest that these are male, not female activities (Fisher, 1984). Other courseware used in computer instruction also has been recognized as being sex-biased in favor of males. For example, stylistic characteristics that invite aggression or competition hold more interest for males than females. (Gage and Berliner, $1988)$.

Like the literature on gender differences in computer education, research of other areas of gender differences shows the same trend. Maccoby (1966) and Maccoby and Jacklin (1974) reviewed literature in gender differences in intellectual functioning and reported that the research does not show consistent differences. Hyde (1981) claims that because of the inconsistent reports it is unreasonable to explain the differential achievement on the basis of innate physiological differences. Rather, performance differences between the sexes are for the most part learned behaviors that are induced by societal expectations, the behavior of adults, and other cultural pressures.

Despite laws against sex-discrimination, the women's movement, and a greater awareness of the need to treat the sexes equally in school, marked degree of sexism can still 
be found in American classrooms (Sadker and Sadker, 1985). Overt discrimination against females has decreased, yet young women are subtly counseled away from drafting and engineering courses and computer related courses. These vocational-technical courses hold the potential for greater lifetime economic return than do courses in cosmetology or clerical work. Counselors often indicate that young women who have interests in "masculine" careers were in need of counseling, but that young women who had interests in "feminine" careers were making appropriate choices (Bornstein, 1982).

Gender roles and gender differences in performance are topics that have long been of interest to educators and researchers. The entry of computers onto the educational scene has only added to the questions without offering definitive answers. Deaux (1984) claims that behavior is influenced to some extent by biological gender, but also is heavily influenced by individual choices, situational pressures, and the types of persons an individual regularly meets in social situations. 


\section{Curriculum Evaluation}

The Saylor, Alexander, and Lewis Model of curriculum evaluation was used as a guide in this study. The Saylor, Alexander, and Lewis model calls for evaluating five

components: 1) the goals, subgoals, and objectives; 2) the program of education as a totality; 3) the specific segments of the education program; 4) instruction; and 5) evaluation program (Oliva, 1988; Saylor, Alexander, and Lewis, 1981).

Saylor, Alexander, and Lewis include as their first component the goals, subgoals, and objectives. In evaluating this component they conclude that the curriculum planners must include an analysis of the needs of the society, an analysis of the needs of the individual, consider the goals, subgoals, and objectives of various groups and subject matter specialists, and finally the use of previous summative data (Oliva, 1988). According to Saylor, Alexander, and Lewis the learners' total educational environment, the characteristics of the learners and the teachers, classroom interaction, and the curriculum design are all evaluated and may affect the choice of instructional goals and objectives (Saylor, Alexander, and Lewis, 1981). The 
use of criterion-referenced and norm referenced tests and other evaluative techniques provide formative and summative data on the success of instruction (Oliva, $1988)$.

Saylor, Alexander, and Lewis (cited in Oliva, 1988, p. 473 , included within their concept of specific segments the following:

the plan for organizing curriculum domains, the designs of the curriculum for each domain, courses offered, other kinds of sets of learning opportunities provided, extra instructional activities sponsored, services provided students, and the kinds of informal relations that characterize the institutional climate.

Saylor, Alexander, and Lewis (1981) recommended formative evaluation of the program of education as a totality by means of "judgment of competent persons, research data on human needs, recommendations of study groups." The recommended summative evaluation of the educational program through "surveys; follow-up studies; judgments of scholars, citizens, and students; test data" (Saylor, Alexander, and Lewis, 1981). 


\section{Florida State Mandates Covering Computer Literacy}

A review of documentation provided by the State Department of Computer Education provided the following history of computer education in the state of Florida.

In response to the Accountability Act of 1976 the Florida Department of Education developed Minimum Student Performance Standards in reading, writing, and mathematics at Grades 3, 5, 8, and 10. These standards were formally adopted in April 1977 and were based upon minimal objectives which were developed cooperatively by the Florida Department of Education, state universities and local school districts. An extensive review of these standards began in November 1977, and continued until February 1979. The revisions to standards prompted by this review are reflected in the document Minimum student Performance Standards for Florida Schools in Reading, Writing, and Mathematics, effective 1985-1990. Student performance, based upon these standards, is measured annually through the statewide assessment program. Mastery of the Grade 10 skills is required in order to receive a high school diploma (Florida state Department of Education, 1986 - 1991). 
In 1983 the Florida Legislature passed the Educational Reform Act of 1983, which expanded the Accountability Act of 1976 to include minimum student performance standards in science and computer literacy. Development of the minimum student performance standards in computer literacy began by setting up a statewide committee in January 1984. This writing committee, consisting of teachers, district supervisors and university professors, developed the initial draft of the standards and specific skills expected of students who progress successfully through Florida's public schools.

Two revisions have been completed since the original writing finished the first drafts. In March 1984, seven meetings were held across the state during which district teachers, supervisors and administrators invited from each of the sixty-seven (67) Florida school districts and the university laboratory schools. School and district parent advisory councils were also invited to participate. Special interest groups, such as parent-teacher organizations, school board members, and professional teacher and supervisor groups attended meetings arranged for them to review the standards and skills. Over forty (40) district superintendents set up special committees of appropriately-specialized personnel for the final review. 
Appropriate Department of Education program specialist assisted in the entire process. The input from these meetings was compiled to produce a second draft for the final field reviews.

The final standards and skills were approved by the State Board of Education on November 5, 1985. Like previous standards for reading, writing, and mathematics, these standards and skills will be covered in statewide assessment starting in 1989. By July 1, 1986, each district school board was required to address student mastery of these standards in its pupil progression plan as prescribed in Sections 232.2456(1)(b), Florida statues (Florida Department of Education, 1986-1991).

State curriculum planners recognized that most teachers who would be providing computer instruction in the classroom were not computer education experts. The Florida State Department of Education provided means to assist teachers in gaining the training and materials needed to provide this instruction. It has provided funds for teacher training and the development of materials to help teachers with simple strategies for the use of the computer in the classroom (Roblyer, 1989). Title II funds (Administered by the Instructional Technology office and designated for mathematics, science, foreign language, and 
computer education) are made available to groups of educators for the writing and publishing of instructional materials and activities which provide teachers with teaching strategies to make effective use of the microcomputer in the classroom (Yahn and Lenkway, 1989). Florida teachers can obtain instructional information and assistance in the use of microcomputers in the classroom from various centers located around the state which are funded by the state. The Florida Department of Education provides for Staff Training Resource Centers which address the needs related to teacher training. Broward County School District is one such center. The University of Central Florida houses a center which was established by the Florida Department of Education primarily to address the need for $\mathrm{K}-12$ computer literacy materials. It also produces other instructional computing resources. The Florida Center for Instructional Computing was established by the Florida Department of Education for the primary purpose of reviewing and evaluating software and publishing the results for Florida teachers (Roblyer, $1989)$.

The Florida Department of Education also funds six Regional Centers of Excellence in Mathematics, Science, Computers, and Technology. These centers are useful to 
teachers in a specific region or local area, where they can go to preview actual software. These centers are also involved in the writing of instructional materials for using the microcomputer in education. The centers are:

1. The Panhandle Regional Center of Excellence (East Site) - Florida A\&M University, Tallahassee.

2. The Panhandle Regional Center of Excellence (West Site) - University of West Florida, Pensacoloa.

3. The Crown Regional Center of Excellence University of Florida, Gainesville.

4. The East Central Regional Center of Excellence University of Central Florida, Orlando.

5. The South Regional Center of Excellence Florida Atlantic University, Boca Raton.

6. The West Central Regional Center of Excellence University of South Florida, Tampa. (Roblyer, 1989).

One of the general problems facing all computer-using educators is locating high quality software which fills the instructional need after the need has been identified. The State of Florida has initiated several programs to help schools get the computer resources they need. A 
state microcomputer contract has been developed to get the lowest possible prices on equipment and thus maximize dollars available for this purpose. A state-level committee has recently been set up to locate and obtain instructional software at discounted, bulk-purchase rates to meet certain high-profile needs. Some Florida school districts have also negotiated special software rates for their schools, and the Minnesota Educational Computing Corporation (MECC) software is available from the state to school district offices for the cost of copying the disks (Roblyer, 1989).

Mojkowski (1987) observes that "the current buzzwords, 'computer literacy' and 'integrating technology into the curriculum' is useless without clear specifications." While the state mandate lists the minimum standards and provides assistance to teachers it does not dictate how these standards are to be met. Each district was required by the mandate to provide appropriate instruction to assist students in the mastery of these standards (Yahn and Lenkway, 1989). The choice of how to go about doing this was left up to the districts. 


\section{Dade County Public School's Response to Florida}

\section{State Mandates Covering Computer Literacy}

Computer literacy is fast becoming a necessary and basic skill for survival in today's technological society. Recognizing this, the School Board of Dade County decided that a major goal of this system should be to develop a comprehensive, coordinated curriculum in the area of computer education (Neff, 1982 , p. 1).

Dade County Public Schools did not wait for mandates for the Florida Department of Education to recognize the benefits of microcomputers in the schools. Dade County Public Schools first acquired computers for its' schools in 1978. The first 10 instructional computers were TRS 80 Model I's and were used for math instruction. In 1982, the State of Florida reported there were 1068 microcomputers in Dade County schools: 736 Atari, 135 Radio Shack and 90 Apple, 50 Commodore and 50 others. The number of schools using microcomputers for instruction by purpose were reported as follows: computer literacy (92), math (88), programming (53), reading/language arts (48), social studies (25), vocational education (21), science (18), and exceptional education (15) (Di Muzio, 1990). 
The number of computers in Dade County Public Schools has increased from the original 10 in 1978 to over 15,000 as of October 1989. All elementary schools in 1989 had at least 12 microcomputers for instruction. Middle and high schools range in number from 25 microcomputer to over 100 . The Apple computer represents 50 percent of all the microcomputers used for instruction with the remainder being Tandy and IBM MS/DOS computers. The original Atari computers are gradually becoming obsolete (Di Muzio, $1990)$.

The acquisition of microcomputers has come about in several ways including purchases from school funding, donations, and PTA fundraisings. In 1990, Dade County Public Schools in cooperation with Publix supermarkets and Apple computers is acquiring computers through the donation of grocery receipts by shoppers to the school of their choice (Publix, 1990).

Schools that were constructed after 1985 have computers included as part of the initial building construction. New schools have been planned to include 3 computers per elementary classroom, 10-15 in the library/media center and at least one 30 computer lab with networking available throughout the school for elementary, middle, and high school levels. Networks are planned in 
all new and renovated classrooms. As of fall 1989, eleven schools have installed a computer network system in addition to individual computer systems (R. Oates, personal communication, February, 4, 1990).

Recognizing that teachers would need some guidance on simple strategies for enhancing their present teaching methods with computer resources, Dade County Public School produced the Computer Education Curriculum Guide during the summer of 1982. Included in this book was approved computer education courses and corresponding outlines for junior and senior high schools. Also included were the recommended units for the elementary school program. This curricular material was developed and reviewed in conjunction with experienced computer education teachers from various elementary, junior, and senior high school within the county. The information was intended to provide structure and uniformity to the scope and sequence of computer education courses. The curriculum guide was just that a guide, it was expected that program modifications would be necessary due to school-specific differences in such things as equipment type, software availability, or student capabilities (Neff, 1982). The latest revision on this curriculum was completed in 1989 (R. Oates, personal communications, February, 4, 1991). 
While the curriculum guide represented the computer education program for the Dade County Public School it still allowed for schools to determine the best way to provide the computer skills needed by their students.

The following courses of study are outlined in the Computer Education Curriculum Guide and represents Dade County Public School's plan for meeting the state mandates in computer literacy. Dade County Public Schools has not at this time published formal guidelines for integrating the computer into the content area classroom.

1. COMPUTER AWARENESS -- Primary-Intermediate This course is designed to establish computer awareness in grades three through six as well as to emphasize the computer's social impact.

2. WORKING WITH COMPUTERS -- Intermediate This course is designed to follow COMPUTER AWARENESS. WORKING WITH COMPUTERS stresses an understanding of computer functions and the processes needed, e.g., problem solving, languages. The final outcome should be a person knowledgeable in computer vocabulary and capable of using beginning BASIC programming. 
3. COMPUTER LITERACY -- Grades $7-12$

This introductory course is designed to enable students to understand the nature of computers and their impact on society. Topics covered include computer components and terminology, computer capabilities and limitations, computer careers, computer uses in various fields, and computer problem solving.

4. BEGINNING PROGRAMMING -- Grades 7 - 12

Designed to introduce students to the various uses of microcomputers; to give them an opportunity for hands-on experiences with a microcomputer; and to provide instruction and practice in BASIC programming.

5. COMPUTER APPLICATIONS -- Grades $9-12$ Designed to introduce students to the care and uses of microcomputers and to give them an opportunity for hands-on experience.

6. INTRODUCTION TO DATA PROCESSING -- Grades 10 12

This course is designed to give students a general view of the field of Data Processing. One purpose is to acquaint students with requirements of different occupations in Data 
Processing so that they may be guided in their choice of a career. Topics include history and development of computers, current uses of unit record equipment and computer systems, basic machine functions, organization of problems, storage media, input and output devices, and elementary techniques of programming.

Dade County Public School has gone far beyond the publication of a curriculum guide in attempting to help teacher introduce the computer in the classroom. Potential problems facing teachers attempting to use this new technology have been addressed and solutions given. Such problems include software acquisition, teacher training, and hardware purchases.

For Dade County Public Schools, software is available at reasonable cost through the Minnesota Educational Computing Consortium (MECC) program with whom Dade County Public Schools maintains an annual licensing contract. In addition to individual school provisions, teachers have the opportunity to preview software at a central location where ten computers are available for teacher experimentation with a wide variety of instructional software (R. Oates, personal communications, February 4, 1991; Roblyer, 1989). 
To integrate the available computers and software with teacher's instructional practice, the Dade County Public Schools Department of Human Resources provides computer training for teachers through the Dade-Monroe Teacher Education Center (TEC), the Summer Inservice Institute, and various other sources.

The TEC center initiated computer instruction for teachers in 1981. In addition to providing training at central locations, upon request the TEC center will provide any course of instruction on-site for a minimum group of 15 teachers. Computer education courses include computer literacy, programming in various languages, computer program coordinating skills, application of computer skills, integrating the computer into content area and the selection and use of a variety of instructional software. In 1989, TEC offered twenty seven different courses that were appropriate for elementary and high school teachers (Goetz, cited in Di Muzio, 1990).

As a result of participating in computer education courses, teachers can acquire in-service credits for teacher re-certification or to meet additional certification criteria. Courses offered to in-service teachers are based on an annual teachers' needs assessment coordinated by the TEC representative at each school. 
Since April 1989, the state of Florida has included computer literacy as part of the state's requirements for pre-teacher certification. However, there is at the present time no certification for computer literacy, computer programming, or computer education (Di Muzio, 1990)

From the early 1980's until 1991, paid computer training was offered through the Summer Inservice Institute. The initial courses were for computer literacy at the elementary level and programming at the secondary level. As computers became more accessible to teachers, courses focused more on integrating the computer into various curriculum areas such as science (Goetz, cited in Di Muzio, 1990).

Dade County Public Schools's Computer Education and Technology staff consists of a supervisor and four teachers on special assignment. These persons review all hardware purchase orders for appropriateness and advise both on hardware and software orders for schools. In addition, the staff negotiates contracts for high volume discounts with three major computer hardware manufacturers, IBM, Apple and Tandy and with major software companies such as Sunburst, Houghton Mifflin, Springboard and Spinnaker. A variety of special training 
opportunities are offered through staff in areas such as robotics, computers in social studies, and computers in writing. The department has three robots that may be checked out by teachers who have been trained to use them. Two teachers on special assignment exclusively serve Chapter I schools with computer equipment (R. Oates, personal communications, February 4, 1991).

In May, 1990, as part of his reorganization plan, Mr. Paul W. Bell, Superintendent of the Dade County Public Schools, established the Division of Technological Training (DTT) within the Office of Information Technology (OIT). The prime responsibility of DTT is to train Dade County Public School employees to work successfully with all available on-line computer applications housed on the school system's mainframe, as well as office automation systems, and other microcomputer based applications. In carrying out its goal to have Dade County Public School employees become "user-aware", the Division of Technological Training instruct classroom teachers in the operation of computers and the use of software to manage and computerize instruction. "The Division of Technological Training will strive to provide training which will result in the DCPS staff that operates effectively within the new technology and is cross-trained 
for optimum efficiency and access to data" (Tekerman, 1990). Teachers can enroll in classes provided by the Division of Technological Training on a monthly basis with the goal of improving classroom instruction and classroom management.

What is Integrated Curriculum?

"By integration we mean the blending, fusion, or unification of disciplines." (Oliva, 1988). Paul Dressel (1958) defined integrated curriculum as consisting of two parts. The first part gives the learner a unified view of commonly held knowledge. To Dressel a curriculum that provides this is said to be integrated. The second part of integrated curriculum is that it motivates and develops the learners' power to perceive and create new relationships for themselves. He used these two parts together as integrative. It is a curriculum that goes beyond the traditional disciplines and seeks cognitive unity.

The integration subject matter is an optional and often controversial curriculum decision. The choice to integrate subject matter depends upon the philosophy of the nature of knowledge, the nature of learners, and the 
purposes of education. "Generally speaking, educators support the conception of integrating subject matter." (Oliva, 1988)

As early as 1937, Edison Oberholtzer advocated the use of an integrated curricular approach to education. Oberholtzer stated that the individual must and does act in response to the problems or situation which he is faced. It is the task of education to set up its program in such a way that the child may and will develop the ability to consider intellectually and face courageously certain life problems with some skill in finding possible solutions. (Oberholtzer, 1937).

Oberholtzer felt that the integrated curriculum, as apposed to segregated disciplines, would challenge the students with the same kind of complex situations in which the face in real life. (Oberholtzer, 1937).

Hilda Taba supported integrated curriculum by stating, "It is recognized that learning is more effective when facts and principles from one field can be related to another, especially when applying this knowledge." (Taba, 1962). Another supporter of integrated curriculum, Ralph Tyler (1949), stated that "if educational experiences have not appreciable connection, the student develops compartmentalized learning which are not related to each 
other in any effective way when dealing with his own every day life."

The use of an integrative, interdisciplinary curriculum can provide students with a global view of learning and can teach them skills necessary for the transference of knowledge gain in one area to a variety of other areas or problem situations. In our informationbased society it is important that the student be able to relate the pieces of information he/she receives into a whole. Integrative curriculum is one way of offering this to the student. (Nielsen, 1989).

\section{Integration of Microcomputers into science Curriculum}

Over the years, educators have developed many innovative methods of using microcomputers in the classrooms. Although, much microcomputer use is still in specially designated computer courses, research seems to show that indicate that integrating the microcomputer into content area courses has a great potential for helping raise the quality of instruction. By using the computer as a tool for learning, the student is also gains those computer skills perceived necessary in today's society (Roblyer, Castine, and King, 1988). 
Today's science curriculum at all levels focuses on developing skills in solving problems using the scientific method and on actively involving students in scientific investigation. Since computers are one of the scientist's most important tools, it is logical that computer-based methods be an integral part of science instruction. Computer tools lend themselves well to the task of observing and recording, forming and testing hypothesis, and analyzing and communicating results and conclusions. This is true in real scientific endeavors as well as in science education. Computer resources can also help implement some fairly traditional, yet critical, kinds of instructional activities (Collis, 1988; Roberts, Carter, Friel, and Miller, 1988).

Perhaps the most frequently used and versatile computer tool in science education, the simulation is a way to show students real or imaginary systems in a controlled environment. Allessi and Trollip (1985) describe simulations as decision-making aids which are useful to students when the problem they are studying is complex and does not lend itself well to laboratory investigation. They point out that teachers often learn a subject when they are required to teach $i t$, and the students can use simulations in a model-building way that 
requires them to 'teach the computer' about a subject and, thus, learn its themselves.

Several kinds of computer tools have recently become available on the market which Roberts et al. (1988) refer to as microcomputer-based laboratories (MBL's). These may contain data collecting probes such as thermometer or other types of sensors. These tools often accompany students' simulated investigations of how systems work or what effect varying conditions have on organisms. Students can apply skills using data bases, spreadsheets, and graphing tools (all skills mandated by Florida's standards) to help analyze findings from their scientific investigations.

Batey (1985) emphasizes that using computers in science instruction, even more than in most content areas, requires planning and preparation, curriculum development, and well-organized classroom management strategies. Part of this need for careful planning is due to the new emphasis on process-oriented learning activities. These kinds of activities require much more in the way of nontraditional strategies such as small group exploration. They also require monitoring students on an individual basis (Batey, 1985). 
The effectiveness of integrating microcomputers into the science curriculum depends largely on the preplanning of the teacher and the instructional role they are asked to play. Computers seem to be most effective when they are used to support decision-making and exploration, rather than as drill-type activities (Elron, 1983; Bates, 1985; Roblyer, Castine, and King, 1988).

\section{Computer Education at Miami Palmetto Senior High School}

Miami Palmetto Senior High School (MPSH) is a large suburban high school in Miami, Florida. It is part of the Dade County Public Schools (DCPS). Although Miami Palmetto Senior High School is predominately white in its student makeup, the multi-cultural nature of DCPS can be seen in her student enrollment. The 1989-1990

Statistical Abstract of Dade County Public Schools lists the student population of Miami Palmetto Senior High School as following: total student enrollment - 2269; white enrollment - 1448 (63.828); black enrollment - 414 (18.258); Hispanic enrollment - 353 (15.56 8); Asian enrollment - $52(2.298)$ Indian enrollment - 2 (0.098). 
Miami Palmetto Senior High School holds the following as its statement of philosophy:

Miami Palmetto Senior High School provides opportunities for all students to become mature, thinking, skilled young people, well equipped for education, career, personal, and life-long growth. The staff seeks to create an atmosphere conducive to the learning process and one which enables students to develop a positive self-image. These factors combine to enable students to develop as responsible citizens. (Miami Palmetto Senior High School, 1990, $\mathrm{n} \cdot \mathrm{p} \cdot) \cdot$

As part of its objectives, Miami Palmetto Senior High School states that it is committed to "assist in the development of functional skills necessary for an individual to be a contributing member of society" (Miami Palmetto Senior High School, 1990).

In order to fulfill its philosophy and its intended objectives Miami Palmetto Senior High School strives to provide for her students the type of classes necessary to develop complete individuals. Like other high school in Dade County and throughout the nation, Miami Palmetto Senior High School recognized a need to include computer 
education in its curriculum before state mandates were passed.

The introduction of computers into the curriculum at Miami Palmetto Senior High School came through the Business Department. At first the computer was seen as a business tool, much like the adding machine, typewriter, and duplicating machines. The 1977-1978 curriculum at Miami Palmetto Senior High School included only one course (Introduction to Data Processing) using the computer. This course was intended to teach vocational students the use of mechanical punched-card and electronic data machines. The years 1978-1979, 1979-1980; and 1980-1981 also included only one computer related course (General Office (lerk). Like its predecessor, this course approached the use of the computer as any other office machine. (Miami Palmetto Senior High School Curriculum Handbook，1977-1978; 1978-1979; 1979-1980；1980-1981).

By the 1981-1982 school year the computer had evolved from an office machine in the Business Department to a separate course of study within the curriculum of the Math Department. This was the first year that 'computer courses' were taught at Miami Palmetto Senior High School. Introduction to Computers and Programing was offered this year with 63 students enrolled in the courses. Two 
computer courses (Introduction to Computers and Programming and Computer Problem Solving) were offered the following year. (Miami Palmetto Senior High School Curriculum Handbook, 1981-1982; 1982-1983) •

The 1983-1984 school year (the same year the state of Florida passed the Minimum Student Performance Standards for computer literacy) saw the computer come to it own in the total curriculum of the school. The Curriculum Handbook of 1983-1984 listed computer courses in a separate section - Computer Education Department- and included six courses. These courses ranged from Advanced Computer Programming which went beyond simple BASIC programming, to Computer Literacy and Computer Applications; and ESE Computers For Special Learners. This represented a major step forward in computer education in that it was the first time that the computer was recognized as an important part of the curriculum for all levels of students. Prior to this time only "serious students who have successfully completed Algebra I with above average performance." Computer Literacy and Computer Applications was available to all "students who wish to acquire some background in microcomputers." (Miami Palmetto Senior High School Curriculum Handbook, 19831984). The next year continued along the same line with 
seven computer courses offered, including two new one in the Business Department (Microcomputer Business Applications, Beginning and Advanced) •

By the 1983-1984 school year it was obvious to the administration of Miami Palmetto Senior High School that the knowledge of computers was very important to all her students. Not only did research suggest that all students needed to be computer literate, the state had adopted minimum standards for all Florida students. Despite continued growth in enrollment in computer courses, only a small percent of Miami Palmetto Senior High School students had access to these courses. Only 15.848 of Miami Palmetto Senior High School students in 1984-1985 were enrolled in computer courses and this represented the highest percent of Miami Palmetto Senior High School students enrolled in computer courses during any one year. The administration was committed to expand the curriculum in such a way that all Miami Palmetto Senior High School students were afforded an opportunity to not only learn about the computer but to have hands-on experience with one.

During the 1986-1987 school year the administration at Miami Palmetto Senior High School began an intensive probe of the present curriculum to determine the best way 
to provide computer training to all students. At the same time, Mildred Berry, Science Coordinator of DCPS, was striving to bring science education in Dade County into the computer age. Dr. Berry provided funds through her office to place four Apple IIe computers in science departments of all Dade County high schools. Four copies of AppleWorks, an integrated applications program for the Apple IIe, was also provided to each school. This was a small beginning, but it was a beginning.

William McCreary, Miami Palmetto Senior High School Science Department Head, recognized the value of computers in the field of science. He worked closely with Dr. Berry to secure further purchases of computers for the department. By the end of the school year, the science department at Miami Palmetto Senior High School had ten Apple IIe computers and 1 IBM computer. As a result of McCreary's efforts the department also had five CHEM PAC units, a Microcomputer Based Laboratory Unit in chemistry. McCreary was determined to see the science department benefit from the use of this unique teaching tool.

In his search for the most effective method of expanding computer education at Miami Palmetto Senior High School, Peter Bucholtz, principal at Miami Palmetto Senior High School, recognized an ali in Mr. McCreary. Together 
they began planning for a major shift in the science curriculum which would ensure all Miami Palmetto Senior High School students would benefit from the computer and at the same time meet state mandates in computer literacy (Kenzel, personal communications, March 1, 1991).

Elaine Kenzel, Assistant Principal for Curriculum, expressed the administration's view on integrating the computers into the existing curriculum by stating, The less things are taught in isolation the greater amount of learning takes place. I believe that anytime you can combine disciplines and show the students an application of the curriculum, the students comprehend more and feel that what they are learning is of importance. Students need to use the computers and see what computers can do for them -not just learn about them. (Kenzel, personal communications, March 1, 1991).

By introducing the students to the computer as a means of learning material in a required class the student not only would gain the needed computer literacy skills, but also see it as a useful tool. Computers would no longer be just another subject they were required to study (Kenzel, personal communication, March 1, 1991). With this as 
their goal, the administration and McCreary began looking for the most appropriate curriculum to test their beliefs. The administration of Miami Palmetto Senior High selected Biology as a viable content area to integrate with computer literacy. Biology was an excellent choice since all students must take Biology. Only those students who had taken Honors Biology in junior high would miss taken computer literacy in this method. It was determined that the few students not taking Biology at Miami Palmetto Senior High School would receive computer experience as tool in the lab in other science courses -- Chemistry, Physics, etc. During the first two years of the new curriculum, Mr. McCreary would also infuse computer literacy into the Environmental Science curriculum to ensure all students were reached. Any senior who has still not met his/her requirements in computer literacy can take a computer-based tutorial prepared by the science department. At the end of the tutorial the student must prove his/her comprehension on a computer-based test (McCreary, personal communications, February 15, 1991). Another consideration needed to be addressed to ensure success of the program was the teachers. The science department provided teachers who were willing to plan a new program and had the knowledge of computers to 
do so. During the summer following the 1986-1987 school year, one Biology teacher was assigned the task of planning and developing the integrated curriculum. The Biology curriculum was adapted to include the use of computer-based instruction in Biology, actual programs were written to enhance the Biology curriculum, and a unit of computer literacy was developed which would fit into the Biology curriculum (McCreary, personal communications, February 15, 1991; Kenzel, personal communication, March $1,1991)$.

A 10 computer lab was provided for the use by the integrated program. Recognizing that 10 computers was not enough to provide adequate computer experience for the 3035 student Biology classes, Peter Bucholtz provided 3 more computers to start the year with. Using funds available through the science department William McCreary provided 5 more computers before the end of the year bringing the total computers in the lab to 18. The Apple IIe was the computer adopted for the program (McCreary, personal communications, February 15, 1991).

The program has evolved over the four years it has existed. The first year one teacher provided the integrated curriculum with three teachers providing traditional instruction in Biology. Each grading period a 
different section of Biology classes rotated into the integrated program. By the end of the year all Biology students had completed the computer literacy curriculum as well as the Biology Curriculum.

During this first year it became evident that 9 weeks was really not sufficient amount of time to provide enough computer experience for some students. Although all objectives had been met, more actual computer time was needed to guarantee that all students not only knew about computers, but was comfortable with the use of the computer (McCreary, personal communications, February 15, 1991).

By the second year, a second Biology teacher had been trained to teach the integrated program and rotation of students took place each semester instead of each grading period. A second computer lab was provided for the program. This lab was set up with 30 Apple IIe computers for the students and one for the teacher. Software programs were purchased and more programs written to enhance the curriculum.

The 1990-1991 school year was the fourth year that the program has be included in the curriculum. The Integrated Biology/Computer Literacy improved as experience gave birth to new ways to expand and enhance 
the curriculum. Teachers in other science courses began to realize the success of the Biology/Computer Literacy as they used the computers in their own curriculum. Students are definitely benefiting. More students are using the computers to do their work in Science. They are definitely computer literate. My students, 11th and 12th graders, were so well taught the we had a minimum of technical problems in the computer lab and could spend that much more time with the lab itself. (McCreary, personal communications, February 15, 1991).

The science department is not the only department at Miami Palmetto Senior High School which uses the computer to enhance education. Other departments using the computer include music, social studies, and special education.

In a survey taken in March of 1989, 638 of the faculty at Miami Palmetto Senior High School stated that they did consider themselves computer literate and that they either used the computer in their classes or in the preparation for their classes. Of those teachers who use the computer in some aspect of their teaching, 678 have taken some formal training on the computer, ranging from a Specialist Degree in Computer Education to TEC inservice 
courses. (Bullock, Broughton, Harris, 1989). The Professionalism Committee has provided in-house training in the use of the computer as a grade book. Teacher training teachers is a common occurrence at Miami Palmetto Senior High School where computer usage is involved (McCreary, personal communications, February 15, 1991). The administration and staff at Miami Palmetto Senior High School recognized the value of the computer as a managerial as well as a instructional tool in education today .

\section{Summary of Findings in the Literature}

1. In today's technological society there is a need for all students to be provided with basic skills in the use of computers.

2. Skills needed by all students include Computer Literacy skills not programming skills.

3. In many studies males have shown more confidence and skill with the use of computers than females.

4. The State of Florida Department of Education responded to the need for Computer Literacy by mandating that all Florida high school graduates by computer literate. It assists teachers by providing 
curriculum standards, teacher training, computers and software. Florida Department of Education also funds for six Regional Centers of Excellence in Mathematics, Science, Computers, and Technology which are involved in the writing of instructional materials for using the microcomputer and assisting teachers in implementing the computers into the classroom.

5. Dade County Public Schools assists teachers of computer classes by providing curriculum guides for all grade levels, software are reduced costs, and teacher training. The Computer Education and Technology staff consists of experts in Computer Education who provide assistance to classroom teachers, evaluates software, and negotiates contracts for high volume discounts of hardware and software. The Division of Technological Training has as its prime responsibility the training of Dade County Public School employees in successful on-line computer applications housed on the school system's mainframe, as well as microcomputer based applications.

6. Miami Palmetto Senior School's response to the State of Florida mandate that all Florida high school 
graduates by computer literate by integrating

computer literacy skills into the existing Biology curriculum. 


\section{CHAPTER III}

\section{RESEARCH METHODOLOGY}

The purpose of this chapter is to: (1) define the subject population chosen for this investigation; describe the method, materials, and procedures used to collect the data; and (3) describe the statistical procedures to be employed in the analysis of the collected data.

\section{Selection of the Sample}

The subjects participating in this study $(\mathrm{N}=447)$ were all students enrolled in Biology or Honors Biology at Miami Palmetto Senior High School who began and ended the semester with the same teacher. There was a total of 537 students enrolled in Biology or Honors Biology for the 1990-1991 school year. Of this number 90 were eliminated from the study for one of the following reasons: entered too late to participate in the pre-test; withdrew before the administration of the posttest; had a schedule change resulting in a change of teacher at some point throughout the semester. The resulting number of 447 students 
represented 83.28 of the possible student population eligible for this study.

of the 447 subjects participating, $30.68(\mathrm{~N}=137)$ were enrolled in traditional Honors Biology, 33.18 ( $\mathrm{N}=148)$ were enrolled in Integrated Honors Biology/Computer Literacy, and $36.28(\mathrm{~N}=162)$ were enrolled in Integrated Regular Biology/Computer Literacy. Demographically, the subjects participating in this study were 447 tenth graders, (Female, $\mathrm{N}=226 ;$ Male, $\mathrm{N}=221$ ) with a mean age of 15.4 years. Of the selection population, 60.48 (N=270) were White; $19.08(\mathrm{~N}=85)$ were Hispanic; $18.28 \quad(\mathrm{~N}=81)$ were Black; and $2.48(\mathrm{~N}=11)$ were Asian. Using the students school code as an indicator of socioeconomic status, it was revealed that $71.8 \%(\mathrm{~N}=320)$ of the students pay full price for their lunch while $28.28(\mathrm{~N}=127)$ are either on a free or reduce lunch plan. The average percent of students receiving free lunch in high school in Dade County Public Schools is 41.78 as indicated by a phone survey with 10 Dade County High Schools. Miami Palmetto Senior High School falls below that average and is considered an affluent suburban school. 


\section{Instrumentation}

Information gathered for this study was obtained by means of (1) A historical analysis of Dade County Public School's and, more directly, Miami Palmetto Senior High School's approach to computer Education; (2) An analysis of Miami Palmetto Senior High School's present attempts to comply with he state mandate for computer literacy.

\section{Historical Analysis}

The historical analysis of Dade County Public Schools' approach to computer education was conducted by reviewing Dade County Public School Computer Education Curriculum Guide and bulletins prepared by the Computer Education Department of DCPS. Telephone interviews with Rita Oaks, Supervisor - Office of Computer Education, was also conducted to obtain information which was not available in published form.

History of computer education at Miami Palmetto Senior High School was studied by a search through Miami Palmetto Senior High School Curriculum Handbooks and Master Schedule for the years spanning from the 1977-1978 to 1990-1991 school years. The period of twelve years was 
chosen due to the fact that the necessary data is not available before this time. Interviews were conducted with Peter Bucholtz, Miami Palmetto Senior High School Principal; Elaine Kenzel, Miami Palmetto Senior High School Assistant Principal for Curriculum; William McCreary, Science Department Head; and the teachers involved in the study. The information obtained in these interviews was used to determine the logistics of the Integrated Biology/Computer Literacy curriculum, the rationale for choosing Biology as the content area to integrate with Computer Literacy, and the perceived success of the program. Teacher interviews were used to determine teacher satisfaction with the curriculum, problems that need to be addressed with the curriculum, and suggestions for improvement in the curriculum.

Miami Palmetto Senior High School's Approach to Computer Literacy

The present curriculum plans for complying with the state mandates on computer literacy were analyzed by the following methods: Biology Pre/Post Test and Computer Literacy Pre/Post Test. 
Biology Pre/Post Test -- A Biology test developed using the Dade County Public School's Biology Test Bank. The Biology Test Bank, or formally the Biology Instructional Planning and Assessment Tool, was produced by the Subject-Area Testing Department of the Office of Educational Accountability.

The current Biology Test Bank consists of 1,462 multiple-choice items, approximately ten to fifteen per standard. The purpose of the test bank is to facilitate instructional and assessment consistency across the biology curriculum and to enhance students' and teachers' levels of preparedness for the coursewide assessment conducted each spring. (Dade County Public Schools, $1990)$.

All items in the test bank covering the objectives to be covered during the course of this study were typed into a computer test bank. The test bank was then allowed to generate a hundred-question test to ensure random selection of the questions.

\section{Computer Literacy Pre/Post Test -- A Computer} Literacy Test was developed using the Dade County Public School Computer Literacy Test Bank. The Computer Literacy Test Bank, developed by the staff in the Computer Education Office, consists of 250 items covering all DCPS 
objectives for computer literacy. Questions to be used in the test were chosen using the same method as that of the Biology test.

\section{Pass/Fail Ratio Survey - A random survey of 35}

classes at Miami Palmetto Senior School was conducted to determine the average pass/fail ratio. The result of this survey was used to determine the 808 acceptable pass/fail ratio used in hypothesis \#3.

\section{$\underline{\text { Procedures }}$}

Prior to the implementation of the study, a meeting with all teachers involved in the study was conducted to develop a timeline for the administration of the pre/post test and to determine the Biology objectives to be covered during the semester the study was to be conducted. The purpose of the meeting was to ensure that all tests were administered following the same schedule. It also ensured that all students were covering the same material in Biology •

During the first week of the semester, September 4 11, 1990, both the Biology and Computer Literacy PreTests were administered. Students coming in after september 11, 1990 were not included in the study and were not 
administered the pre-test. The tests were scored and raw data recorded at that time. The teachers were given the results of the pretests in order to aid in the instruction of the classes.

For the five month period that followed, classes were conducted according to the curriculum plans. Students in the Integrated Biology/Computer Literacy classes received two weeks of concentrated computer literacy. The remaining time the computer was used as a tool to enhance the Biology curriculum while the classes covered the Biology objectives. Hands-on experiences on the computer included word processing, data bases construction, spreadsheet construction, tutorials, and computer-based labs. The traditional Biology classes covered the Biology objectives using a combination of lecture, multi-media instruction, labs, discussion, and group work.

Posttesting was conducted as part of the semester exam. Both Biology and Computer Literacy tests were given between February 4 and February 8, 1991. The test were scored and raw materials recorded. The scores were recorded by each teacher as the student's semester exam grade.

Throughout the length of this study, every effort was made to accommodate the needs of the teachers as well as 
to minimize any clerical or administrative demands upon participating instructors. Teachers were given tests packets for both pretest and posttests which included the tests papers in numerical order, answer sheets, pencils, and answer keys. Both pretest and posttests were scored for each teacher.

\section{Basic Design and Analysis of Data}

The statistic test, analysis of covariance (ANCOVA), is used in two major ways, "as a technique for controlling extraneous variables and as a means of increasing power" (Gay, 1981). Covariance is a form of ANOVA and is a statistical, rather than an experimental, method that can be used to equate groups on one or more variables. ANCOVA adjusts posttest scores for initial differences on some variable and compares adjusted scores. In this way the groups are equalized with respect to the control variable and then compared. Thus, "for a study based on a pretestposttest control group design, covariance is a superior method for controlling for pretest differences" (Gay, $1981)$.

Chi-square statistics was used to test hypothesis \#1 by comparing students in the study who received passing 
grades with those in the study who did not receive a passing grade. Passing grades were assigned by each teacher after evaluation of the student's work throughout the semester, not just the posttest. Dade County Public Schools uses the standard of 658 as minimum for a passing grade in any class.

Hypothesis \#2 was tested for a significant difference in means of Biology Pretest and Biology Posttest using ANCOVA analysis. The analysis was conducted on both Regular Biology students receiving the integrated curriculum and the Honors Biology Students receiving the integrated curriculum.

Hypothesis \# 3 was tested by calculating a simply percentage of students passing the Computer Literacy portion of the curriculum in the Integrated Biology and Computer Literacy classes.

In overall analysis, the demographic variables of gender and ethnic group membership was examined and analyzed through the use of covariance tests to determine if they differed across the groups. An additional and important use of demographic data is to make it possible to present results according to subgroups of interest as well as for the respondee as a whole (Greenberg, 1987). 
Statistical analyses for this study were perform by means of the SPSS- $\mathrm{X}$ statistical package, and interpreted at a chosen .01 level of significance. The power of this study was further enhanced by using a large sample size; reliable and valid tests; and by using homogeneous groups, 10th grade Biology students at Miami Palmetto Senior High School. 


\section{CHAPTER IV}

\section{ANALYSIS OF DATA}

In this chapter data were analyzed and presented according to the purposes described in Chapter I and the procedures presented in Chapter III. The analyses involve both descriptive and inferential statistical procedures and include analysis of covariance (ANCOVA) and chi-square analyses. The .01 level of significance was selected for all tests of significance.

\section{Initial Equivalence of the Groups}

A series of crosstabulations and chi square procedures were conducted on the demographic data to determine if the groups differ with respects of sex and ethnic group membership between the integrated biology and computer literacy classes and the traditional biology classes. Table 1 and Table 2 show that there is no significant difference between these groups. 
Table 1

Chi-Square Test for Equivalence of Groups for Sex

\begin{tabular}{cc|c|c|r} 
& & Count & Male & Female \\
TEACHER & & 1 & 2 & \\
Integrated & & & & \\
ROW \\
TOTAL
\end{tabular}

\begin{tabular}{ccccc} 
Chi-square & D.F. & significance & Min. E. F. & E.F. $<5$ \\
\hline 0.11977 & 1 & 0.7293 & 61.049 \\
0.21655 & 1 & 0.6417 & (Before Yates Correction)
\end{tabular}

Table 2

Chi-square Test for Equivalence of Groups for Ethnic Group Membership

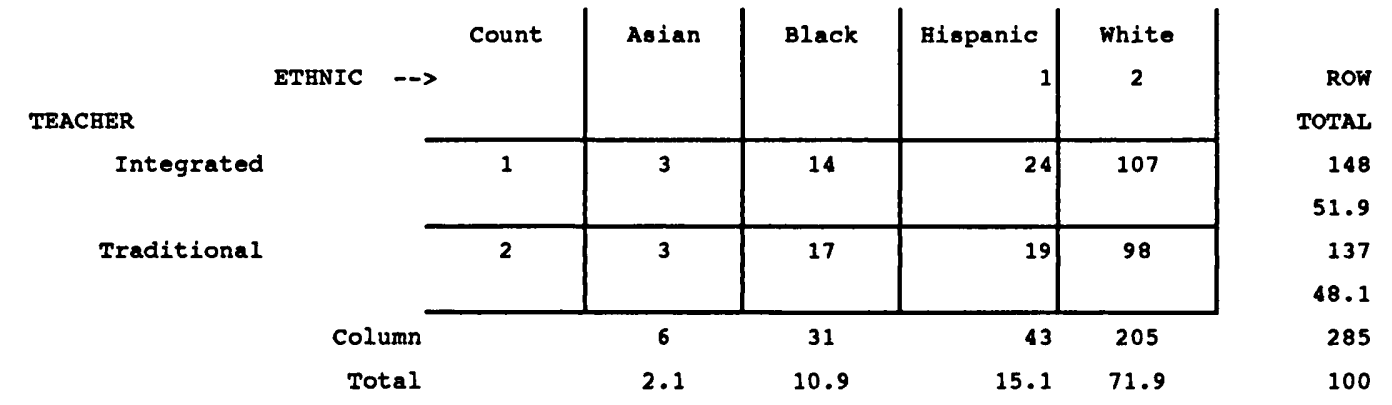

\begin{tabular}{ccccc} 
Chi-Square & D.F. & Significance & Min. E. F. & E.F. $<5$ \\
\hline 0.84354 & 3 & 0.839 & 2.884 & $2(258)$
\end{tabular}


Hypothesis \#1

Hypothesis \#1 stated: Students receiving the integrated curriculum of Biology and Computer Literacy will not have a significantly lower proportion of passing grades in Biology than those receiving the traditional curriculum.

Chi-square tests indicated that as predicted there was no significant difference between the number of students passing Biology while taking traditional Biology and the number taking the Integrated Biology and Computer Literacy $\left(\mathrm{X}^{2}=.601 ; \mathrm{p}=.43\right)$. Therefore, null hypothesis failed to be rejected. The results of the chisquare test are shown in Table 3 .

Table 3

Chi-Square Test for Independence of Passing Grades and Curriculum

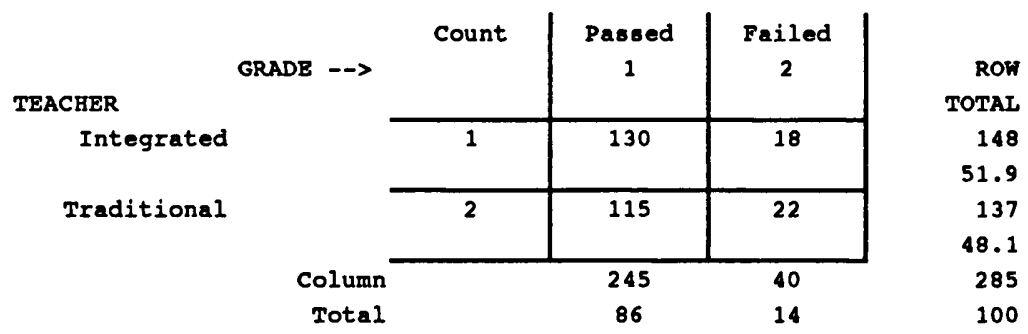

\begin{tabular}{ccccc} 
Chi-Square & D.F. & Significance & Min. E. F. & E. F. $<5$ \\
\hline 0.60133 & 1 & 0.4381 & 19.228 & none \\
0.89514 & 1 & 0.3441 & (Before Yates Correction)
\end{tabular}




\section{Hypothesis \#2}

Hypothesis \#2 stated: Students receiving the integrated curriculum of Biology and Computer Literacy will not perform significantly lower on a Biology posttest than those receiving Biology in a traditional classroom.

Analysis of Covariance results indicated that as predicted there was no significant difference in the results on the Biology Posttest of the students in the Integrated Biology and Computer Literacy classes and those in the traditional Biology classes when controlled with the Biology Pretest $\left(F_{1,280}=.855 ; P<.356\right)$. Therefore the null hypothesis failed to be rejected. The results of the analysis of covariance are shown in Table 4.

Table 4

Analysis of Covariance Test for Biology Posttest Scores

\begin{tabular}{|c|c|c|c|c|c|}
\hline Source of variation & sum of & df & Mean & $\mathbf{F}$ & Significance \\
\hline & Squares & & Square & & of $F$ \\
\hline Covariates & 2631.045 & 1 & 2631.045 & 14.464 & 0.00 \\
\hline BIOLOGY PRE & 2631.045 & 1 & 2631.045 & 14.464 & 0.00 \\
\hline Main Effects & 1401.071 & 2 & 700.536 & 3.851 & 0.022 \\
\hline GROUP & 392.931 & 1 & 392.931 & 2.16 & 0.143 \\
\hline sEX & 1026.604 & 1 & 1026.604 & 5.644 & 0.018 \\
\hline 2-Way Interactions & 155.479 & 1 & 155.479 & 0.855 & 0.356 \\
\hline GROUP/SEX & 155.479 & 1 & 155.479 & 0.855 & 0.356 \\
\hline Explained & 4187.596 & 4 & 1046.899 & 5.755 & 0.00 \\
\hline Residual & 50931.232 & 280 & 181.897 & & \\
\hline Total & 55118.828 & 284 & $194 \ldots 80$ & & \\
\hline
\end{tabular}


The interaction between sex and the type of curriculum (teacher) is not significant $\left(\mathrm{F}_{1,280}=.855 ; \mathrm{P}<\right.$ 356). This indicates the type of curriculum did not effect the performance of either males or females.

There was a significant difference for the main effect of $\operatorname{sex}\left(F_{1,280}=5.644 ; \quad P<.018\right)$. A comparison of means and standard deviations for Biology pretest and Biology posttest is shown in Table 5 .

Table 5

Means and standard Deviations of Biology Pretest / Postest by Sex

\begin{tabular}{|ll|c|c|c|c|}
\hline \multicolumn{3}{|c|}{} & \multicolumn{2}{|c|}{} \\
\cline { 3 - 6 } & & \multicolumn{2}{c|}{ INTEGATED } & \multicolumn{2}{c|}{ TRADITIONAL } \\
\cline { 3 - 7 } & & MALE & FEMALE & MALE & FEMALE \\
\cline { 3 - 6 } & & & & & \\
& MIOLOGY PRETEST & 34.73 & 34.35 & 38.37 & 36.59 \\
& STDEV & 11.17 & 9.7 & 8.88 & 9.06 \\
& & & & & \\
& MEANS & 59.16 & 61.2 & 59.54 & 64.72 \\
& STDEV & 15.01 & 14.23 & 15.73 & 13.64 \\
\hline
\end{tabular}

The means for females taking the Integrated Biology and Computer Literacy classes and traditional Biology classes were lower on the Biology pretest than the males (Integrated Biology and Computer Literacy classes - males $=34.73 ;$ females $=34.35 ;$ traditional Biology - males $=$ $38.37 ;$ females $=36.59)$. However, the means for females on the Biology posttest taking the Integrated Biology and Computer Literacy classes and traditional Biology classes were higher than that of the males (Integrated Biology and 
Computer Literacy classes - males $=59.16$; females $=$ $61.20 ;$ traditional Biology - males $=59.54 ;$ females $=$ $64.72)$. The results indicate that females performed significantly better than males regardless of the type of curriculum, Integrated Biology and Computer Literacy or traditional Biology.

Hypothesis \#3

Hypothesis \#3 stated: Fewer than 808 of the students receiving the integrated curriculum of Biology and Computer Iiteracy will successfully meet the intended objectives for Computer Literacy as demonstrated by obtaining a passing grade in Computer Literacy for the semester.

Students taking the Integrated Biology and Computer Literacy received passing grades in Computer Literacy based on grades received on the Computer Literacy Posttest and successfully completing weekly computer literacy assignments using AppleWorks applications software (word processing, data base, and spreadsheet), Biology tutorial software, and MBL (Microcomputer Based Labs) assignments. Passing grades were based on the assessments of the teacher in the classroom. 
Hypothesis \#3 was tested by comparing the number of students that met the intended objectives (received passing grades) with those who did not (failed to receive passing grades). Eighty-two percent of the students taking the Integrated Biology and Computer Literacy classes passed the Computer Literacy course, therefore the null hypothesis \#3 was rejected.

\section{Summary}

Chi-square and analysis of covariance were used to test null hypothesis \#1 and null hypothesis \#2. A comparison of passing grades and failing grades was used to test null hypotheses \#3. Null hypotheses \#1 and \#2 failed to be rejected while hypothesis \#3 was rejected.

1. Students receiving the integrated curriculum of Biology and Computer Literacy did not have a significantly lower proportion of passing grades in Biology than those receiving the traditional curriculum.

2. Students receiving the integrated curriculum of Biology and Computer Literacy did not perform significantly lower on a Biology posttest than 
those receiving Biology in the traditional

classroom.

3. At least 808 of the students receiving the integrated curriculum of Biology and Computer

Literacy did successfully meet the intended objectives for Computer Literacy as demonstrated by obtaining a passing grade in Computer Literacy for the semester. 


\section{CHAPTER V}

SUMMARY, CONCLUSION, AND RECOMMENDATIONS

\section{Summary}

The purpose of this study was to examine the effects of integrating Computer Literacy into a traditional curriculum - Biology. Comparisons were made between scores on Biology Pretest and Biology Posttest taken by students in Integrated Biology and Computer Literacy classes and traditional Biology classes. Comparisons were also made between the numbers of students receiving passing grades in Biology in Integrated Biology and Computer Literacy classes and those taking traditional Biology classes. Finally, the success of the integrated curriculum at meeting the intended objectives for Computer Literacy was evaluated by comparing the number of students (taking Integrated Biology and Computer Literacy classes) passing Computer Literacy with those not passing Computer Literacy.

This study was conducted at Miami Palmetto Senior High School between September 1990 and February 1991. Four hundred and forty seven students participated in the 
study. Data was collected by means of Biology Pretest, Biology Posttest, Computer Literacy Pretest, Computer Literacy Posttest, and students' semester grades. The administration of the both pretests was given during the first week of the semester, September 4-11, 1990 . Posttesting was conducted as part of the semester exams, February 4-8, 1991. Semester grades were collected at the end of the first semester, February 8, 1991. The statistic tests, analysis of covariance (ANCOVA) and Chi-square analysis, were performed to test the three hypotheses. Statistical analyses were performed on a Zenith z-386 Sx Computer System utilizing SPSS-PC statistical package. Results were interpreted at the .01 level of significance.

The effects of the data results on the hypotheses are discussed in the following section.

\section{Results and Discussion}

Critics of American education have frequently commented on the fragmented curriculum offered in American Schools. Phrases such as 'smorgasbord' and 'shopping mall curriculum' have been used to described the way 
learners progress through school, selecting courses and compartmentalizing learned concepts into separate and distinctly knowledge clusters. One result of curriculum based on the present organization of knowledge into disciplines, or subject areas, is a loss of understanding of the interrelations among subjects (Kersh, 1989, p. 2) •

Integrative curriculum, in contrast to traditional subject-based models, attempts to untie the knowledge bundles we call subject areas or subject disciplines. Integrative curriculum seeks to unify a student's educational activities across subject-matter boundaries, and to focus the direction of teaching on the integrative process in which students must engage if they are to organize their knowledge and experience. Integrative education should serve to bring together the parts and pieces of one's life into an integrated whole (Kersh, 1989, p.2).

"Generally speaking, educators support the conception of integrating subject matter." (Oliva, 1988). While the principles of integrating disciplines may be viewed by 
more educators as a positive step, the actual decision to do so is often a controversial curriculum decision for an individual teacher. First of all, teachers are frequently reluctant to alter what they are familiar patterns of primarily lecture/demonstration methods and directed seatwork. This tendency to use traditional methods is frequently reinforced in teachers' pre-service training, where traditional methods are used to train the teachers themselves (Roblyer, 1989). Secondly, teachers are concerned with the time constraints of integrating second discipline into their regular curriculum which many already find difficult to complete in one semester or year (Mojkowski, 1987). Jim Berty, Integrated Biology and Computer Literacy teacher, expressed this concern saying: The time that is used to complete the computer objectives does have an affect on the amount of time that can be used for the biology curriculum and I feel that there is not now enough time in 1 year to adequately complete a biology curriculum. (Berty, personal communications, March 15, 1991).

The purpose of this paper is to determine if Computer Literacy can be integrated into a existing curriculum successfully and in the process to answer some of the concerns that teachers have regarding this type of 
curriculum planning. Trollip and Alessi (1988, p. 70) state the goals of integrating the computer into the existing curriculum very well when they say:

There are two major goals for incorporating computers into the classroom. The more important of the two is to facilitate learning for the students, improving the quality and quantity of what they know and, consequently, their overall capability of functioning in society. The second goal is to ensure that students are comfortable in using computers and have a reasonable understanding of how they work. We believe that a successful realization of the first goal will lead naturally to the second goal. That is, if computers are integrated into the teaching and learning of all subjects, then students will become adept at using them in a variety of ways.

Using the two goals stated above as desirable goals for integrating Computer Literacy and Biology, the results of the data collected in this project will now be discussed.

Null hypothesis \#1 states that students receiving the integrated curriculum of Biology and Computer Literacy will not have a significantly lower proportion of passing grades in Biology than those receiving the traditional 
curriculum. Stating this hypothesis addresses the concerns of the teachers who feel that taking time out of the existing curriculum to integrate another curriculum will not leave sufficient time to teach all the objectives of the existing curriculum. It was believed that successfully integrating the two curriculums would not take away from the existing curriculum, in this case Biology. The result of the Chi-square test indicated that there was no significant difference between the number of students passing Biology regardless of which curriculum they were receiving - the traditional Biology curriculum or the Integrated Biology and Computer Literacy curriculum. Therefore, it can be concluded that the Biology curriculum was not harmed by integrating it with computer literacy.

Null hypothesis \#2 also addressed this concern by stating: Students receiving the integrated curriculum of Biology and Computer Literacy will not perform significantly lower on a Biology posttest than those receiving Biology in a traditional classroom. Analysis of Covariance results indicated that there was no significant difference in the results of the Biology posttest of regardless of which curriculum they were receiving - the 
traditional Biology curriculum or the Integrated Biology and Computer Literacy curriculum.

With the results of the chi-square test and the anocova tests for the two hypotheses the conclusion was made that the Biology curriculum was not hurt by the integration of Computer Literacy. However, by showing no significant differences (in favor of Integrated Biology and Computer Literacy) between the results of the posttest and the passing rate, the conclusion was also made that the integration of computer literacy and Biology did not benefit the Biology curriculum significantly.

Successful implementation of computer literacy in the schools depends on many factors. Two major factors for successful implementation are teachers' attitudes toward computers and their levels of expertise with computers (Battista and Krockover, 1982; Johnston, 1987; Stevens, 1982; Wagschal, 1984). "MY main approach to educational change has been through working with teachers. If I can change a teacher, that teacher can change the education of hundreds of students" (Moursund, 1984).

Curriculum change, development and innovation is carried out by classroom teachers. They are supported by advisers, trainers and educational researchers, who may influence but do not control what happens in the 
classroom. Therefore, the attitudes of classroom teachers to the use of microcomputers in education in general, and towards their relevance to and applications within specific areas of the curriculum, will determine the success and failure of computer literacy (Johnston, 1987; Wagschal, 1984).

Fox (1985) points out that teachers' attitudes towards the new technology are influenced by their needs for security, access and support. Many teachers still have only very limited experience (if any at all) on computers. Stevens (1981) indicates that teachers have anxieties about learning computing skills and learning how to structure content and classroom environments to accommodate technology. She also stressed that to push teachers to upgrade their technological skills complicates the problem by adding to the anxieties of teachers. Woodrow (1987) surveyed a group of teachers and student teachers to evaluate their attitudes toward the computer. Eighty-six percent of the teachers and student teachers surveyed indicated that they would like to receive further computer training. Most were in favor of including instructional applications of computers in teacher training programs. This seemed to reflect a belief among the teachers that computer applications will 
increase and that beginning teachers should have expertise in the field.

In a study completed by Vermette, Orr, and Hall (1986) it was found that the attitudes of teachers toward computers do not necessarily represent a polarization of strongly favorable and unfavorable viewpoints. Many teachers are willing and enthusiastic about incorporating the computers into their curriculum. Schools with computer-enthusiastic teachers produced involvement in computer activities by more teachers, computer use by more students, use for more applications, more time-in-use at elementary schools, and more equity of use in secondary schools (Becker, 1984).

Ortega (cited in Roblyer, 1989, preface) states that the problem is not lack of enthusiasm on the part of the teachers but lack of proper training in effective methods of integrating the computers into the curriculum.

For many teachers and administrators, these are frustrating and perplexing times. As educators, they are at the front lines of the so-called Microcomputer Revolution, and they are continually being bombarded with demands for change. They are being told that their very survival as professionals depends on their quick and effective adoption of technology. They 
enjoined to be creative and innovative, and they are often handed at least some of the tools they will need. What they are given very little of is any specific information on how to go about integrating these technological tools into what they are already doing (Ortega, cited in Roblyer, 1989, preface). The decision to integrate computer literacy into the Biology curriculum at Miami Palmetto Senior High School took into consideration the enthusiasm of the teachers. William McCreary, Science Department Head, recognized the value of computers in the field of science. Under his leadership, the science department provided teachers who were willing to design and implement an new program using computers in the existing curriculum. These teachers were computer literate themselves and not intimidated by the computer (Kenzel, personal communication, March 1, 1991).

However, of the three teachers presently teaching the Integrated Biology and Computer Literacy curriculum none have had formal instruction on strategies of integrating computers into the curriculum. Whatever success the program has experienced thus far can be accredited to the teachers' enthusiasm, creativity, shared planning, and determination. It is believed that more formal training and team teaching with experienced teachers in integrating 
computers into the curriculum would result in more learning in the traditional subject material.

The second aspect of integrating computers into the curriculum involves software. Software must support current curricula, and the more specific its use, the better. Selection of such software is a long and tedious process (Vakos, 1986). Often selection of software is done by reading a description of the software in a catalogue. Once the software is purchased, it is found to be lacking in instructional value or simply drill and practice.

By the Spring of 1983, several thousands of microcomputer programs were available for sale and the number increases each year. Grayson (1984) says that while some of these programs are excellent, many others, are very poor. One indication of the problem of quality software is that probably more than 20,000 pieces of educational software have been written, but less than 10 percent have been evaluated by a dependable organization. It is estimated that perhaps 95 percent of all these programs marketed should never have been offered for sale and definitely not used in the classroom (Grayson, $1984)$. 
Educational software is constantly improving, but the cost of that software is often prohibitive to many students. Class sets of a program could cost anywhere from $\$ 100.00$ to thousands of dollars. AppleWorks (the application program used by many classes utilizing the Apple Iie computers) costs approximately $\$ 200.00$ apiece 30 copies would be $\$ 1600.00$. Tutorial and lab software range from approximately $\$ 50.00$ apiece to $\$ 200.00-\$ 300.00$ apiece. Class sets of several pieces of software could result in several thousand dollars allocated for software. Most schools do not have the funds to purchase sufficient quantities and qualities of software (Blitter, 1986).

Dade County Public Schools provides software to teachers at a reasonable cost through the Minnesota Educational Computing Consortium. The office of Computer Education is also seeking site or county licensing contracts for many educational software packages including AppleWorks. In addition to individual school provisions, teachers have the opportunity to preview software at a central location where ten computers are available for teacher experimentation with a wide variety of instructional software (R. Oates, personal communications, February 4, 1991; Roblyer, 1989). 
At the time of this study very few software programs were available through site licensing contracts. Software packages were purchases through limited science funds which also had to cover science lab equipment and supplies. Most software packages were purchases as individuals, requiring one student at a time to utilize the program. Several BASIC programs were written by the staff of the science department, but writing computer programs is a very lengthy procedure and the results often are not comparable to software on the market. However, due to staggering software costs many excellent programs were not available for the use with the curriculum. Until monies are made available for site licenses of many good educational software programs, the problems teachers experience with software will not be solved.

The results of the Analysis of Covariance showed no significant interaction between the sex of the student and the type of curriculum the student was taking. This finding is a departure from much of the research found in the literature on gender differences in computer education. As indicated in Chapter II of this study, many researchers feel that females do not work as well as males do with computers (Harris, 1984; Chambers and Clark, 1987; 
Chen, 1986; Miura and Hess, 1984; Reyes and Stanic, 1988; and Richman, 1988).

One explanation of this discrepancy may have been given by Smith (1987) inadvertently in a study done in 1987 of 491 students from all grade levels. Smith concluded that the younger the female students were the more positive their attitudes were towards computers. Elementary female students had the highest mean scores of all female students on a confidency scale. Female junior high students in Smith's study had higher confidence levels than did the female senior high students. If Smith's research has universal application then as these elementary and junior high females move into high school the differences between the genders should decrease, as shown in this the study of this paper.

While there was no significant difference in regards to gender between the traditional biology classes and the integrated biology and computer literacy classes, there was a significant difference for the main effect of gender. The means for females on the biology posttest taking the integrated biology and computer literacy classes and the traditional biology classes were higher than that of the males. Regardless of the method of instruction, females scored significantly higher than the 
males. The study of biology requires good reading skills and vocabulary development, areas where females tend to do better than males as seen in chapter II. The results of this study supports the literature in this area.

The data indicates that the second goal stated by Trollip and Alessi (1988) was reached successfully. Null hypothesis \#3 spoke to this goal as it stated: At least 808 of the students receiving the integrated curriculum of Biology and Computer Literacy will successfully meet the intended objectives for Computer Literacy as demonstrated by obtaining a passing grade in Computer Literacy for the semester. An acceptable percentage (828) of students in the integrated curriculum successfully completed the curriculum to the satisfaction of the teacher in the classroom. Students passing the Computer Literacy portion of the curriculum not only had to successfully complete a test on the computer literacy objectives, they also had to demonstrate an ability to use the computer as a tool for word processing, data base, and spreadsheet. They had to demonstrate the ability to use the computer as a lab instrument and as a tutorial. Students used the computer on the average of two days a week and had weekly assignments required to illustrate their knowledge and ability to use the computer. 
The hypothesis assumed 808 as an acceptable percentage of students successfully completing the computer literacy objectives. The State of Florida mandates for computer literacy do not state an acceptable level of passing rate for students taking the computer literacy. The percentage of $80 \%$ was chosen after evaluating other courses taught at Miami Palmetto Senior High School. Twenty-five teachers who taught other disciplines to the students involved in this study were asked what percent of students passed their classes for the same semester the study was conducted. The average percentage passing rate was 85.08 with the range extending from a low of 75.38 to a high of 91.38 . With this information available, the percentage of 808 was chosen because it was midway between the low percentage and the average. Thus, the null hypothesis was rejected by the data.

An important finding of this study was illustrated by combining the results of the three null hypothesis. Students in the integrated curriculum not only met the biology objectives as well as those in the traditional curriculum, they also successfully completed the intended objectives for computer literacy. Two sets of objectives were successfully completed in the integrated classes in 
the same amount of time used to complete one set of objectives in the traditional biology classes. Therefore, the integrated curriculum was the more efficient means of meeting the intended objectives of both biology and computer literacy.

By integrating the use of computers into the biology curriculum the students were able to successfully gain skills important in our society today while mastering content material in the biology curriculum.

\section{Conclusions}

The study showed that students taking the Integrated Biology and Computer literacy performed equally with those taking the traditional biology on a Biology posttest scores and passing rates in both biology and computer literacy. This indicates that Miami Palmetto Senior High's answer to the state mandate on computer literacy is successful.

Students taking the integrated curriculum still received a full Biology curriculum. Results show that they performed as well as those in the traditional curriculum. However, they also successfully completed the intended objectives for another required skill -- computer 
literacy. Therefore, the integrated curriculum may be a more efficient means of meeting the intended objectives of both Biology and Computer Literacy. In a time of crowded curriculums, it is important to note that the integration of computers into an existing curriculum is not only successful but also a more efficient than teaching the use of computer and the content area separately.

The Integrated Biology and Computer Literacy Curriculum has been successful overall. Students are learning Biology and becoming confident on using the computer. Parents are pleased with the program. The program meets the needs of many of our students. (Kenzel, personal communications, March 1, 1991.)

Students are definitely benefiting. More students are using the computers to do their work in Science. They are definitely computer literate. The instruction success is very obvious. (McCreary, personal communications, February 15, 1991).

\section{Implications}

The implications of these findings are that the mandated computer literacy requirements can be met by integrating computer literacy into an existing curriculum. 
"For most students, the way to ensure that the computer has the desired professional impact is to make it a natural part of each field, not a separate, and hence intimidating, field of its own (Trollip and Alessi, 1988). In this study, the use of computers was a teaching method and a skills the students acquired. Developing the skills needed to use the computer achieves the expectations of the state mandate on computer literacy. Using the computer as a teaching method allowed the students to gain these skills while meeting the intended content area objectives of biology. The fact that both sets of intended objectives -- computer literacy and biology -are met in the same amount of time as is traditionally used to cover one set of intended objectives adds to the success of the program.

By integrating the computer into the curriculum in this way the students did not see the computer as completely separate subject area, but as a tool used to achieve a goal -- learn biology. Students can then use this tool to achieve other goals in their lives -- in the pursuit of other content areas. Schools should take advantage of the computer as a tool in every subject area. Then students will truly be computer literate. 


\section{$\underline{\text { Recommendations }}$}

The conclusions drawn from this study serve as a basis for several recommendations. These fall into two categories: recommendations for educational practice and recommendations for future research.

Recommendations for educational practice:

1. Strategies for integrating computers into the traditional curriculum should be incorporated in the training of pre-service teachers. New teachers should come into the profession not only computer literate, but with the skills on how to implement that knowledge in whatever curriculum they are teaching.

2. Teachers already in the field should be encouraged to seek out and obtain training in the strategies for integrating computers into the traditional curriculum. This can be achieved through good, effective in-service programs as well as paid college classes. In-service trainers should be teachers who have successfully integrated the computer into their curriculum.

3. Teachers involved in integrating computers into the curriculum should team teach or work cooperatively 
with experienced teachers until they are comfortable with the new technology. Teachers training teachers should be utilized as one means of helping teachers to obtain the needed strategies to successfully integrate computers into the curriculum.

4. As students develop skills using computers in content areas, more computers will be needed in the schools, more creative uses of the computers needs to be implemented by teachers, and more teachers involved in integrating computers into content areas.

Recommendations offered for future research:

1. Similar studies should be conducted in various types and levels of schools including elementary, middle, and high schools to determine if the results of this study may be generalized to a wider population.

2. Similar studies should be conducted using computer literacy skills in other traditional disciplines -English, Social Studies, Math, etc., to determine if the results of this study may be generalized over various disciplines. 
3. Similar studies should be conducted in which student attitude and teacher attitude is taken into consideration.

4. Similar studies should be conducted in a less affluent school to determine if the results may be generalized over various socioeconomic groups. 


\section{BIBLIOGRAPHY}

Abdel-Gaid, Samiha. (1986). A Systematic Procedure for Constructing a Valid Microcomputer Attitude Scale. Journal of Research in Science Teaching. $\underline{23}$ (9) 823839.

Allessi, S. \& Trollip, S. (1985). Computer-based Instruction: Methods and Development. Englewood Cliffs, New Jersey: Prentice-Hall. Anderson, R. E., Klassen, D. L., Johnson, D. L. (1981).

In Defense of a Comprehensive View of Computer Literacy - A Reply to Luehrmann. Mathematics Teachers, 74, 687-690. Anderson, S. (1972). Sex Differences and Discrimination in Education. Worthington, Ohio: Charles A. Jones Publishing Co.

Apple, Michael. (1979). Ideology and Curriculum. Boston: Routledge and Kegan Paul. Apple, Michael, and Weis, Lois. (1983). Ideology and Practice in Schooling. Philadelphia: Temple University Press.

Baggett, Freeman E. "Development and Implementation of an Elementary School Computer Assisted Instruction Program." Dissertation. Nova University, 1984. 
Barnes, B. J., \& Hill, S. (1983). Should Young Children Work with Microcomputers - Logo with Lego? The Computing Teacher, 10, (9), 11-14.

Battista, M. T., \& Krockover, G. H. (1984). The Effects of Computer Use in Science and Mathmetics Education upon the Computer Literacy of Preservice Elementary Teachers. Journal of Research 21, 39-46. Battista, Michael, \& Steele, Kathleen. (1984). The Effect of Computer-Assisted and Computer Programming Instruction on the Computer Literacy of High Ability Fifth Grade Students. School Science and Mathematics, 84, 649-658. Batey, A. (1985). Integrating Microcomputers into Science Education. Computer Technology Program: Reports to Decision Makers. The Northwest Regional Educational Laboratory, Portland, Orgon. (ERIC Document Reproduction Service No. ED 264 086). Baumbach, Donna. Ed. (1987) Instructional Materials for Florida's Minimum Performance Standards in Computer Literacy. Orlando, Florida: UCF/DOE Instructional Computing Resource Center, University of Central Florida. 
Baumgarte, Roger. (1984). Computer Anxiety and Instruction. Paper presented at the Spring Meeting of the Southeastern Psychological Association, Atlanta, Ga.

Becker, Henry. (1986). Our National Report Card:

Preliminary Results from the New Johns Hopkins Survey. Classroom Computer Learning, $\underline{6}$ (4), 30-33. Becker, Henry. (1983). School Uses of Microcomputers: Reports from a National Survey. The John Hopkins University, Baltimore, Issues 1-3. Becker, Henry. (1984). The Social Context of Using Computers in Schools: It's Not Just a Matter of Good Software. Paper Presented at the Workshop on Computer Literacy, Paris, France. Becker, Henry. (1987). Using Computers for Instruction. BYTE, 9 , 149-162. Becker, Henry, \& Sterling, Carleton. (1987). Equity In School Computer Use: National Data and Neglected Considerations. Journal of Educational Computing Research, $\underline{3}, 289-311$.

Benson, G. (1984). Enhancing Learning Opportunities Through the Challenge of Technology. NASSP Bulletin, $\underline{68}(475), 64-77$. 
Berg, Roger. (1983). Resisting Change: What the

Literature Says About Computers in the Social Studies

Classroom. Social Education, May, 314-316.

Bernary, J. (1973). Sex Differences: An Overview.

(Module 26). New York: MSS Modular Publication.

Berstein, R. J. (1976). The Restructuring of Social and

Political Thought. Philadelphia: University of Pennsylvania Press.

Bitter, G., \& Gore, K. (1986). Curricular Implications of a Computer for Every Student. Computers in the Schools, 3 (2), 15-21.

Bliss, J., Chandra, P., \& Cox. M. (1986). The Introduction of Microcomputers into a School. In: Smith, P. R. (Ed.) Advances in Computer Assisted Learning. Selected Proceedings from the CAL 85 Symposium. Oxford: Pergamon. Boris, Blai. (1988). Technology in Education.

International Journal of Instructional Media, 15, 195-200.

Bork, Alfred. (1984). Computers in Education Today -And Some Possible Futures. Phi Delta Kappan, 66, 239-243. 
Bornstein, R. (1982). Sexism in Education. In M. P.

Sadker \& D. M. Sadker (Eds.). Sex Equity Workbook for Schools. White Plains, NY: Longman, 1982. Boss, J. S. (1982). Sexism Among the Micros. The Computing Teacher, 9 , (5). Bozeman, William. (1988). Microcomputers in Education: The Second Generation. T.H.E. Technological Horizons in Education Journal, $15,(6), 82-86$. Braun, L. (1980-81). Computer-Aided Learning and the Microcomputer Revolution. Programmed Learning and Educational Technology, 17-18, 223-229. Bullock, C., Broughton, B., and Harris, C. (1990). Miami Palmetto Senior High Request for Proposal - Computer Instruction Management. (Grant Proposal Presented to Dade County Public School Computer Education Department) •

Carnegie Quarterly. (1985). From Drill sergeant to Intellectual Assistant. Computers in the Schools, $30,3-4$.

Chambers, S. M., \& Clarke, V. A. (1987). Is Inequity Cumulative? the Relationship Between Disadvantaged Group Membership and Students' Computing Experience, Knowledge, Attitudes and Intentions. Journal of Educational Computing Research, $\underline{3}, 495-518$. 
Chen, M. (1986). Gender and Computers: The Beneficial Effects of Experience on Attitudes. Paper presented at the Annual Meeting of the American Educational Research Association. San Francisco. Cohen, J., \& Cohen. P. (1984). Opening Doors: Taking Sex-Role Stereotyping Out of Science and Mathematics. School Science and Mathematics, 84, 566-572.

Coleman, J. S. (1966). Equality of Educational

Opportunity. Washington, DC: U. S. Government Printing office.

Collis, B. (1988). Computers, Curriculum, and WholeClass Instruction. Belmont, California: Wadsworth Publishing Company.

Collis, B. (1985). Sex Differences in Secondary School Student's Attitudes Toward Computer. The Computing Teacher, $12,33-36$.

Cross, R. T. (1988). Task Value Intervention: Increasing Girls' Awareness of the Importance of Mathematics and Physical Science of Career Choice. School Science and Mathematics, 88, 397-411. Culp, George. (1986). "Computer - Using" Teachers and Programing Knowledge: Must Reality Deter Creativity? Educational Technology, 16, (2), 39-45. 
Dade County Public Schools. (1990) 1989-1990

Statistical Abstract of Dade County Public Schools. Miami, Florida: Dade County Public Schools.

Dede, C. (1989). Planning Guidelines for Emerging

Instructional Technologies. Educational Technology,

24 (4), 7-12.

Deaux, K. (1989). From Individual Differences to Social

Categories: Analysis of a Decade's Research on

Gender. American Psychologist.

Dennis, J., \& Standiford, S. (1984). The Computer and

the Teacher-Educator: Or Should It Be Vice-versa?

Educational Leadership, 22, (4), 27-31.

DeVault, Vere, \& Harvey, John. (1985). Teacher Education

and Curriculum Development in Computer Education.

THE Technological Horizons in Education Journal, 12,

$(7), 83-86$.

Dewey, John. (1915). The School and Society. Chicago:

University of Chicago Press.

Dickey, Edwin, \& Kherlopian, Richard. (1987). A Survey

of Teachers of Mathematics, Science, and Computers on

the Uses of Computers in Grades 5-9 Classrooms.

Educational Technology, 27, (6), 10-14. 
Di Muzio, Meri. (1990). A Survey of Fourth Grade Classroom Teachers' Computer Use and Perceptions Concerning Computer Use, Access, Software and Training in Dade County Public Schools (Doctoral dissertation, University of Miami, 1990). Manuscript submitted for publication.

Dressel, Paul. (1958). The Meaning and Significance Integration, in The Integration of Educational Experiences, The Fifty-seventh Yearbook of the National Society for the Study of Education. Chicago: University of Chicago.

Eisenberg, Yehuda. (1986). The Effects of Computer-Based Instruction on College Students' Interest and Achievement. Educational Technology, 26, (4), 40-43. Elron, O. (1983). Teaching With Computer Simulations. Science and Children, $\underline{20}$ (8), 13-17. Fennema, E. (1982). Women and Mathematics: Does Research Matter? Journal for Research in Mathematics Education, $\underline{12}$.

Fennema, E. (1987). Effective Teaching for Girls and Boys: The Same or Different? In D. C. Berliner \& B. V. Rosenshine (Eds.). Talks to Teachers. New York: Random House. 
Fetler, Mark. (1985). Sex Differences on the

California Statewide Assessment of Computer Literacy. Sex Roles, 13, (3/4), 181-191.

Fisher, G. (1984). Access to Computers. The Computing

Teacher. $11,24-27$.

Fisher, S., \& Pulos, S. (1983). Educational Implications

of Adolescents' Attitudes Towards Computers and Video

Games. Proceedings of EdCompCon. Institute of

Electrical and Electronics Engineers.

Flake, Jamice, McClintock, Edwin, \& Turner, Sandra.

(1985) . Fundamentals of Computer Education,

Belmont, California: Wadsworth Publishing Company.

Florida State Department of Education. (1986).

Minimum Student Performance Standards for Florida

Schools 1986 - 1991. Department of Education:

Tallahassee, Florida.

Fox, J. (1985). Humanistic CAL: Teachers' needs and Learners' needs in the Design and use of Computer assisted Language Learning Systems. In: Brumfit, C., Phillips, M. and Skehan, P. (Eds.) Computers in English Language Teaching. Oxford: Pergamon. Gage, N. L., \& Berliner, David. (1988). Educational Psychology. Dallas: Houghton Mifflin Company. 
Gay, L. R. (1981). Educational Research. Columbus, Ohio: Charles E. Merrill Publishing Co.

German, Kenneth. (1987/88). Attitudes Toward Computer Instruction. Journal of Computers in Mathematics and Science Teaching, I, (1-2), 22-28.

Good, Thomas, \& Brothy, Jere. (1986). Educational Psychology. New York: Longman. Good, Thomas, \& Brothy, Jere. (1987). Looking in Classrooms. New York: Harper and Row. Gordon, Sheldon. (1983). Results of a Project for Developing an Academic Computing Program. AEDS Journal, Winter, 113-121.

Grayson, Lawrence. (1984). An Overview of Computers in

U. S. Education. T.H.E. Technological Horizons in Education Journal, 12, (1), 78-87

Green, D. H. (1977). Attitudes. Motivation in Education.

Green, Michael. (1985). Computing Courses Guard Students Against Psychological Obsolescence. T.H.E Technological Horizons in Education Journal, 13, (2), 101-103.

Greenfield, P. M. (1984). Mind and Media, Boston: Harvard University Press. 
Griswold, Philip. (1983). Some Determinants of Computer Awareness Among Education Majors. AEDS Journal, 16, 92-103.

Hannafin, Michael, and Cole. D. D. (1983). "A

Comparison of Factors Affecting the Elective

Selection of Introductory Computer Courses. $\underline{\text { AEDS }}$ Journal, 16, 218-227.

Hannafin, Michael, Dalton, David, \& Hooper, Simon. (1987).

Computers in Education: Ten Myths and Ten Needs.

Educational Technology, 17, (10), 8-14.

Harter, Paula; and Gehrke, Nathalie. (1990). Integrative

Curriculum: A Kaleidoscope of Alternatives.

Educational Horizons, $68,(1), 12-17$.

Heinssen, Robert, Glass, Carol, \& Knight. (1987).

Assessing Computer Anxiety: Development and

Validation of the Computer Anxiety Rating Scale.

Computers in Human Behavior, 3 , 49-59.

Hoko, J. Aaron. (1986). What is the Scientific Value

of Comparing Automated and Human Instruction?

Educational Technology, 16, 16-19.

Hunka, S. (1981). CAI Developments in Canada.

Technological Horizons in Education, $\underline{8},(1), 57-59$.

Hyde, J. (1981). How Lare are Cognitive Gender

Differences? American Psychologist, $\underline{36}$. 
Ingersoll, G. M., \& Smith, C. D. (1984). Availability and Growth of Microcomputers in American Schools. T.H.E. Journal, 12 (1), 84-87.

Johnson, D. C., Anderson, R. E., Hansen, T. P., \& Klassen, D. L. (1980) - Computer Literacy - What is It? Mathematics Teacher, 73, 91-96. Johnson, D. C., Anderson, R. E., Hansen, T. P., \& Klassen, D. I. (1980). The Affective and Cognitive Effects of Microcomputer Based Science Instruction. Journal of Educational Technology Systems, 9 , 329-355. Johnston, Vivien. (1987). Attitudes towards Microcomputers in Learning: 1. Pupils and Software for Language Development. Educational Research, 29, (1), 47-55.

Johnston, Vivien. (1987). Attitudes towards Microcomputers in Learning: 2. Teachers and Software for Language Development. Educational Research, 29, (2), 137-145.

Joiner, M. L., Miller, S. R., and Silverstein, B. J. (1981). Potentials and Limits of Computers in Schools. In: Thomas, J. L. (Ed.), Microcomputers in Schools, Phoenix: Oryx Press. Jorde, Paula. (1986). Microcomputers: Tempering the Pro-Innovation Bias. Education, 106, 388-393. 
Judd, Wallace. (1983). A Teacher's Place in the Computer Curriculum. Phi Delta Kappan, 65 (9), 120-122. Kersh, Mildred. (1989). Integrative Curriculum for the 21 st Century. Educational Horizons, 68, (1), 2 . Kiesler, S., Sproull, L, \& Eccles, J. (1984). Poolhalls, Chips and War Games: Women in the Culture of Computing. Psychology of Women Quarterly 17, (3), 40-49.

Klausmeier, Herbert. (1985). Education Psychology. New York: Harper and Row. Konvalina, John, Stephens, Larry, \& Wileman, Stanley. (1983). Identifying Factors Influencing Computer Science Aptitude and Achievement. AEDS Journal, $\underline{46}$ (3), 106-111.

Kramer, C. (1974). Folk Linguistics. Psychology Today, 8, (6), 82-85.

Kulik, James, \& Bangert-Drowns, Robert. (1989). Computer-Assisted Learning. Handbook of Educational Ideas and Practices. 833-841.

Laubacher, Marilyn R. (1982). Computer Literacy. An ERIC Fact Sheet. ERIC Clearinghouse on Information Resources, Syracuse, N. Y. 
Laurillard, Diana. (1987). Computers and the

Emancipation of Students: Giving Control to the Learner. Instructional Science, 16, 3-18. Lawton, Johnny, \& Gerschner, Vera. (1982). A Review of the Literature on Attitudes Towards Computers and Computerized instruction. Journal of Research and Development in Education, 16, (1), 50-55. Lenkway, Peter. (1986). Minimum Student Performance Standards in Computer Literacy: Florida's New State Law. T. H. E. Technological Horizons in Education Journal, 13, (9), 74-77.

Lepper, M. R. (1985). Microcomputers in Education. American Psychologist, 40, 1-18.

Levin, G. (1985). Computers and Kids: The Good News. Psychology Today, September, 50-51.

Levin, H. M. (1983). About Time for Educational Reform. Stanford University. (No. 83-A19, IFG).

Levin, H., \& Meister, G. (1986). Is CAI Cost-Effective? Phi Delta Kappan, 68, 745-749.

Linn, Marcia. (1985). Gender Equity in Computer Learning Environment. Computers and the Social Sciences, 1 , (1), 19-27. 
Lockheed, M. E. (1985). Women, Girls, and Computers:

A first Look at the Evidence. Paper presented at the annual meeting of the American Association for the Advancement of Science, Los Angeles.

Lockheed, M. E., \& Frakt, S. B. (1984). Sex Equity:

Increasing Girls' use of Computers. The Computing

Teacher, 11 (8), 16-19.

Luehrmann, A. (1984). The Best Way to Teach Computer

Literacy. Electronic Learning, $\underline{3}, 7$.

Luehrman, A. (1985). A Computer Literacy - What Should

It be? Mathematics Teacher, 74, 682-686.

Maccoby, E. (1966). Six Differences in Intellectual

Functioning. In E. Maccoby (Ed.) The Development of

Sex Differences, Stanford: University of California

Press.

Maccoby, E. \& Jacklin, C. (1974). The Psychology of Sex

Differences, Stanford: Stanford University Press. Maddux, C. (1986). The Educational Backlash: Can the

Swing of the Pendulum be Halted? Computers in the

Schools, $3,(2), 27-30$.

Manning, A. (1984). Why Aren't Women Hacking It? The

Computer Gender Gap. USA Today, (October 16, 1984), 3D. 
Manuel, S. \& Quest, J. (1988). Curriculum and

Environment Interact. American School and

University, 60 (11), 22-23.

Masuda, Y. (1980). The Information Society as Post-

Industrial Society. Tokyo: Institute for the

Information Society.

Mckye, G. (1983). Computers in Education: Software

Cataloguing Project. AEDS Monitor, $22(1,2), 9-10$.

Mojkowski, C. (1987). Technology and Curriculum: Will

the Promis Revolution Take Place? NASSP Bulletin, 71 (496), 113-118.

Molnar, A. R. (1981). The Coming of Computer

Literacy: Are We Prepared For It? Educational

Technology, January, 26-28.

McClintock, Robert. (1986). Into the Starting Gate:

On Computing and the Curriculum. Teachers College

Record, 88, 191-213.

McCorduck, Pamela, \& Russell, Avery. (1986). From Drill

Sergeant to Intellectual Assistant: Computers in

Schools. Principal, 16-21.

McMeen, George. (1986). The Impact of Technological

Change on Education. Educational Technology, 42-45. 
Melmed, Arthur S. (1986). The Technology of American Education: Problem and Opportunity. T.H.E. Technological Horizons in Education Journal, September, 77-81. Milone, Michael. (1989). Classroom or Lab How to Decide Which is Best. Classroom Computer Learning. 34-43. Miami Palmetto Senior High School. (1977, 1978, 1979, $1980,1981,1982,1983,1984,1985,1986,1987,1988$, 1989, 1990). Curriculum Handbook. Miami, Florida: Dade County Public Schools. Miami Palmetto Senior High School. (1982). Statement of Philosophy and Objects. Ten Year Study. Miami, Florida: Dade County Public Schools. Mischel, H. (1974). Sex Bias in the Evaluation of Professional Activity. Journal of Educational Psychology, 66, 157-166. Miura, I. T. (1985). Factor Contributing to Middle School Computer Interests and Use. Paper presented at the Annual Meeting of the American Psychological Association, Los Angeles. Miura, I. T., \& Hess, R. D. (1984). Enrollment Differences in Computer Camps and Summer Classes. The Computer Teacher, II (8), 8-22. 
Miura, I. T., \& Hess, R. D. (1983). Sex Differences in Computer Access, Interest and Usage. Paper presented at the Annual Meeting of the American Psychological Association, Anaheim, Ca.

Mohamedali, M. H., Messer, D. J., \& Fletcher B. (1987). Factors Affecting Microcomputer Use and Programming Ability of Secondary School Children. Journal of Computer Assisted Learning, 3, 224-239.

Molnar, A. (1978). The Next Great Crisis in American Education: Computer Literacy. AEDS Journal, 12, 1120 .

Morris, David. (1988-89). A Survey of Age and

Attitudes Toward Computers. Journal of Educational Technological Systems, 17, (1), 73-78. Moskowitz, Jay, \& Birman, Beatrice. (1985). Computers in the Schools: Implications of Change. Educational Technology, 25, (1), 17-14. Moursund, David. (1975). What is Computer Literacy? Orgen Council for Computer Education, $\underline{2}, 2$. Moursund, David. (1984). To Improve Education. Creative Computing, 10, (11), 180-186.

Murphy, John, \& Pardeck, John. (1985). The Technological 
World-view and the Responsible Use of Computers in the Classroom. Journal of Education. 167, (2), 98187 .

Naisbitt, J. (1982). Megatrends. New York: Warner Books. National Commission on Excellence in Education. (1983). A Nation At Risk. Washington, D. C.: U.S. Department of Education. Neff, M. ED. (1982). Computer Education Curriculum Guide. Miami, Florida: Dade County Public Schools. Nielsin, M. Elizabeth. (1989). Integrative Learning for Young Children: A Thematic Approach. Educational Horizons. $68,(1), 18-24$. Norusis, Marija J. (1988). The SPSS Guide to Data Analysis for SPSSx. United States: SPSS Inc. Norton, Priscilla, \& Resta, Virginia. (1986). Investigating the Impact of Computer Instruction on Elementary Student's Reading Achievement. Educational Technology, 26, (3), 35-41. Oberholtzer, E. (1937). An integrated Curriculum in Practice. New York: Teachers College Press. Okey, J. (1984). Integrating Computers into Science 
Instruction. Paper presented at the Annual Meeting of the National Association for Research in Science Teaching, New Orleans, La. (ERIC Document Reproduction Service No. ED 244777 ).

Oliva, Peter F. (1988). Developing the Curriculum.

London: Scott, Foresman and Company.

Onderson, A, Welch, W. W., \& Harris, L. J. (1984).

Inequities in Opportunities for Computer Literacy.

The Computing Teacher, $11,(8)$.

Papert, S. (1980). Mindstorms: Children, Computers,

and Powerful Ideas. New York: Basic Books.

Parker, J., \& Widmer, C. (1984). Some Disturbing Data:

Sex Differences in Computer Use. In: Bonnette, D.

T. Proceedings of the Sixth Annual National

Educational Computing Conference. Norfolk, Virginia. Posner, George J., \& Rudnitsky, Alan. (1986). A Guide

to Curriculum Development for Teachers. 3rd ed. New York: Longman.

Preskill, Hallie. (1988). Teachers and Computers: A

Staff Development Challenge. Educational Technology, $\underline{28},(3), 24-26$.

Preston, R. (1962). Reading Achievement of German and American Children. School and Society, 90. 
Pulos, Steven, \& Fisher, Sarah. (1987). Adolescents' Interest in Computers: The Role of Attitude and Socioeconomic Status. Computers in Human Behavior, 3, (1), 29-58.

Pulos, S., Fisher, S., \& Stage, E. K. (1985). Growing Up in a Computer World. Paper presented at the Annual Meeting of the American Psychological Association, Los Angeles.

Randhawa, Bikkar, \& Hunt, Dennis. (1984). Computers and Computer Literacy in Contemporary Psychological Socio-Economic and Educational Context. $\underline{\text { AEDS }}$ Journal, 47, 1-11.

Reed, w. (1986). Teachers' Attitudes Toward Educational Computing: Instructional Uses, Misuses, and Needed Improvements. Computers in the Schools, $\underline{3}(2), 73-80$.

Reyes, Laurie Hart, \& Stanic, George. (1988). Race, Sex, Socioeconomic Status, and Mathematics. Journal for Research in Mathematics Education, 19, 26-43. Richman, Ellen. (1988). Equity in Technology. The Computer Teacher, 15, (5), 35-37. Roberts, N., Carter, R., Friel, S., Miller, M. (1988) Integrating Computers into the Elementary and Middle School. Englewood Cliffs, New Jersey: Prentice. 
Roblyer, M. D., Ed. (1989). Making the Most of

Microcomputers in the Classroom. Tallahassee,

Florida: Department of Education, State of Florida. Roblyer, M. D., Castine, W. H., \& King, F. J. (1988).

Assessing the Impact of Computer-Based Instruction:

A Review of Recent Research. New York: Haworth

Press.

Rosenholtz, S. (1985). Political Myths about

Education Reform: Lessons from Research on Teaching.

Phi Delta Kappan, 66, 349-355.

Sadker, M. P., \& Sadker, D. M. (1982). Sex Equity

Handbook for Schools. White Plains, NY: Longman. Sanders, J. S. (1984). The Computer: Male, Female or

Androgynous? The Computing Teacher, 11, 31-34.

Sanders, J. S. (1985). Making the Computer Neuter. The

Computing Teacher, 12, 23-37.

Saracho, O. N. (1982). The Effects of a Computer-

Assisted Instruction Program on Basic Skills

Achievement and Attitudes Towards Instruction of

Spanish-speaking Migrant Children. American

Educational Research Journal, 19, 201-219. 
Saylor, J. Galen; Alexander, William; \& Lewis, Arthur. (1981). Curriculum Planning for Better Teaching and Learning. 4th ed. New York: Holt, Rinehart and winston.

Schroth, Martin. (1988). Elements of Computer Literacy for Teachers. Unpublished paper. Paper Submitted to Dr. James Wells in Partial Fulfillment of EDG 7362 . Miami: Florida International University Schubert, J. G. (1987). Cooperative Learning, Equity and Computer Learning. Presentation at the Annual Meeting of the America Educational Research Association, Chicago, Il.

Schubert, J. G. (1984). Females and Microcomputer Use in School: Some insights into Traditional Patterns. Paper Presented to the Annual Meeting of the American Educational Research Association, New Orleans, La. Schubert, J. G. (1986). Gender Equity in Computer Learning. tip Theory Into Practice, 25, 267-275. Self, Charles C. A Position on a Computer Literacy Course. (1983). Paper Presented at the University of Massachusetts-Amherst. Sherman, J. E. (1980). Sex Differences in Mathmetics. Mathmetics Teacher, 15, (4). 
Shivey, Joe. (1984). Computer Utilization in

Education: Problems and Prerequisites. $\underline{\text { AEDS }}$

Journal, Spring, 24-31.

Smith, Sara Dawn. (1987). Relationships of Computer

Attitudes to Sex, Grade-Level, and Teacher Influence. Education, 106, 338-344.

Smith, Sara Dawn. (1987). Computer Attitudes of Teachers and Students in Relationship to Gender and Grade Level. Journal of Educational Computing Research, $\underline{3}$, 479-494.

Stanton, William. (1985). Adults and Computers. THE

Technological Horizons in Education, 12, (7), 92-93. Steier, Lloyd. (1987). Computer Technology and

Education. The Alberta Journal of Educational

Research, 33, (2), 82-95.

Steele, Kathleen, Battista, Michael, \& Krockover, Gerald.

(1984). Using Microcomputer-Assisted Mathematics

Instruction to Develop Computer Literacy. School

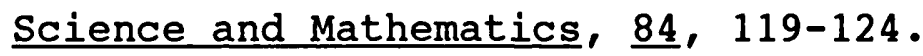

Stevens, Dorothy. (1982). Educators' Perception of

Computers in Education: 1979 and 1981. $\underline{\text { AEDS }}$

Journal, 15, 1-15.

Stevens, Dorothy. (1984). Why Computers in Education

May Fail. Education, 104, 370-376. 
Suppes, Patrick, \& Fortune, Ronald. (1985). ComputerAssisted Instruction: Possibilities and Problems. NASSP Bulletin, 69, $(480), 30-34$.

Swadener, Marc, \& Hannaflin, Michael. (1987). Gender

Similarities and Differences in Sixth Graders'

Attitudes toward Computers: An Exploratory Study.

Educational Technology, 27, (1), 37-41.

Swadener, Marc, \& Jarrett, Karen. (1986/87). Computer

Use in Content Areas in Secondary Schools. Journal

of Computers in Mathematics and Science Teaching, $\underline{6}$ $(1-2), 12-14$.

Taba, Hilda. (1962). Curriculum Development: Theory

and Practice. New York: Harcourt Brace Jovanovich. Tekerman, Joseph. (1990). Division of Technology

Training Course Offerings 1990-1991. Miami, Florida:

Dade County Public Schools.

Tetenbaum, T., \& Mulkeen, T. (1986). Computers as an

Agent for Educational Change. Computers in the

Schools, 2, (4), 91-103.

Tiegr, T. (1980). On the Biological Basis of Sex

Differences in Aggression. Child Development, $\underline{51}$. Toffler, A. (1980). The Third Wave. New York: Bantam. 
Trollip, Stanley, \& Alessi, Stephen. (1988).

Incorporating Computers Effectively into Classrooms. Journal of Research on Computing in Educating, 21, 70-81.

Troutman, A., White, J., \& Breit, F. (1988). The Micro Goes to School: Instructional Applications of Microcomputer Technology. Pacific Grove, California: Brooks/Cole Publishing Company. Tyler, Ralph. (1949). Basic Principles of Curriculum and Instruction. Chicago: University of Chicago Press.

Vakos, Harry. (1986). Ten Steps to Putting Together a Comprehensive Plan for Computer Education. T.H.E. Technological Horizons in Education Journal, 13, (10), 56-59.

van Deusen, Jean, \& van Deusen, Robert. (1989). Don't Buy Computers Unless ... . Principal, 69, (2), 1015 .

Vetter, B. (1983). Manpower Comments, 20, 29. Vermette, Sandra, Orr, Robert, \& Hall, Michael. (1986). Attitudes of Elementary School Students and Teachers Toward Computers in Education. Educational Technology, January, 41-46. 
Vernot, David. (1987). Thirteen Concerns Teachers Still

Raise About Computers. Instructor, Fall, 17-21. Wagschal, Peter. (1984). A Last Chance for Computers in the Schools? Phi Delta Kappan, 23 (12) 251-254. Wagschal, Peter. (1986). Computers in the Schools: Lessons From Television. Curriculum Review, 25, (3), 32-34 .

Walker, Decker. (1983). Reflections on the Educational Potential and Limitations of Microcomputers. Phi Delta Kappan, $\underline{22}$ (10), 103-107.

Ware, M. C., \& Stuck, M. F. (1984). Sex-role Messages Vis-a-Vis Microcomputer use: A Look at the Pictures. A Paper presented at the Annual Meeting of the American Educational Research Association, New Orleans, La. 153-165.

Watson, J. Allen, Calvert, Sandra, \& Brinkley, Vickie. (1987). The Computer/Information Technologies Revolution: Controlversial Attitudes and Software Bottlenecks - A Mostly Promising Progress Report. Educational Technology, 27, (2), 27-11. Webb, N. (1984). Microcomputer Learning in Small Groups: Cognitive Requirements and Group Process. Journal of Educational Psychology, 76 (6), 1076-1088. 
Wedman, John. (1988). Increasing the Use of Instructional Media in the Schools. Educational Technology, 28, (10), 26-31.

Whatley, Myra.. (1984). Integrating Computer Literacy into the Vocational Curriculum. Paper Presented at the Microcomputers and High Technology in Vocational Education Conference (pp. 6-63). Madison, Wi. Whiteside, C., and James, R. (1986). Utilizing

Teachers' Concerns to Improve Computer Implementation. Computers in the Schools, 2, (4), 29-41.

Willis, Paul. (1977). Learning to Labour. Farnborough: Saxon House. Woodrow, Janice. (1987). Educators'Attitudes and Predispositions towards Computers. Journal of Computers in Mathematics and Science Teaching, $\underline{6}$, (3), 27-37

Yahn, Christina, and Lenkway, Peter. ED. (1989). Interactive Lessons for Integrating the Computer Literacy Minimum Student Performance Standards. Tallahassee, Florida: Florida Department of Education. 
COMPUTER EDUCATION COURSES

MIAMI PALMETTO SENIOR HIGH SCHOOL

INTRODUCTION TO DATA PROCESSING -- Business Education Department. Prerequisite: Above average grades; interest ingraining some knowledge about computers with the possibility of pursuing this interest upon graduation. Objectives: The student will be able to define manual mechanical punched-card and electronic data processing terminology, and perform basic operations related to data processing. Content: This course is designed to provide fundamental knowledge concerning the procedures and functions relating to computer programming, flowcharting, and language used in data processing.

GENERAL OFFICE CLERR -- Business Education Department. Course Description: This is a laboratory course designed to develop desirable work habits and familiarity in the use of a variety of office machines. Minimum instruction includes: addinglisting machines, calculators, duplicating machines, and an introduction to key-punch and bookkeeping machines. 


\section{INTRODUCTION TO COMPUTERS AND PROGRAMMING -- Math}

Department. Course Description This introductory computer course offers interested students the opportunity to gain skills and concepts concerning computers, the social effect of computers, computer language, and computer programming. The content consists of topics dealing with the definitions, history, language distinctions, general system commands, text files, and a peripheral commands of computers. Students will learn how to write and run programs in BASIC. Selection Consideration: Designed for the serious mathematics student who has completed Algebra II A, B, with above average performance; teacher recommendation.

\section{COMPUTER PROBLEM SOLVING -- Math Department. Course}

Description: This course is a continuation of Introduction to Computers and Programming and offers the student the opportunity to gain additional skills and concepts in more advanced programming techniques. The content consists of topics dealing with functions, subroutines, converging processes, matrices, etc. Students will be assigned one of the more major projects during each semester for which they must design, write, and process a program (s) 
and accompanying software and courseware. Selection Considerations: Successful completion of introduction to computers and Programming with above average performance; teacher recommendation.

COMPUTER LITERACY AND COMPUTER APPLICATIONS -- Computer Education Department. Course Description: This introductory course is designed to enable students to understand the nature of computers and their impact on society. Topics covered include computer components and terminology, computer capabilities and limitations, computer careers, computer uses in various fields, and computer problem solving. It is designed to introduce students to the care and uses of microcomputers and to give students an opportunity for some hands-on experience. Selection Consideration: Designed for students who wish to acquire some background in microcomputers.

PROGRAMMING IN BASIC -- Computer Education Department. Course Description: This course is designed to provide a coordinated introduction to the creative process of designing algorithms and writing computer programs in BASIC. Also covered will be the impact of computers on society and computer terminology. Selection Considerations: Designed for the serious 
student who has successfully completed Algebra I with above average performance. Teacher Recommendation. INTERMEDIATE PROGRAMMING -- Computer Education Department. Course Description: This course is designed to be a sequel to Programming in Basic. Topics of study will include string handling, file processing, and graphics. Selection Considerations: Successful completion of two semesters of Programming in Basic. Teacher Recommendation.

\section{ADVANCED COMPUTER PROGRAMMING (HONORS) -- Computer}

Education Department. Course Description: An elaboration of some of the more difficult topics in microcomputer programming, this course may include the study of high level languages other than BASIC. Selection Considerations: For the student who has successfully completed Intermediate Programming or who has the recommendation of the instructor.

COMPUTER IAB AIDE -- Computer Education Department. Course Description: This course is designed for those students who wish to assist in the computer education program. Selection Consideration: Teacher recommendation. 
EX STUdENT VOC/DATA PROCESSING BASIC I -- Computer Education Department. Course Description: Ex Student Voc/Data Processing, Basic $I$, is designed to provide specialized vocational education designed to meet the needs of handicapped learners with provisions for: history and development of data processing, current uses of visual display terminals and computer systems, basic peripheral equipment functions, input and output devices, and elementary techniques of programming. Selection Consideration: Exceptional student.

MICROCOMPUTER BUSINESS APPLICATIONS, BEGINNING -- BusinesS Education. Course Description: This course is designed to provide an introduction to microcomputers, a basic understanding of the function of the components of a microcomputer system, and the application of business concepts using the basic language, topics include flowcharting concepts, data entry procedures, accounting application of business concepts using the basic language. Selection Considerations: Student interest in automated accounting occupations. 
MICROCOMPUTER BUSINESS APPLICATIONS, ADVANCED -- BusinesS

Education. Course Description: This course is designed to teach flowcharting techniques, file handling, advanced accounting applications, word processing techniques, and advanced programming language(s). Selection Considerations: The student will display a mastery of skills acquired in Microcomputer Applications, Beginning.

\section{INTRODUCTION TO COMPUTERS/COMPUTER APPLICATIONS --}

Computer Education Department. Course Description. The purpose of Introduction to Computers is to provide students opportunities to understand the capabilities, applications and social implications of computer technology. The content should include, but not be limited to, computer components and terminology, computer capabilities and limitations, computer problem solving and the role and implications of computers in society. The purpose of Computer Applications is to introduce students to the care and uses of microcomputers and to give them an opportunity for as much hands-on experience as possible. The content should include, but not be limited to, simple programming and the use of commercially available software. Topics may include 
the demonstration and utilization of software programs in data management, word processing, spreadsheet analysis, graphics, authoring languages and the use of telecommunications packages. Selection Considerations: This course is designed for the student who has had no previous microcomputer course or experience.

AP ADVANCED PLACEMENT COMPUTER SCIENCE -- Computer

Education Department. Course Description: The purpose of this course is to treat the applications of computing within the context of programming methodology, algorithms, and data structures. The content should include, but not be limited to, that determined by the Advanced Placement Program. Selection Considerations: Teacher recommendation required. Suggested Prerequisite: Computer Programming III.

ESE - COMPUTERS FOR SPECIAL LEARNERS -- Computer Education Department. Course Description: This course is designed to provide opportunity for students to achieve computer literacy. The content should include, but not be limited to, proper use and selection of appropriate software and adaptive devices. Selection Considerations: This course is 
designed to meet the special needs of exceptional students. This course may be repeated for multiple credit.

INTRODUCTION TO COMPUTERS (COMPUTER LITERACY) -- BusinesS Education. This course is offered to meat the RAISE requirement of .50 credits in Performing/Fine Arts and the .50 credit in Practical Arts. These .50 credits are required of all students planning to graduate in 1987 and thereafter. Course Description: The purpose of this course is to provide students opportunities to understand the capabilities, applications and social implications of computer technology. The content should include, but not be limited to, computer components, and terminology, computer capabilities and limitations, computer careers, computer uses in various fields, and computer problem solving the role and implications of computers in society. Selection Considerations: This course is designed for the student who has had no previous microcomputer coursework or experience. (Students who take this class should be those who are not planning to continue with computer courses. It is a textbook course with very little actual work with computers.) 
WORD PROCESSING -- Business Education. Course

Description: This course is designed to reinforce and extend skills required for recording and transcribing machine recorded diction utilizing word processing equipment. Oral and written communication skills are reinforced.

BIOLOGY/COMPUTER IITERACY -- Science Department. Course Description: The purpose of Biology is to provide students with general exploratory experiences and activities in the fundamental concepts of life. Opportunities to understand the interactions of science with technology and society should be provided. The content should include, but not be limited to scientific method, scientific measurement, laboratory safety and use of apparatus, cell biology, cell reproduction, basic principles of genetics, biological changes through time, classification and taxonomy, microbiology, structure and function of plants, structure and function of animals, structure and function of the human body, and ecological relationships. Laboratory investigations of selected topics in the content which also include the use of the scientific method, measurement, laboratory apparatus and safety are an integral part of the 
course. (Computer literacy is part of this course. Students planning to graduate in 1988-1989 and thereafter are required to demonstrate mastery of basic computer literacy skills through successful completion of a computer education course or unit of study in computer literacy. Students taking Biology or Honors Biology will have a unit of study which incorporates the state standards and skills required for computer literacy.)

The above descriptions of computer courses offered at Miami Palmetto Senior High School were taken from the Miami Palmetto Senior High School Curriculum Handbook years 1977-1978, 1978-1979, 1979-1980, 1980-1981, 1981-1982, 1982-1983, 1983-1984, 1984-1985, 19851986, 1986-1987, 1987-1988, 1988-1989, 1989-1990, and 1990-1991. 


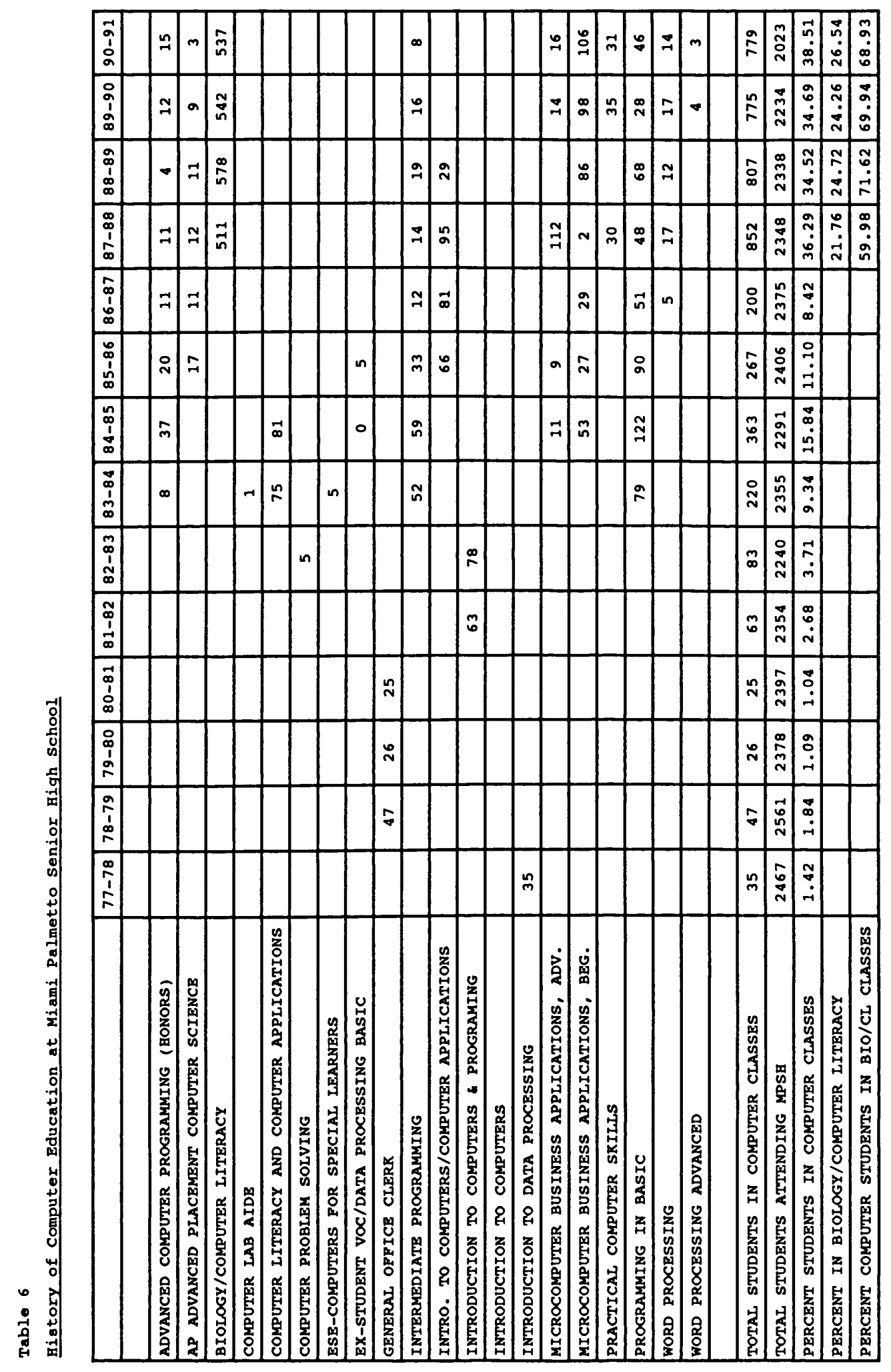


1. Theresa got several programs from the public domain. Which of the following is illegal?

a. Making several copies to store.

b. Making copies and giving them to friends.

c. Charging $\$ 2.00$ for the cost of a disk that contains a public domain program.

d. Selling the programs she did not like.

2. Which of the following storage media causes the slowest storage of information?

a. hard disks

b. floppy disks

c. storage speed is the same for all storage media

d. tapes

3. Which of the following would be impossible if computers did not exist?

a. 24-hour services

b. flying a space shuttle

c. playing games

d. banking

4. Ann's parents just gave her a tape cassette unit for her computer. What advantage does this provide Ann? a. There is no advantage.

b. Ann can now hear her programs in her tape recorder.

c. Programs now can be saved and not lost even if Ann turns her computer off.

d. Ann's programs will run much faster.

5. Many large businesses use a data base to store personal information. A major advantage of a computer data base is

a. the need for fewer employees

b. efficiency and accuracy of information

c. ease in planning office parties

d. that no one can have any secrets

6. Name the job created by the use of computers.

a. weather forecaster

b. robotics engineer

c. banker

d. accountant 
7. A special purpose computer is the

a. computer found in programming classes

b. minicomputer

c. supercomputer

d. computer found in most home telephones

8. Without authorization, George finds a way to enter a national security computer. George does not change any information. He just looks and learns a lot of interesting facts about the nation. What could be a result of his action?

a. George is not in trouble because he did not change any information.

b. George's computer, as well as the government's computer, can be damaged.

c. George could be arrested, fined or imprisoned

d. The government's computer program could be completely destroyed

9. A computer is always involved when you

a. play electrical musical instruments

b. cook dinner

c. write a letter to a friend in another city

d. play a video game

10. A disadvantage of using a computer data base to store personal information about an individual is that

a. misinformation cannot be corrected

b. it is totally unaccessible to the individual

c. no one can have an unpublished telephone number

d. one's right to privacy might be threatened

11. Choose the correct logical steps the computer follows to balance a checking account:

I. Add all the checks and subtract from the previous balance. II. Give the current balance.

III. Obtain the previous balance and checks written.

a. II, I, III

b. II, III, I

c. III, I, II

d. I, II, III 
12. Marc's dad wants to store his many friends' names and addresses on a disk. What is one of the advantages of storing all the information using a disk drive?

a. Marc's father can now use that information on any brand of computer.

b. Any error will be eliminated when the disk drive is used.

c. Marc's program will not be able to be copied unless Marc's personal secret code is entered.

d. The disk drive can be used to save large amounts of information that might not otherwise fit in main memory

13. Jim is writing a program on a computer. He things that he can use this program in his science class next year, so he stores in on his disk. What is the advantage of storing his program using a disk drive? a. Jim's program will be saved for later use.

b. Any math errors Jim made will be corrected by the disk drive.

c. Jim's science teacher will be very impressed with his scientific knowledge

d. Jim's disk can now be used on the school computer which is a different brand from his

14. John bought a new program. He wants to find out how to use the program. Which of the following is the best place to find out how to use the program?

a. Computer Textbook

b. Computer Instruction Manual

c. Program documentation

d. Computer Software catalog

15. The automobile industry uses computers to paint cars. is one of the main advantages of

using computers for this kind of work.

a. repetition of the same task

b. selection of colors

c. usage of less expensive paint

d. more car sales

16. Which of these tasks could be better performed by a computer?

a. choosing your favorite outfit

b. alphabetizing 1000 names

c. playing a musical instrument

d. deciding on your essay topic 
17. Because of computerization there has been an increased number of

a. jobs deal with large amounts of information

b. men are being promoted to executive positions

c. jobs require manual labor

d. women are staying home to raise a family

18 .

using computers in a nuclear plant because temperature control is a critical factor.

a. a shorter work week

b. accuracy

c. reducing nuclear waste

d. elimination of foreign spies

19. What is the function of random-access memory (RAM)?

a. to store the programs and data that are being used

b. to allow the processed information to be given to the user

c. to allow users to enter information into the computer

d. to store instructions and commands permanently

20. The series of programs that coordinate all the functions within a computer is called the

a. data base system

b. record and file system

c. electrical system

d. operating system

21.

computers. has been made possible by

a. The complex telephone system we have today

b. Architectural design

C. Publishing

D. Transatlantic flight

22 .

without computers.

would not be possible today

a. 24-hour electronic banking

b. banking

c. mailing lists

d. grocery shopping 
23. Which of the following is an example of a general purpose computer?

a. a mainframe computer used by a business

b. a computer in a microwave

c. a computer that controls an automobile engine

d. a computer video game at an arcade

24 .

a. supercomputers

are special purpose computers.

b. computers built into appliances

c. microcomputer

d. minicomputers

25. Based on today's new technologies, a possible future impact of computers on the way people live is

a. weeding and gardening by computer

b. total electronic child care

c. elimination of poverty

d. purchasing food without leaving home

26. Software can be stored on a

a. monitor

b. joystick

c. tape

d. keyboard

27. Bill is going to use a new blank disk to store the articles that will appear in the school newspaper next week. Which of the following is a true statement?

a. Some brands of computers would allow Bill to store the articles on disk without initializing or formatting.

b. It is necessary for the disk to be initialized or formatted only if Bill wants to store numbers on it

c. The disk has to be initialized or formatted before Bill can store the articles

d. Because Bill will be using the disk for information storage only, the disk does not have to be initialized or formatted. 
28. The correct flow of data through a computer system is a. get the information, processes the information, and output the results

b. output the results, process the information, and get the information

c. get the information, output the results, and process the information

d. process the information, output the results, and get the information

29. Computers will not have a major impact on the way people
a. play sports
b. cook
c. learn
d. drive

30. What controls the internal functions of a computer?
a. spreadsheet software
b. word processing software
c. operating system software
d. data base software

31. A job created by the use of computers is

a. school principal

b. grocery clerk

c. typist

d. data system analyst

32. $A(n)$

computer.

a. video game computer

b. sensor computer

c. supercomputer

d. electronic calculator

33. Computer have affected jobs by

a. increasing the need for manual labor

b. replacing many factory workers with robots

c. decreasing the female work force

d. increasing the number of fast food workers 
34. Jane wants to know if the math computer program she selected is too advanced for her. Where can she find this information?

a. computer textbook

b. mathematics textbook

c. computer user's guide

d. program documentation

35. Which of the following is a function of a computer operating system?

a. to control internal functions of the computer

b. to produce a hardcopy of a program

c. to allow the user to enter corrections to word processing documents

d. to add and compare numbers

36. Which of the following programs is required to run any other program?

a. data base

b. menu

c. catalog

d. operating system

37. A good rule to follow in to prevent losing or altering computer program is to

a. try not to use the program too frequently

b. make a back-up copy of the program

c. be a member of a computer user's club

d. buy inexpensive programs

38. Ann just bought a computer. Last year in school she used a different brand of computer. Can Ann use the disk she used in school in her new computer?

a. No, Ann needs to buy another disk

b. Yes, but only after she initializes the disk on her computer

c. Yes, Ann's disk works in any brand of computer

d. Yes, but Ann has to send it back to the manufacturer so it can be demagnetized

39. The job of computers came into existence. did not exist until

a. banker

b. traffic controller

c. data entry operator

d. game designer 
40. One way computers are used in medicine is

a. making people go for regular check-ups

b. performing emergency operations when the doctors cannot be reached

c. monitoring life support systems

d. forcing patients to pay their bills

41. Which of the following is NOT an example of program documentation?

a. computer textbooks

b. the program user's manual

c. menus displayed while the program is running

d. graphics screens showing program name and author(s) displayed while the program is running

42. Ms. Smith bought a geography program so that her students could learn the U.S. capitals. Which of the following is legal?

a. making one backup copy to store

b. making copies to sell to all her students

c. making several copies of the program to rent to

the students who have problems memorizing

d. making copies to give to other geography teachers

43. Before saving a program or data to a brand new disk, one must first

a. notify the publisher

b. write the description on the label

c. initialize the disk

d. punch a hole in the disk

44. Which of the following is an example of a special purpose computer?

a. mainframe computer

b. temperature controlling computer

c. microcomputer

d. minicomputer

45. Computers are being used to store personal information on many aspects of an individual's life. A major problem with this data base on individual is a. minority hiring

b. the right to privacy

c. storing a lot of information

d. the right to own a computer 
46. In the automobile industry computers can be used in

a. assuring that all employees come to work

b. supervising the employees

c. deciding on the hiring and firing of employees

d. simulating the impact of cars during an accident

47. Because information on a disk is easily destroyed or altered, whenever possible one should

a. buy programs that are stored on brand new disks

b. become a member of a local bulletin board

c. make a back-up copy of the program

d. buy programs that cost less than $\$ 100.00$

48. Choose the job which DID NOT come about because of computers.

a. software engineer

b. video graphics designer

c. business manager

d. robotics engineer

49. The spelling program you are using requires a brand new data disk. To prepare the data disk you should first

a. initialize the disk

b. punch a hole in the disk

c. write protect the disk

d. clean the disk thoroughly with a magnetic media cleaner

50. In a high school, what is the greatest advantage of using a computer to print the report cards?

a. the report cards will look much nicer

b. students will learn about computers

c. student report cards can be produced in less time

d. fewer students will fail

51. is one of the consequences that computerization has had on our society.

a. delay in obtaining credit information

b. retaining of personnel to keep up with the new technology

c. more paperwork

d. a decrease in crime 
52. In the arts, computers have many uses. The theater can use computers to

a. ensure that the artists perform at their best

b. program complicated light changes before the performance

c. insure that all shows are filled to capacity

d. ensure that the performance starts on time

53.

greatly affected by computers.

most likely will NOT be

a. manufacturing cars

b. traveling

c. typing letters

d. camping

54. You just bought a computer game program. Where is the best place to find out the computer equipment necessary in order to run your new program?

a. computer textbooks

b. program user's manual

c. software catalog

d. computer manuals

55. One of the major disadvantages of a tape as a storage medium is that

a. tapes are very expensive

b. tapes have to be cleaned after every use

c. data stored on tapes cannot be accessed randomly

d. data can be lost because tapes are too fast

56. Which of the following tasks would be performed best by

a computer in a large company?

a. preparing the payroll

b. deciding on the entry level salary

c. designing the company's products

d. determining the most valuable employee

57. One reason for making a back-up of a computer program is in case

a. the program is lost

b. the back-up copy might run faster than the original

c. you want to give a copy to a friend

d. the heat of the computer might burn the disk 
58. Which of the following indicates the correct flow of data through a computer?

a. input, processing, output

b. processing, input, output

c. input, output, processing

d. output, processing, input

59. How have computers affected office work?

a. the need for offices is becoming practically nonexistent

b. offices are now more socially oriented

c. office automation has increased

d. offices are now less crowded

60. As a consequence of computerization, secretaries have had to learn

a. new skills such as word processing

b. decision-making techniques

c. managerial abilities

d. shorthand skills

61. You bought a brand new computer program game package. You take the disk out and boot the system, yet nothing happens. What have you failed to do?

a. Read computer magazine reviews of the program

b. read your textbook

c. read your computer manual

d. read the program documentation

62. Mrs. Henry purchased copyrighted software for the computer in her math class. Which of the following uses is NOT legal?

a. making one backup copy to store

b. using the program to learn programming techniques

c. making copies to sell to all of her students to use on their home computers

d. using the program on one computer for several classes during the day 
63. Without permission from the school, Pat a member of the computer club finds a way to change information in the school computer. Which of the following is NOT a probable consequence of his action?

a. Pat could go to jail

b. The modem used is probably damaged.

c. A lot of time and money might have to be spend correcting and verifying information that might have been altered.

d. Pat could be arrested or fined.

64. What is one of the media in which software can be stored?
a. cathode ray tubes (CRT)
b. keyboards
c. card readers
d. tapes

65. What is the greatest advantage of using a computer to calculate and print the bills for a small business?

a. The bills can be produced in less time.

b. The bills will be more colorful.

c. More customers will pay their bills.

d. The customers will not complain.

66. Data flow through a computer system consists of a. processing, input, output.

b. output, input, processing.

c. input, output, processing.

d. input, processing, output.

67. By saving programs on a diskette Katie can

a. send her programs to her brother in college easier.

b. run her programs on any brand of computer.

c. make her programs run faster.

d. run her programs on any tape player.

68. Adam, without permission, has found a way to change students' grades in the school computer. This action could lead to

a. destroying someone's chance to be accepted into the college of his choice.

b. damage to his modem.

c. damage to the hardware of his computer.

d. loss of all programs in Adam's computer. 
69. One of the main disadvantages of

that information must be retrieved sequentially.

a. floppy disks

b. hardcopies

c. ROM

d. tapes

70. What is a major advantage of using a computergenerated data base containing information on a large number of people?

a. Everyone will have the opportunity to meet a lot of people.

b. Data bases are very portable so anyone can obtain a copy just by asking.

c. Anyone can access any data base through the use of a telephone.

d. A lot of information can be obtained in short time.

71.

the computer.

is a job better done by

a. Typing 5000 address labels

b. Writing a novel

c. Creating a new recipe

d. Landscaping a home

72. In the future, computerization may have an impact on the way people live by allowing them to

a. have major surgical operations done in their own home.

b. access the information of a public library at home.

c. make world peace.

d. eliminate bacteria from the environment.

73. John is writing a program on a computer. He frequently stores his work on his disk. What is the advantage of storing information using a disk drive? a. The disk clears up any errors.

b. The disk loses the information when the computer is turned off.

c. The disk containing the information can be used on any brand of computer.

d. The information will not be lost is electricity goes off. 
74. The is the "brain" of the computer.

a. Chip

b. Central processing unit (CPU)

c. Arithmetic/logic unit (ALU)

d. Disk drive

75. The task best performed by a computer is:

a. welcoming visitors to your home.

b. counting the number of outfits in your closet.

c. counting the cars that use a particular street.

d. deciding how many people to invite to your party.

76. A common place where software can be stored is a(n)

a. disks.

b. printer.

c. long playing record.

d. input device.

77. What job was created by the use of computers?

a. medical researcher

b. accountant

c. programmer

d. pilot

78. Which of the following is a reason for making a backup copy of a computer program?

a. The program stored on the disk can be destroyed.

b. The program stored on the disk cannot be copied.

c. The back-up runs faster than the original.

d. The heat of the computer may burn the disk.

79. What is the purpose of an input device?

a. Entering information into a computer

b. Providing electrical power

c. Showing information

d. storing data

80. What is a typical use of computers in the home?

a. Making dental appointments for the family.

b. Selecting TV programs that the family will enjoy.

c. Keeping a record of the family finances.

d. Keeping the house in proper order. 
81. Unauthorized by the school system, John discovers a way to change the information in the school

district's computer. What could be one result of his actions?

a. Destroying important school records.

b. Changing programs in his computer.

c. Damaging hardware in the school's computer.

d. Burning out parts of his computer.

82. The devices that make the result of the processed data available to people are called

a. output devices.

b. memory devices.

c. storage devices.

d. input devices.

83. Choose the correct logical sequence of steps the computer follows in order to print an alphabetized list of names.

I. Print the list of names on the printer.

II. Get all the names.

III. Alphabetize the name.
a. I, III, II
b. III, I, II
c. II, III, I
d. I, II, III

84. Ralph bought a computer game. Which of the following uses is illegal?

a. Lending the program to his friend.

b. Making one backup copy to store.

c. Making one copy to sell.

d. Giving a demonstration of the program to several computer classes.

85. The purpose of read-only memory (ROM) is to

a. buy two copies of the same program.

b. manage the computer's communication with the disk drive.

c. store instructions and commands that cannot be changed.

d. help the user in using the printer. 
86. To avoid information being lost or destroyed on a disk, if possible one should

a. buy two copies of the same program.

b. avoid buying expensive computer programs.

c. make a back-up copy of the program.

d. buy the same programs your best friend buys.

87. Peter just bought a new box of disks for his computer class. He wants to have all the disks ready to be used. The first thing Peter must do is a. label the disks with the correct identification. b. punch a hole in the disk.

c. initialize the disks.

d. store his favorite introductory program on all the disks.

88. Many departments in a large university need access to information about the students, faculty and staff. A major advantage of using a computer data base is that a. information never needs to be updated.

b. personal information about professors is readily available to students.

c. the people in the different departments get to know each other better.

d. it avoids the need to have separate files for each department.

89. In the future we can possibly expect to see computerization. in many homes, as a result of

a. robots vacuuming the carpets

b. a decreased number of appliances

c. a fool-proof alarm system

d. totally computerized child care

90. We would not have

not exist.

a. telegraphs

b. telephones

c. telepathy

d. telecommunication networks

91. Which of the following storage media allows for the fastest storage of information?
a. ROM
b. tape
c. hardcopy
d. hard disk 
92. In which of the following can software be stored?

I. Disks; II. Tapes. III. ROM cartridges. IV. Input devices.
a. III, IV
b. I, II
c. I, II, III
d. I, II, III, IV

93. The software that the computer uses to manage its own operations is the
a. operating system.
b. spreadsheet.
c. data base.
d. word processor.

94. In the library, computers are used to

a. review new books for purchase.

b. return books to shelves.

c. supervise staff.

d. help librarians keep track of books due.

95. We can find games, languages and many other types of software stored in a(n)
a. mouse.
b. voice synthesizer.
c. ROM cartridge
d. optical scanner

96. A very intelligent computer student accessed the local credit bureau computer and changed some of the data stored in it. As a result of this action. a. the modem used could be damaged

b. the power supply of the computer might need to be repaired.

c. the computer being used could be damaged.

d. someone's credit record could be temporarily ruined.

97. Mary obtained a math program from a public domain software catalog. Which of the following actions is legal?

a. Mary made several copies to give to her friends as gifts.

b. Mary sold her copy.

c. Mary made several copies to sell.

d. Mary rents her copy for $\$ 3.00$ a day. 
98. The task of is best done by a computer.

a. searching the phone directory for a specific name.

b. reviewing a movie.

c. organizing clothes by color in a closet.

d. deciding the verdict in a trial.

99. At the checkout counter at many grocery stores, a computer reads the information about an item from a label code. One of the main advantages in using these computers is

a. checking out is quicker and more accurate.

b. customers like to see stores keep up with the times.

c. to compare American eating habits with those of other countries.

d. the cashier can then have more time to socialize with the customers.

100. Compared to a floppy disk the faster, and can hold a great deal more information than a floppy disk.
a. ROM
b. tape
c. hard disk
d. hardcopy 


\section{BIOLOGY PRE/POST TEST}

1. In common biological classification systems, which pair is most closely related?

a. birds and bats

b. fish and whales

c. people and pigs

d. spiders and grasshoppers

2. Which organisms are identified by their shapes?
a. algae
b. bacteria
c. euglena
d. fungi

3. What are the simplest plants?
a. algae
b. ferns
c. fungi
d. mosses

4. Which feature of mosses has prevented them from adapting to drier regions?

a. lack of a food-manufacturing system

b. lack of a vascular system

c. lack of an advanced reproductive system

d. lack of leaf-like structures

5. Which animal belong to phylum Porifera?
a. hydra
b. jellyfish
c. sponge
d. squid

6. What are the three body parts of an adult mollusk? a. head or foot, the visceral mass, and the mantle b. head, mouth, and the visceral mass

c. heat-foot, trunk, and the mantle

d. mouth, the visceral mass, and foot

7. Which type of symmetry does the larval stage of the starfish exhibit?
a. asymmetrical
b. bilateral
c. horizontal
d. radial 
8. Which organs grind up food for the crayfish?
a. digestive gland and teeth
b. green glands and mandibles
c. mandibles and stomach teeth
d. stomach and intestine

9. Which chordate structure runs along the mid-dorsal part of the body?

a. aorta

b. endoskeleton

c. gill slit

d. nerve cord

10. Which organism is a cephalochordate?
a. lancelet
b. sea squirt
c. squid
d. starfish

11. Which characteristic is found ONLY in mammals?
a. body covering of fur or hair
b. constant body temperature
c. internal skeleton
d. giving birth to living young

12. What is a possible disadvantage of an exoskeleton?
a. It does not offer protection for the organism.
b. It prevents water loss from the body.
c. It prevents sexual reproduction in organisms.
d. It may limit the size of an organism.

13. Which structure is possessed by vertebrates but is lacking in most invertebrates?

a. Coelenteron

b. Coelom

c. Ostium

D. Ventral nerve cord

14. Which type of symmetry does NOT divide an organism into corresponding sections?

a. asymmetrical

b. bilateral

c. radial

d. spherical 
15. What is a definition of territoriality?

a. The behavior of an organism to migrate during the spring of the year.

b. The behavior of an organism to raise its young only in certain habitats.

c. The behavior of an organism to defend the area to which it lives against intruders.

d. The behavior of an organism to return to a special area to die.

16. Which organism's body temperature fluctuates with that of its environment?
a. a heterothermic organism
b. a homoiothermic organism
c. a mesothermic organism
d. a poikilothermic organism

17. Which pathway does food follow through the human digestive system?

a. from esophagus to small intestine to stomach to large intestine

b. from esophagus to small intestine to large intestine

c. from large intestine to small intestine to stomach to esophagus

d. from stomach to large intestine to small intestine to esophagus

18. What is the first step in blood clotting?

a. the activation of prothrombin

b. the formation of fibrin

c. the liberation of calcium

d. the rupture of platelets and release of thromboplastin

19. Which part of the nephron uses natural diffusion to return water and other filtered substances to the bloodstream?

a. Bowman's capsule

b. collecting tubule

c. distal convoluted tubule

d. proximal convoluted tubule 
20. Which list includes only sensory receptors in the skin?

a. auditory, pain, pressure, and temperature receptors

b. olfactory, temperature, and pain receptors

c. touch, pressure, pain, and temperature receptors

d. visual, temperature, pain, and touch receptors

21. What are collar cells?

a. They are pore-containing cells in the outer layer of the sponge.

b. They are flagellated cells in the outer body layer of the sponge.

c. They are flagellated cells in the inner body layer of the sponge.

d. They are ameboid cells in the sponge.

22. Which kingdom includes groups of multicellular organisms lacking a cell wall?

a. Animalia

b. Fungi

c. Monera

d. Plantae

23. During an epidemic of cholera, why is it important to boil drinking water?

a. Boiling kills microorganisms that live in drinking water and cause cholera.

b. Boiling water can be used to wash the bodies of people killed by the disease.

c. Boiling water keeps away insects which spread cholera.

d. Hot water relieves the symptoms of cholera

24. How does a respiratory system provide sufficient gas diffusion for the needs of a multicellular organism?

a. It increases the available surface for gas exchange.

b. It decreases the available surface for gas exchange.

c. It increases the amount of oxygen needed by the organism.

d. It decreases the amount of oxygen needed by the organism. 
25. When does fertilization take place?
a. When a sperm becomes an egg.
b. When a sperm becomes an embryo.
c. When a sperm enters an egg.
d. When a sperm enters another sperm.

26. If sunlight were permanently removed from an ecosystem, what would be the immediate effect on the ecosystem?

a. The consumers would be overcome with fear.

b. The decomposers would quickly die from lack of food.

c. The number of herbivores would increase sharply.

d. The producers would be unable to make food.

27. Which organ interacts with the pancreas in order to maintain the proper balance of blood glucose level in the bloodstream?

a. the large intestine

b. the liver

c. the spleen

d. the stomach

28. How does water flow through sponges?

a. It enters and leaves through the osculum.

b. It enters and leaves through the pores.

c. It enters through the osculum and leaves through the pores.

d. It enters through the pores and leaves through the osculum.

29. Which is the correct ascending order of the food chain?

a. bacteria $\rightarrow$ wolves $\rightarrow$ sheep $\rightarrow$ grass

b. bacteria $\rightarrow$ sheep $\rightarrow$ grass $\rightarrow$ wolves

c. grass $\rightarrow$ bacteria $\rightarrow$ sheep $\rightarrow$ wolves

d. grass $\rightarrow$ sheep $\rightarrow$ wolves $\rightarrow$ bacteria

30. Why must earthworms live in a moist environment?

a. Their skin must stay moist to lubricate their burrows.

b. Their skin must stay moist to absorb oxygen.

c. They dray the moisture into their digestive system.

d. They need the moisture to grow the food they eat. 
31. What are well-known agents of environmental disease? a. bacteria and fungi

b. foods and garbage

c. pets and fleas

d. pollen and pollutants

32. What describes nonrenewable natural resources?
a. resources that are man-made
b. resources that are no longer useful
c. resources that cannot be replenished
d. resources that will last forever

33. Which type of neuron carries impulses from sensory neurons to motor neurons?
a. afferent neuron
b. associative neuron
c. efferent neuron
d. receptor neuron

34. Which type of muscle is attached directly to a bone?

a. smooth muscle

b. cardiac muscle

c. skeletal muscle

d. involuntary muscle

35. Which gland produces the hormone that is vital in maintaining the body's metabolism?

a. pineal

b. pituitary

c. thymus

d. thyroid

36. Which effect does emphysema have on the body?

a. The alveoli become filled with fluid.

b. The bronchioles contract as a result of an allergic reaction.

c. The linings of the bronchial tubes become inflamed.

d. The walls of the air sacs break down, reducing the respiratory surface.

37. How can tapeworm infection be prevented?

a. cook beef thoroughly

b. cook fish thoroughly

c. kill all snails

d. wear shoes 
38. Which features do arthropods have in common?
a. jointed legs and segmented bodies
b. segmented bodies and stinging cells
c. segmented bodies and two shells
d. jointed legs and stinging cells

39. How is a taxonomic key used?

a. It is used to find fossils.

b. It is used to identify and classify organisms.

c. It is used to determine the rules of nomenclature.

d. It is used to determine the type of environment in which an organism lives.

40. Which characteristic is used to classify plants in broad groupings?

a. The presence or absence of cellular structure.

b. The presence of absence of leaf cellulose.

c. The presence or absence of reproductive structures.

d. The presence or absence of vascular tissue.

41. How is most of a plant's water transported from its roots to its leaves?
a. through the cambium layer
b. through the cortex
c. through the phloem
d. through the xylem

42. Which gland produces insulin?
a. pancreas
b. pituitary
c. thymus
d. thyroid

43. What type of disease is leukemia?
a. contagious
b. deficiency
c. degenerative
d. hereditary

44. What is indicated by an increase in the number of white blood cells?
a. the body is bleeding
b. the body is carrying more oxygen
c. the body is fighting a bacterial infection
d. the body is tense 
45. What is the function of the human bladder?
a. to absorb salt
b. to filter solid wastes
c. to produce hormones
d. to store urine

46. Which chordate subphylum contains the greatest number of species?
a. Agnathia
b. Cephalochordata
c. Urochordata
d. Vertebrate

47. What is an example of structural adaptation?
a. hibernation
b. learned behavior
c. positive reinforcement
d. protective coloration

48. What is the function of villi in the small intestines?
a. to increase the surface area
b. to mix the food in the small intestine
c. to secrete enzymes
d. to slow down the passage of food

49. What controls the amount of light entering the eye?
a. the iris
b. the lens
c. the retina
d. the sclera

50. Which type of neuron is involved with the process of seeing?
a. associative neuron
b. effector neuron
c. motor neuron
d. sensory neuron

51. Which biome is characterized by conifer forests?
a. deserts
b. grassland
c. Taiga
d. Tundra 
52. Why is the pituitary gland often called the master gland of the body?
a. It is closest to the brain.
b. It is the biggest gland.
c. It produces hormones that control other glands.
d. It was the first gland to be discovered.

53. How many jointed legs are there in adult insects?
a. 2
b. 4
c. 6
d. 8

54. Which term describes a dog learning to respond to commands?
a. conditioning
b. experimenting
c. instinct
d. reflex behavior

55. Which organ helps break down toxins and excess amino acids?
a. bladder
b. kidney
c. liver
d. skin

56. What supports, protects, and makes up the framework
of your body?
a. ligaments
b. muscles
c. tendons
d. skeleton

57. What fertilizes an egg?
a. gonad
b. ovum
c. sperm
d. zygote

58. Into which environment have the tracheophytes evolved and dominated?
a. air
b. fresh water
c. land
d. salt water 
59. How are plant growth hormones used?

a. to change leaf shape

b. to increase fruit yield

c. to increase photosynthesis

d. to prevent plant disease

60. Which phylum includes animals with stinging cells?

a. Coelenterata (Cnidaria)

b. Echinodermata

c. Mollusca

d. Porifera

61. Which structure is used by the insect to receive messages from the environment?
a. abdomen
b. antennae
c. legs
d. wings

62. Which order has the largest mammals?
a. Carnivora
b. Insectivora
c. Monotremata
d. Proboscidea

63. Which organisms are invertebrates?
a. amphibians
b. birds
c. echinoderms
d. reptiles

64. Which organism has the longest gestation period?
a. dog
b. elephants
c. horse
d. human

65. Which hormone regulates the rate of metabolism in the human body?
a. $\mathrm{ACTH}$
b. FSH
c. Thyroxine
d. Vasopressin 
66. What is the function of nephrons?
a. to carry oxygen
b. to digest fat
c. to filter blood
d. to produce hormones

67. Which structure enables a hydra to react to its environment?
a. axon
b. brain
c. contractile vacuole
d. nerve net

68. Which structure is used by clams to burrow in the sand?
a. foot
b. mantle
c. radula
d. shell

69. Which organism is an amphibian?
a. frog
b. penguin
c. shark
d. turtle

70. Which gland secretes testosterone?
a. Adrenal medulla
b. ovary
c. pancreas
d. testis

71. What are the final products of protein digestion?

a. amino acids

b. glycerol

c. simple starches

d. simple sugars

72. Which type of blood cell is most numerous in the blood?

a. lymph cell

b. platelet

c. red blood cell

d. white blood cell 
73. Which term describes animals that obtain energy from eating other live animals?
a. primary consumers
b. producers
c. scavengers
d. secondary consumers

74. What are organic catalysts that break down food?
a. enzymes
b. minerals
c. starches
d. sugars

75. Which blood vessel primarily transports deoxygenated blood?
a. arteriole
b. artery
c. capillary
d. vein

76. What usually serves as a density-dependent check on population growth?
a. drought
b. forest fires
c. onset of freezing temperatures
d. starvation

77. Which kind of immunity does a baby receive from its mother before birth?
a. active immunity
b. natural immunity
c. passive immunity
d. viral immunity

78. How are plants with special water- and foodconducting tissues classified?
a. Bryophytes
b. Mycophytes
c. Nonvascular plants
d. Vascular plants

79. Which organisms belong in the phylum Annelida?
a. earthworms
b. hookworms
c. roundworms
d. tapeworms 
80. What is a characteristic of ALL mollusks?
a. a shell
b. a soft body
c. a hard body
d. radial symmetry

81. Which blood solids help prevent excessive blood loss?

a. erythrocytes

b. leukocytes

c. lymphocytes

d. thrombocytes

82. Which organ is responsible for regulating proper fluid balance in the blood?
a. heart
b. kidney
c. pancreas
d. thyroid

83. Which major factor will be the greatest effect on the future health of people?
a. an increase in food resources
b. an increase in life expectancy
c. an increase in use of antibiotics
d. an increase in water contaminated by toxins or wastes

84. Which type of muscle is most directly involved in digestion?
a. smooth muscle
b. cardiac muscle
c. skeletal muscle
d. striated muscle

85. Under normal conditions, which substance is completely reabsorbed and returned to the bloodstream by the human kidney?
a. glucose
b. urea
c. uric acid
d. water

86. How many chromosomes are in an unfertilized human egg?
a. 23
b. 43
c. 46
d. 92 
87. Which phylum includes ONLY filter feeders?

a. Coelenterata (Cnidaria)

b. Echinodermata

c. Mollusca

d. Porifera

88. Which member in the bee community lays eggs?
a. drone
b. queen
c. soldier
d. worker

89. Which behavior of an animal is built-in or inborn?
a. instinct
b. learned behavior
c. patterned behavior
d. stimulus

90. Which blood vessel is involved in the exchange of gases, nutrients, and wastes between the cell and the bloodstream?
a. artery
b. bronchial
c. capillary
d. vein

91. What is the function of white blood cells?
a. to absorb water
b. to digest food
c. to fight disease
d. to filter air

92. In which biome would the largest number of animals be found in the canopy?

a. deciduous forest

b. desert

c. Taiga

d. Tropical rain forest

93. What are receptors for smell?
a. auditory cells
b. cones
c. olfactory cells
d. rods 
94. Which chemicals are found in most endoskeletons?
a. calcium and chitin
b. calcium and phosphorus
c. chitin and phosphorus
d. silica and iron

95. Which type of disease is rickets?
a. contagious
b. deficiency
c. degenerative
d. hereditary

96. What is the $\mathrm{Ph}$ inside the stomach?
a. $\mathrm{Ph} 2$
b. $\mathrm{Ph} 4$
c. $\mathrm{Ph} 6$
d. $\mathrm{Ph} 7$

97. What must happen before a disease becomes infectious? a. Its pathogens must be acted upon by antibodies.

b. Its pathogen must be carried by a vector.

c. Its pathogen must be soluble in the plasma of the host's bloodstream.

d. Its pathogen must be transmitted from an affected host to a healthy one.

98. Which change was most important in the adaptation of plants to life on land?

a. The adapted plant had fewer chromosomes.

b. The cytoplasm was reduced.

c. The plant developed a longer, thinner shape.

d. The plant developed a thicker cell wall.

99. Which cells are responsible for transporting oxygen?
a. erythrocytes
b. leukocytes
c. lymphocytes
d. monocytes

100. Where are sebaceous glands located?
a. around the adipose tissue
b. around the hair follicles
c. around the papillae
d. around the sweat glands 
Table 7

Biology / Computer Literacy Raw Data

\begin{tabular}{|c|c|c|c|c|c|c|c|c|c|}
\hline sTU & & & & BIO & BIO & COMP & COMP & STA & sTA \\
\hline NOM & ETE & SBX & TBA & PRB & POST & PRB & POST & $\mathbf{R B A}$ & МАTH \\
\hline 1 & 4 & 1 & 1 & 45 & 65 & 48 & 88 & 7 & 8 \\
\hline 2 & 4 & 2 & 1 & 41 & 78 & 59 & 71 & 6 & 8 \\
\hline 3 & 4 & 1 & 1 & 21 & 79 & 51 & 82 & 7 & 9 \\
\hline 4 & 1 & 2 & 1 & 57 & 68 & 50 & 78 & 7 & 7 \\
\hline 5 & 4 & 1 & 1 & 45 & 85 & 61 & 88 & 8 & 8 \\
\hline 6 & 4 & 1 & 1 & 41 & 78 & 53 & 84 & 8 & 9 \\
\hline 7 & 3 & 2 & 1 & 43 & 87 & 55 & 84 & 7 & 7 \\
\hline 8 & 4 & 1 & 1 & 39 & 68 & 56 & 83 & 8 & 6 \\
\hline 9 & 3 & 2 & 1 & 33 & 75 & 63 & 87 & & \\
\hline 10 & 4 & 1 & 1 & 44 & 68 & 71 & 90 & 9 & 9 \\
\hline 11 & 4 & 2 & 1 & 32 & 77 & 66 & 82 & 8 & 8 \\
\hline 12 & 2 & 2 & 1 & 37 & 66 & 43 & 81 & 8 & 7 \\
\hline 13 & 4 & 2 & 1 & 42 & 59 & 70 & 81 & 7 & 8 \\
\hline 14 & 4 & 1 & 1 & 34 & 55 & 41 & 67 & 7 & 9 \\
\hline 15 & 4 & 1 & 1 & 34 & 43 & 51 & 41 & 7 & 6 \\
\hline 16 & 4 & 2 & 1 & 39 & 65 & 61 & 77 & 7 & 7 \\
\hline 17 & 4 & 2 & 1 & 34 & 70 & 56 & 89 & 7 & 7 \\
\hline 18 & 3 & 2 & 1 & 54 & 67 & 66 & 89 & 9 & 9 \\
\hline 19 & 4 & 2 & 1 & 31 & 66 & 24 & 78 & & \\
\hline 20 & 4 & 2 & 1 & 36 & 55 & 41 & 64 & 6 & 5 \\
\hline 21 & 4 & 1 & 1 & 40 & 55 & 53 & 80 & 7 & 9 \\
\hline 22 & 4 & 1 & 1 & 36 & 69 & 74 & 91 & 7 & 8 \\
\hline 23 & 4 & 1 & 1 & 30 & 71 & 37 & 79 & 8 & 5 \\
\hline 24 & 4 & 2 & 1 & 45 & 78 & 67 & 86 & 8 & 9 \\
\hline 25 & 4 & 1 & 1 & 35 & 68 & 32 & 83 & 6 & 9 \\
\hline 26 & 3 & 1 & 1 & 26 & 42 & 36 & 39 & 6 & 5 \\
\hline 27 & 4 & 1 & 1 & 32 & 66 & 39 & 79 & 7 & 7 \\
\hline 28 & 4 & 1 & 1 & 23 & 57 & 64 & 82 & 7 & 7 \\
\hline 29 & 4 & 2 & 1 & 17 & 38 & 71 & 80 & 8 & 8 \\
\hline 30 & 3 & 1 & 1 & 44 & 50 & 63 & 82 & 6 & 6 \\
\hline 31 & 4 & 1 & 1 & 42 & 59 & 53 & 82 & 8 & 8 \\
\hline 32 & 4 & 1 & 1 & 33 & 70 & 54 & 86 & 7 & 8 \\
\hline 33 & 4 & 1 & 1 & 33 & 60 & 61 & 72 & 6 & 5 \\
\hline 34 & 2 & 1 & 1 & 39 & 51 & 32 & 48 & 6 & 5 \\
\hline 35 & 4 & 1 & 1 & 35 & 62 & 41 & 73 & 8 & 8 \\
\hline 36 & 4 & 1 & 1 & 31 & 66 & 55 & 90 & 9 & 8 \\
\hline 37 & 4 & 2 & 1 & 41 & 52 & 56 & 76 & 5 & 5 \\
\hline 38 & 4 & 2 & 1 & 41 & 84 & 31 & 79 & 7 & 8 \\
\hline 39 & 4 & 2 & 1 & 48 & 49 & 48 & 78 & 8 & 6 \\
\hline 40 & 4 & 2 & 1 & 49 & 47 & 67 & 86 & 6 & 7 \\
\hline 41 & 4 & 1 & 1 & 51 & 49 & 58 & 78 & 8 & 5 \\
\hline 42 & 4 & 2 & 1 & 30 & 60 & 51 & 72 & 7 & 6 \\
\hline 43 & 4 & 1 & 1 & 32 & 31 & 39 & 32 & 5 & 5 \\
\hline 44 & 4 & 1 & 1 & 46 & 71 & 66 & 73 & 6 & 8 \\
\hline 45 & 2 & 2 & 1 & 37 & 56 & 67 & 78 & 6 & 6 \\
\hline 46 & 4 & 1 & 1 & 49 & 59 & 60 & 79 & 8 & 7 \\
\hline 47 & 4 & 1 & 1 & 51 & 55 & 69 & 84 & 8 & 6 \\
\hline 48 & 4 & 2 & 1 & 54 & 62 & 74 & 94 & 9 & 9 \\
\hline 49 & 2 & 1 & 1 & 40 & 52 & 50 & 54 & 5 & 6 \\
\hline
\end{tabular}


Table 7

Biology / Computer Literacy Raw Data

\begin{tabular}{|c|c|c|c|c|c|c|c|c|c|}
\hline STU & & & & BIO & BIO & COMP & COMP & STA & STA \\
\hline NUM & ETR & SEX & TEA & PRB & POST & PRB & POST & RRA & MATB \\
\hline 50 & 4 & 1 & 1 & 46 & 73 & 64 & 85 & 8 & 9 \\
\hline 51 & 4 & 1 & 1 & 48 & 40 & 61 & 80 & 7 & 6 \\
\hline 52 & 4 & 2 & 1 & 42 & 69 & 62 & 88 & 8 & 7 \\
\hline 53 & 4 & 2 & 1 & 50 & 67 & 75 & 96 & 8 & 9 \\
\hline 54 & 2 & 1 & 1 & 31 & 78 & 53 & 86 & 8 & 9 \\
\hline 55 & 3 & 2 & 1 & 38 & 60 & 65 & 60 & 8 & 9 \\
\hline 56 & 3 & 2 & 1 & 28 & 35 & 61 & 35 & 6 & 3 \\
\hline 57 & 4 & 2 & 1 & 46 & 87 & 64 & 57 & 8 & 9 \\
\hline 58 & 4 & 1 & 1 & 43 & 57 & 69 & 62 & 8 & 5 \\
\hline 59 & 4 & 1 & 1 & 28 & 35 & 28 & 63 & 5 & 6 \\
\hline 60 & 4 & 2 & 1 & 25 & 35 & 38 & 68 & & \\
\hline 61 & 2 & 2 & 1 & 21 & 63 & 45 & 80 & & \\
\hline 62 & 2 & 1 & 1 & 35 & 64 & 42 & 72 & 6 & 9 \\
\hline 63 & 3 & 1 & 1 & 34 & 76 & 53 & 74 & 6 & 4 \\
\hline 64 & 4 & 1 & 1 & 44 & 61 & 54 & 83 & 6 & 4 \\
\hline 65 & 4 & 2 & 1 & 21 & 63 & 67 & 91 & 7 & 8 \\
\hline 66 & 4 & 1 & 1 & 31 & 67 & 33 & 75 & 6 & 7 \\
\hline 67 & 4 & 2 & 1 & 35 & 55 & 76 & 84 & & \\
\hline 68 & 3 & 1 & 1 & 32 & 65 & 36 & 63 & 6 & 8 \\
\hline 69 & 4 & 1 & 1 & 21 & 78 & 24 & 69 & 8 & 8 \\
\hline 70 & 4 & 1 & 1 & 31 & 46 & 60 & 84 & 7 & 6 \\
\hline 71 & 4 & 1 & 1 & 37 & 75 & 60 & 87 & 6 & 9 \\
\hline 72 & 3 & 1 & 1 & 41 & 64 & 70 & 88 & 6 & 6 \\
\hline 73 & 4 & 2 & 1 & 31 & 54 & 54 & 74 & 7 & 6 \\
\hline 74 & 4 & 1 & 1 & 36 & 67 & 73 & 79 & 6 & 6 \\
\hline 75 & 4 & 1 & 1 & 36 & 61 & 41 & 75 & 9 & 9 \\
\hline 76 & 4 & 1 & 1 & 21 & 77 & 58 & 80 & 7 & 9 \\
\hline 77 & 4 & 1 & 1 & 46 & 77 & 86 & 91 & 7 & 6 \\
\hline 78 & 3 & 2 & 1 & 21 & 79 & 44 & 79 & 6 & 8 \\
\hline 79 & 3 & 2 & 1 & 30 & 82 & 30 & 92 & 9 & 9 \\
\hline 80 & 4 & 1 & 1 & 21 & 73 & 46 & 85 & 8 & 9 \\
\hline 81 & 4 & 1 & 1 & 12 & 63 & 30 & 86 & 6 & 8 \\
\hline 82 & 4 & 2 & 1 & 31 & 63 & 69 & 87 & 7 & 9 \\
\hline 83 & 3 & 2 & 1 & 44 & 59 & 49 & 72 & 5 & 6 \\
\hline 84 & 3 & 1 & 1 & 52 & 61 & 62 & 88 & 8 & 6 \\
\hline 85 & 1 & 1 & 1 & 51 & 70 & 57 & 67 & & \\
\hline 86 & 4 & 2 & 1 & 31 & 64 & 39 & 86 & 8 & 8 \\
\hline 87 & 4 & 1 & 1 & 17 & 64 & 48 & 88 & 8 & 8 \\
\hline 88 & 4 & 2 & 1 & 31 & 32 & 36 & 77 & 8 & 8 \\
\hline 89 & 4 & 1 & 1 & 38 & 73 & 36 & 86 & 6 & 5 \\
\hline 90 & 4 & 2 & 1 & 52 & 50 & 35 & 80 & 8 & 7 \\
\hline 91 & 4 & 1 & 1 & 21 & 40 & 70 & 70 & 6 & 5 \\
\hline 92 & 4 & 1 & 1 & 35 & 79 & 40 & 84 & 7 & 9 \\
\hline 93 & 4 & 1 & 1 & 32 & 54 & 42 & 78 & 8 & 6 \\
\hline 94 & 4 & 1 & 1 & 31 & 71 & 58 & 83 & 8 & 6 \\
\hline 95 & 4 & 2 & 1 & 19 & 53 & 28 & 88 & 5 & 6 \\
\hline 96 & 4 & 1 & 1 & 32 & 49 & 55 & 83 & 9 & 7 \\
\hline 97 & 4 & 2 & 1 & 24 & 54 & 57 & 82 & 8 & 8 \\
\hline 98 & 4 & 1 & 1 & 35 & 70 & 48 & 74 & 7 & 6 \\
\hline 99 & 4 & 1 & 1 & 32 & 35 & 21 & 34 & 4 & 4 \\
\hline
\end{tabular}


Table 7

Biology / Computer Literacy Raw Data

\begin{tabular}{|c|c|c|c|c|c|c|c|c|c|}
\hline STU & & & & BIO & BIO & COMP & COMP & STA & STA \\
\hline NUM & ETR & SBX & TBA & PRB & POST & PRB & POST & RBA & MATE \\
\hline 100 & 4 & 1 & 1 & 45 & 31 & 57 & 78 & 8 & 6 \\
\hline 101 & 1 & 1 & 1 & 32 & 75 & 60 & 73 & & \\
\hline 102 & 4 & 2 & 1 & 10 & 54 & 43 & 81 & 8 & 6 \\
\hline 103 & 4 & 2 & 1 & 21 & 55 & 58 & 78 & 6 & 6 \\
\hline 104 & 4 & 1 & 1 & 30 & 60 & 32 & 83 & 7 & 9 \\
\hline 105 & 2 & 1 & 1 & 23 & 50 & 42 & 77 & 7 & 9 \\
\hline 106 & 4 & 2 & 1 & 24 & 69 & 72 & 91 & 8 & 6 \\
\hline 107 & 4 & 1 & 1 & 19 & 47 & 38 & 74 & 8 & 7 \\
\hline 108 & 3 & 1 & 1 & 39 & 37 & 38 & 75 & 7 & 6 \\
\hline 109 & 3 & 1 & 1 & 18 & 69 & 33 & 81 & 7 & 7 \\
\hline 110 & 4 & 2 & 1 & 35 & 55 & 40 & 80 & 9 & 7 \\
\hline 111 & 4 & 2 & 1 & 27 & 67 & 35 & 86 & 8 & 7 \\
\hline 112 & 4 & 1 & 1 & 36 & 58 & 51 & 67 & 9 & 7 \\
\hline 113 & 3 & 2 & 1 & 38 & 42 & 32 & 49 & & \\
\hline 114 & 4 & 2 & 1 & 18 & 47 & 30 & 82 & 8 & 8 \\
\hline 115 & 4 & 1 & 1 & 29 & 42 & 41 & 86 & 8 & 9 \\
\hline 116 & 4 & 1 & 1 & 35 & 68 & 41 & 71 & 5 & 6 \\
\hline 117 & 4 & 1 & 1 & 26 & 62 & 42 & 72 & 6 & 4 \\
\hline 118 & 4 & 2 & 1 & 62 & 76 & 72 & 91 & 7 & 7 \\
\hline 119 & 3 & 2 & 1 & 38 & 68 & 52 & 60 & 7 & 8 \\
\hline 120 & 3 & 2 & 1 & 19 & 42 & 33 & 67 & 8 & 6 \\
\hline 121 & 4 & 2 & 1 & 40 & 37 & 56 & 73 & & \\
\hline 122 & 3 & 1 & 1 & 35 & 75 & 60 & 88 & 7 & 6 \\
\hline 123 & 3 & 1 & 1 & 32 & 62 & 47 & 78 & 8 & 6 \\
\hline 124 & 4 & 1 & 1 & 46 & 59 & 57 & 73 & 8 & 9 \\
\hline 125 & 4 & 1 & 1 & 43 & 60 & 53 & 77 & 7 & 6 \\
\hline 126 & 2 & 2 & 1 & 42 & 30 & 49 & 29 & 6 & 2 \\
\hline 127 & 3 & 2 & 1 & 51 & 80 & 79 & 91 & 8 & 8 \\
\hline 128 & 4 & 1 & 1 & 42 & 68 & 60 & 73 & 5 & 8 \\
\hline 129 & 2 & 1 & 1 & 29 & 54 & 53 & 58 & 5 & 5 \\
\hline 130 & 3 & 2 & 1 & 19 & 31 & 34 & 61 & 7 & 9 \\
\hline 131 & 4 & 2 & 1 & 24 & 61 & 38 & 48 & 4 & 7 \\
\hline 132 & 3 & 1 & 1 & 16 & 68 & 31 & 76 & 7 & 9 \\
\hline 133 & 4 & 1 & 1 & 21 & 60 & 49 & 84 & 9 & 8 \\
\hline 134 & 4 & 2 & 1 & 37 & 63 & 39 & 84 & 4 & 5 \\
\hline 135 & 4 & 1 & 1 & 19 & 64 & 38 & 81 & 7 & 8 \\
\hline 136 & 2 & 2 & 1 & 37 & 26 & 57 & 83 & 5 & 7 \\
\hline 137 & 4 & 2 & 1 & 21 & 67 & 57 & 79 & 6 & 5 \\
\hline 138 & 4 & 2 & 1 & 24 & 37 & 69 & 81 & 5 & 8 \\
\hline 139 & 4 & 2 & 1 & 39 & 39 & 39 & 63 & 5 & 5 \\
\hline 140 & 4 & 1 & 1 & 37 & 76 & 61 & 83 & 8 & 8 \\
\hline 141 & 4 & 1 & 1 & 39 & 60 & 41 & 61 & 4 & 4 \\
\hline 142 & 2 & 2 & 1 & 36 & 67 & 30 & 76 & 6 & 5 \\
\hline 143 & 4 & 1 & 1 & 25 & 46 & 50 & 64 & 5 & 4 \\
\hline 144 & 2 & 2 & 1 & 25 & 67 & 30 & 70 & 8 & 5 \\
\hline 145 & 4 & 2 & 1 & 40 & 64 & 53 & 81 & 9 & 9 \\
\hline 146 & 2 & 2 & 3 & 20 & 84 & 24 & 48 & 4 & 3 \\
\hline 147 & 3 & 1 & 3 & 39 & 60 & 66 & 87 & 9 & 6 \\
\hline 148 & 3 & 2 & 3 & 27 & 71 & 36 & 62 & 6 & 5 \\
\hline 149 & 3 & 2 & 3 & 35 & 79 & 53 & 75 & 5 & 6 \\
\hline
\end{tabular}


Table 7

Biology / Computer Literacy Rav Data

\begin{tabular}{|c|c|c|c|c|c|c|c|c|c|}
\hline sTu & & & & BIO & BIO & COMP & COMP & STA & STA \\
\hline NUM & ETH & SEX & TEA & PRB & POST & PRB & POST & REA & MATH \\
\hline 150 & 3 & 2 & 3 & 18 & 44 & 63 & 50 & 6 & 4 \\
\hline 151 & 3 & 2 & 3 & 29 & 80 & 42 & 79 & 7 & 5 \\
\hline 152 & 3 & 1 & 3 & 27 & 69 & 47 & 58 & 4 & 4 \\
\hline 153 & 3 & 1 & 3 & 22 & 76 & 53 & 40 & 5 & 4 \\
\hline 154 & 2 & 2 & 3 & 22 & 22 & 35 & 35 & 3 & 4 \\
\hline 155 & 2 & 2 & 3 & 33 & 78 & 59 & 50 & 5 & 5 \\
\hline 156 & 2 & 1 & 3 & 29 & 82 & 49 & 73 & 4 & 6 \\
\hline 157 & 2 & 1 & 3 & 30 & 85 & 49 & 78 & 6 & 6 \\
\hline 158 & 3 & 2 & 3 & 11 & 17 & 48 & 50 & 3 & 2 \\
\hline 159 & 4 & 1 & 3 & 38 & 43 & 41 & 62 & & \\
\hline 160 & 2 & 1 & 3 & 26 & 43 & 32 & 50 & 4 & 6 \\
\hline 161 & 4 & 1 & 3 & 34 & 80 & 25 & 67 & 7 & 7 \\
\hline 162 & 2 & 2 & 3 & 25 & 38 & 36 & 29 & 5 & 5 \\
\hline 163 & 2 & 2 & 3 & 27 & 66 & 35 & 67 & 3 & 5 \\
\hline 164 & 2 & 2 & 3 & 22 & 40 & 40 & 80 & 4 & 2 \\
\hline 165 & 4 & 2 & 3 & 28 & 23 & 57 & 54 & 7 & 7 \\
\hline 166 & 4 & 2 & 3 & 20 & 56 & 23 & 77 & 5 & 6 \\
\hline 167 & 2 & 2 & 3 & 26 & 5 & 24 & 34 & 5 & 9 \\
\hline 168 & 3 & 2 & 3 & 27 & 62 & 34 & 65 & 4 & 4 \\
\hline 169 & 4 & 2 & 3 & 47 & 69 & 51 & 38 & 7 & 8 \\
\hline 170 & 3 & 2 & 3 & 22 & 44 & 21 & 2 & 3 & 3 \\
\hline 171 & 3 & 1 & 3 & 26 & 58 & 23 & 73 & 7 & 4 \\
\hline 172 & 4 & 2 & 3 & 32 & 84 & 26 & 80 & 5 & 5 \\
\hline 173 & 3 & 2 & 3 & 21 & 57 & 24 & 74 & 4 & 4 \\
\hline 174 & 3 & 2 & 3 & 25 & 88 & 37 & 76 & 9 & 6 \\
\hline 175 & 4 & 1 & 3 & 46 & 66 & 48 & 6 & 6 & 6 \\
\hline 176 & 2 & 1 & 3 & 16 & 27 & 10 & 84 & 5 & 5 \\
\hline 177 & 2 & 2 & 3 & 17 & 30 & 27 & 43 & 4 & 2 \\
\hline 178 & 2 & 2 & 3 & 12 & 62 & 19 & 55 & 4 & 4 \\
\hline 179 & 4 & 1 & 3 & 33 & 77 & 47 & 55 & 7 & 5 \\
\hline 180 & 2 & 1 & 3 & 24 & 50 & 34 & 77 & & \\
\hline 181 & 3 & 2 & 3 & 22 & 60 & 23 & 32 & 3 & 4 \\
\hline 182 & 2 & 1 & 3 & 15 & 70 & 30 & 72 & 2 & 4 \\
\hline 183 & 2 & 2 & 3 & 14 & 56 & 30 & 43 & 4 & 5 \\
\hline 184 & 1 & 1 & 3 & 34 & 39 & 36 & 64 & 6 & 8 \\
\hline 185 & 3 & 1 & 3 & 21 & 50 & 29 & 43 & 3 & 5 \\
\hline 186 & 2 & 2 & 3 & 16 & 66 & 35 & 53 & 4 & 3 \\
\hline 187 & 4 & 1 & 3 & 31 & 65 & 55 & 76 & 8 & 6 \\
\hline 188 & 4 & 2 & 3 & 16 & 72 & 37 & 74 & 6 & 9 \\
\hline 189 & 2 & 1 & 3 & 22 & 65 & 43 & 74 & & \\
\hline 190 & 4 & 1 & 3 & 34 & 59 & 42 & 42 & 5 & 7 \\
\hline 191 & 3 & 1 & 3 & 25 & 62 & 37 & 48 & 5 & 4 \\
\hline 192 & 3 & 2 & 3 & 30 & 31 & 44 & 32 & & \\
\hline 193 & 4 & 2 & 3 & 26 & 21 & 36 & 58 & 2 & 4 \\
\hline 194 & 4 & 2 & 3 & 0 & 76 & 2 & 56 & & \\
\hline 195 & 2 & 1 & 3 & 23 & 56 & 37 & 78 & & \\
\hline 196 & 2 & 1 & 3 & 25 & 45 & 41 & 64 & 5 & 6 \\
\hline 197 & 3 & 1 & 3 & 14 & 58 & 33 & 51 & 4 & 5 \\
\hline 198 & 4 & 2 & 3 & 29 & 86 & 41 & 33 & 5 & 5 \\
\hline 199 & 2 & 2 & 3 & 28 & 73 & 43 & 40 & 3 & 4 \\
\hline
\end{tabular}


Table 7

Biology / Computer Literacy Raw Data

\begin{tabular}{|c|c|c|c|c|c|c|c|c|c|}
\hline STU & & & & BIO & BIO & COMP & COMP & STA & STA \\
\hline NUM & ETR & SBX & TBA & PRB & POST & PRE & POST & RBA & MATE \\
\hline 200 & 3 & 1 & 3 & 29 & 73 & 37 & 71 & & \\
\hline 201 & 4 & 1 & 3 & 32 & 52 & 35 & 50 & 5 & 7 \\
\hline 202 & 2 & 1 & 3 & 14 & 64 & 35 & 58 & 4 & 2 \\
\hline 203 & 4 & 1 & 3 & 13 & 81 & 35 & 74 & 3 & 5 \\
\hline 204 & 3 & 2 & 3 & 31 & 86 & 38 & 28 & 5 & 6 \\
\hline 205 & 2 & 1 & 3 & 21 & 11 & 28 & 27 & 3 & 3 \\
\hline 206 & 2 & 1 & 3 & 28 & 62 & 31 & 47 & 4 & 3 \\
\hline 207 & 4 & 2 & 3 & 25 & 49 & 35 & 47 & & \\
\hline 208 & 4 & 1 & 3 & 37 & 70 & 56 & 70 & & \\
\hline 209 & 2 & 1 & 3 & 25 & 61 & 47 & 59 & 6 & 4 \\
\hline 210 & 2 & 2 & 3 & 31 & 83 & 33 & 28 & 4 & 3 \\
\hline 211 & 2 & 1 & 4 & 29 & 37 & 28 & 26 & 2 & 5 \\
\hline 212 & 3 & 1 & 4 & 27 & 77 & 25 & 58 & & \\
\hline 213 & 4 & 2 & 4 & 32 & 77 & 24 & 33 & 5 & 5 \\
\hline 214 & 4 & 2 & 4 & 20 & 68 & 33 & 64 & & \\
\hline 215 & 3 & 1 & 4 & 24 & 73 & 28 & 23 & 5 & 5 \\
\hline 216 & 2 & 2 & 4 & 22 & 42 & 34 & 41 & 3 & 4 \\
\hline 217 & 3 & 2 & 4 & 26 & 56 & 41 & 53 & 2 & 2 \\
\hline 218 & 3 & 1 & 4 & 36 & 46 & 35 & 35 & 6 & 6 \\
\hline 219 & 4 & 1 & 4 & 35 & 76 & 28 & 37 & 6 & 6 \\
\hline 220 & 4 & 1 & 4 & 33 & 78 & 25 & 45 & 4 & 4 \\
\hline 221 & 1 & 1 & 4 & 17 & 59 & 37 & 36 & 4 & 2 \\
\hline 222 & 2 & 2 & 4 & 17 & 46 & 26 & 63 & 4 & 3 \\
\hline 223 & 4 & 2 & 4 & 22 & 47 & 36 & 55 & 5 & 5 \\
\hline 224 & 4 & 2 & 4 & 41 & 84 & 28 & 76 & 7 & 7 \\
\hline 225 & 2 & 1 & 4 & 31 & 60 & 32 & 35 & 5 & 2 \\
\hline 226 & 4 & 2 & 4 & 37 & 80 & 31 & 58 & 7 & 3 \\
\hline 227 & 4 & 1 & 4 & 36 & 48 & 37 & 36 & 6 & 4 \\
\hline 228 & 1 & 2 & 4 & 15 & 72 & 28 & 28 & 1 & 8 \\
\hline 229 & 4 & 2 & 4 & 34 & 73 & 36 & 58 & 8 & 6 \\
\hline 230 & 4 & 1 & 4 & 27 & 51 & 42 & 22 & 4 & 4 \\
\hline 231 & 3 & 1 & 4 & 23 & 76 & 38 & 60 & 3 & 3 \\
\hline 232 & 2 & 2 & 4 & 17 & 69 & 39 & 71 & 5 & 4 \\
\hline 233 & 3 & 1 & 4 & 15 & 61 & 22 & 26 & & \\
\hline 234 & 1 & 2 & 4 & 25 & 48 & 26 & 28 & 3 & 3 \\
\hline 235 & 2 & 2 & 4 & 28 & 77 & 23 & 22 & 4 & 7 \\
\hline 236 & 4 & 2 & 4 & 30 & 55 & 39 & 27 & 6 & 6 \\
\hline 237 & 4 & 2 & 4 & 29 & 69 & 43 & 72 & 5 & 6 \\
\hline 238 & 4 & 1 & 4 & 31 & 82 & 40 & 84 & 4 & 4 \\
\hline 239 & 4 & 1 & 4 & 33 & 62 & 42 & 54 & 4 & 6 \\
\hline 240 & 4 & 2 & 4 & 39 & 69 & 34 & 31 & 5 & 9 \\
\hline 241 & 3 & 2 & 4 & 34 & 72 & 41 & 53 & 4 & 5 \\
\hline 242 & 4 & 1 & 4 & 30 & 48 & 49 & 58 & 7 & 8 \\
\hline 243 & 3 & 2 & 4 & 18 & 43 & 32 & 45 & 6 & 6 \\
\hline 244 & 2 & 2 & 4 & 29 & 21 & 38 & 23 & 3 & 5 \\
\hline 245 & 2 & 2 & 4 & 29 & 31 & 21 & 20 & 4 & 3 \\
\hline 246 & 4 & 2 & 4 & 27 & 38 & 43 & 51 & 3 & 1 \\
\hline 247 & 2 & 1 & 4 & 28 & 78 & 47 & 40 & & \\
\hline 248 & 4 & 1 & 4 & 33 & 58 & 50 & 58 & 6 & 6 \\
\hline 249 & 2 & 2 & 4 & 26 & 24 & 39 & 29 & 2 & 1 \\
\hline
\end{tabular}


Table 7

Biology / Computer Literacy Raw Data

\begin{tabular}{|c|c|c|c|c|c|c|c|c|c|}
\hline STO & & & & BIO & BIO & COMP & COHP & STA & STA \\
\hline NOM & ETB & SBX & TEA & PRE & POST & PRB & POST & REA & MATB \\
\hline 250 & 2 & 2 & 4 & 25 & 56 & 45 & 23 & 6 & 2 \\
\hline 251 & 2 & 1 & 4 & 32 & 48 & 48 & 32 & & \\
\hline 252 & 2 & 2 & 4 & 36 & 78 & 45 & 46 & 4 & 6 \\
\hline 253 & 2 & 2 & 4 & 26 & 78 & 75 & 63 & & \\
\hline 254 & 3 & 2 & 4 & 58 & 78 & 42 & 81 & 8 & 9 \\
\hline 255 & 4 & 1 & 4 & 32 & 87 & 35 & 56 & 7 & 6 \\
\hline 256 & 4 & 1 & 4 & 29 & 89 & 44 & 86 & 5 & 6 \\
\hline 257 & 4 & 2 & 4 & 18 & 81 & 41 & 80 & 3 & 4 \\
\hline 258 & 3 & 2 & 4 & 31 & 18 & 44 & 23 & & \\
\hline 259 & 2 & 1 & 4 & 20 & 29 & 39 & 40 & 5 & 4 \\
\hline 260 & 2 & 2 & 4 & 30 & 39 & 48 & 32 & 5 & 5 \\
\hline 261 & 1 & 1 & 4 & 27 & 86 & 35 & 77 & 3 & 6 \\
\hline 262 & 2 & 2 & 4 & 24 & 60 & 22 & 26 & 3 & 1 \\
\hline 263 & 4 & 1 & 4 & 45 & 83 & 36 & 82 & & \\
\hline 264 & 3 & 2 & 4 & 26 & 21 & 34 & 58 & & \\
\hline 265 & 4 & 1 & 4 & 39 & 86 & 50 & 61 & 7 & 6 \\
\hline 266 & 3 & 2 & 4 & 48 & 68 & 79 & 78 & 6 & 5 \\
\hline 267 & 4 & 1 & 4 & 32 & 72 & 34 & 32 & 6 & 3 \\
\hline 268 & 4 & 2 & 4 & 36 & 56 & 30 & 54 & 8 & 6 \\
\hline 269 & 3 & 2 & 4 & 29 & 27 & 32 & 40 & 3 & 6 \\
\hline 270 & 4 & 1 & 4 & 40 & 65 & 20 & 40 & 8 & 8 \\
\hline 271 & 4 & 2 & 4 & 40 & 72 & 27 & 83 & 5 & 6 \\
\hline 272 & 2 & 1 & 4 & 32 & 53 & 37 & 67 & 5 & 5 \\
\hline 273 & 3 & 1 & 4 & 21 & 67 & 23 & 48 & 5 & 3 \\
\hline 274 & 4 & 1 & 4 & 29 & 44 & 32 & 39 & & \\
\hline 275 & 4 & 2 & 4 & 31 & 68 & 42 & 30 & 7 & 4 \\
\hline 276 & 4 & 2 & 4 & 31 & 54 & 65 & 73 & 5 & 4 \\
\hline 277 & 4 & 2 & 4 & 33 & 33 & 25 & 60 & 5 & 1 \\
\hline 278 & 3 & 2 & 4 & 22 & 58 & 27 & 56 & 4 & 3 \\
\hline 279 & 4 & 2 & 4 & 25 & 59 & 30 & 29 & 6 & 6 \\
\hline 280 & 4 & 2 & 4 & 26 & 59 & 23 & 40 & 8 & 8 \\
\hline 281 & 4 & 2 & 4 & 27 & 68 & 30 & 77 & 5 & 5 \\
\hline 282 & 4 & 2 & 4 & 18 & 65 & 12 & 78 & 2 & 1 \\
\hline 283 & 3 & 2 & 4 & 43 & 40 & 49 & 71 & 5 & 7 \\
\hline 284 & 3 & 2 & 4 & 21 & 67 & 22 & 33 & 6 & 7 \\
\hline 285 & 2 & 2 & 4 & 20 & 33 & 36 & 21 & 3 & 4 \\
\hline 286 & 4 & 1 & 4 & 14 & 83 & 44 & 60 & 6 & 7 \\
\hline 287 & 3 & 1 & 4 & 22 & 53 & 24 & 23 & 1 & 4 \\
\hline 288 & 4 & 1 & 4 & 26 & 62 & 32 & 28 & 5 & 3 \\
\hline 289 & 2 & 2 & 4 & 12 & 24 & 24 & 25 & 3 & 3 \\
\hline 290 & 3 & 2 & 4 & 28 & 48 & 31 & 66 & 4 & 5 \\
\hline 291 & 3 & 1 & 4 & 26 & 65 & 44 & 32 & 6 & 4 \\
\hline 292 & 3 & 2 & 4 & 27 & 66 & 38 & 33 & 4 & 6 \\
\hline 293 & 2 & 1 & 4 & 30 & 65 & 36 & 41 & 4 & 5 \\
\hline 294 & 4 & 1 & 4 & 39 & 67 & 66 & 73 & 7 & 8 \\
\hline 295 & 2 & 2 & 4 & 27 & 62 & 26 & 29 & 2 & 3 \\
\hline 296 & 4 & 2 & 4 & 34 & 67 & 32 & 67 & & \\
\hline 297 & 4 & 2 & 4 & 44 & 81 & 21 & 78 & & \\
\hline 298 & 4 & 2 & 2 & 35 & 77 & & & 7 & 6 \\
\hline 299 & 4 & 1 & 2 & 39 & 56 & & & 6 & 7 \\
\hline
\end{tabular}


Table 7

Biology / Computer Literacy Rav Data

\begin{tabular}{|c|c|c|c|c|c|c|c|c|c|}
\hline STU & & & & BIO & BIO & COMP & COMP & STA & STA \\
\hline NUY & ETYH & SEX & TEA & PRB & POST & PRB & POST & RBA & MATH \\
\hline 300 & 4 & 2 & 2 & 43 & 64 & & & 8 & 8 \\
\hline 301 & 4 & 1 & 2 & 45 & 69 & & & 8 & 7 \\
\hline 302 & 2 & 1 & 2 & 42 & 54 & & & 7 & 7 \\
\hline 303 & 2 & 1 & 2 & 34 & 66 & & & 6 & 5 \\
\hline 304 & 4 & 1 & 2 & 26 & 69 & & & 6 & 7 \\
\hline 305 & 3 & 2 & 2 & 46 & 72 & & & 7 & 6 \\
\hline 306 & 4 & 2 & 2 & 35 & 82 & & & & \\
\hline 307 & 1 & 2 & 2 & 45 & 65 & & & 6 & 9 \\
\hline 308 & 4 & 2 & 2 & 48 & 75 & & & 8 & 9 \\
\hline 309 & 4 & 2 & 2 & 24 & 58 & & & 8 & 8 \\
\hline 310 & 4 & 2 & 2 & 36 & 61 & & & 8 & 8 \\
\hline 311 & 4 & 2 & 2 & 47 & 61 & & & 8 & 9 \\
\hline 312 & 4 & 2 & 2 & 43 & 75 & & & 8 & 6 \\
\hline 313 & 3 & 1 & 2 & 38 & 55 & & & 7 & 9 \\
\hline 314 & 3 & 1 & 2 & 47 & 72 & & & 7 & 6 \\
\hline 315 & 2 & 2 & 2 & 31 & 47 & & & 6 & 4 \\
\hline 316 & 2 & 1 & 2 & 76 & 76 & & & 7 & 9 \\
\hline 317 & 4 & 1 & 2 & 31 & 75 & & & 6 & 7 \\
\hline 318 & 4 & 2 & 2 & 33 & 39 & & & 4 & 6 \\
\hline 319 & 3 & 2 & 2 & 28 & 74 & & & 5 & 5 \\
\hline 320 & 4 & 1 & 2 & 23 & 82 & & & 6 & 6 \\
\hline 321 & 4 & 2 & 2 & 44 & 46 & & & 5 & 5 \\
\hline 322 & 4 & 2 & 2 & 41 & 61 & & & 7 & 8 \\
\hline 323 & 3 & 1 & 2 & 44 & 71 & & & & \\
\hline 324 & 3 & 2 & 2 & 32 & 73 & & & & \\
\hline 325 & 4 & 2 & 2 & 46 & 68 & & & 6 & 9 \\
\hline 326 & 4 & 1 & 2 & 38 & 51 & & & 8 & 9 \\
\hline 327 & 4 & 1 & 2 & 35 & 77 & & & 7 & 5 \\
\hline 328 & 4 & 2 & 2 & 29 & 51 & & & 5 & 5 \\
\hline 329 & 2 & 1 & 2 & 41 & 83 & & & 6 & 5 \\
\hline 330 & 4 & 2 & 2 & 47 & 47 & & & 6 & 7 \\
\hline 331 & 4 & 1 & 2 & 36 & 54 & & & 5 & 6 \\
\hline 332 & 4 & 1 & 2 & 33 & 51 & & & 9 & 8 \\
\hline 333 & 2 & 1 & 2 & 45 & 67 & & & 7 & 5 \\
\hline 334 & 3 & 2 & 2 & 36 & 49 & & & 7 & 8 \\
\hline 335 & 4 & 1 & 2 & 28 & 87 & & & 6 & 6 \\
\hline 336 & 4 & 2 & 2 & 34 & 72 & & & & \\
\hline 337 & 4 & 1 & 2 & 35 & 59 & & & 7 & 9 \\
\hline 338 & 4 & 1 & 2 & 42 & 76 & & & 6 & 5 \\
\hline 339 & 4 & 1 & 2 & 36 & 74 & & & 5 & 5 \\
\hline 340 & 4 & 1 & 2 & 32 & 82 & & & 5 & 9 \\
\hline 341 & 4 & 1 & 2 & 39 & 56 & & & 6 & 7 \\
\hline 342 & 4 & 2 & 2 & 35 & 51 & & & 5 & 5 \\
\hline 343 & 4 & 2 & 2 & 43 & 65 & & & 9 & 7 \\
\hline 344 & 4 & 1 & 2 & 44 & 62 & & & 6 & 6 \\
\hline 345 & 2 & 1 & 2 & 29 & 85 & & & 6 & 5 \\
\hline 346 & 4 & 1 & 2 & 47 & 61 & & & 8 & 8 \\
\hline 347 & 2 & 1 & 2 & 34 & 65 & & & 8 & 8 \\
\hline 348 & 4 & 2 & 2 & 57 & 85 & & & 9 & 9 \\
\hline 349 & 4 & 2 & 2 & 51 & 64 & & & 8 & 6 \\
\hline
\end{tabular}


Table 7

Biology / Computer Literacy Raw Data

\begin{tabular}{|c|c|c|c|c|c|c|c|c|c|}
\hline STU & & & & BIO & BIO & COMP & COMP & STA & STA \\
\hline NUM & ETH & SEX & TEA & PRB & POST & PRB & POST & REA & MATH \\
\hline 350 & 3 & 2 & 2 & 47 & 57 & & & 6 & 9 \\
\hline 351 & 4 & 1 & 2 & 32 & 39 & & & 7 & 6 \\
\hline 352 & 2 & 1 & 2 & 28 & 44 & & & 6 & 7 \\
\hline 353 & 2 & 1 & 2 & 56 & 73 & & & 8 & 9 \\
\hline 354 & 4 & 2 & 2 & 44 & 70 & & & 7 & 6 \\
\hline 355 & 4 & 2 & 2 & 43 & 60 & & & 8 & 8 \\
\hline 356 & 3 & 1 & 2 & 35 & 65 & & & 9 & 9 \\
\hline 357 & 3 & 1 & 2 & 40 & 55 & & & 7 & 5 \\
\hline 358 & 4 & 1 & 2 & 37 & 85 & & & 8 & 5 \\
\hline 359 & 3 & 2 & 2 & 37 & 26 & & & 7 & 6 \\
\hline 360 & 4 & 1 & 2 & 31 & 45 & & & 7 & 6 \\
\hline 361 & 4 & 1 & 2 & 14 & 39 & & & 8 & 7 \\
\hline 362 & 4 & 2 & 2 & 48 & 80 & & & 7 & 9 \\
\hline 363 & 4 & 1 & 2 & 44 & 62 & & & 9 & 3 \\
\hline 364 & 4 & 2 & 2 & 49 & 68 & & & & \\
\hline 365 & 4 & 1 & 2 & 38 & 64 & & & 5 & 7 \\
\hline 366 & 4 & 1 & 2 & 39 & 70 & & & 6 & 7 \\
\hline 367 & 2 & 2 & 2 & 27 & 58 & & & 8 & 9 \\
\hline 368 & 4 & 1 & 2 & 35 & 45 & & & 7 & 7 \\
\hline 369 & 4 & 1 & 2 & 21 & 71 & & & & \\
\hline 370 & 4 & 2 & 2 & 38 & 48 & & & 5 & 7 \\
\hline 371 & 4 & 1 & 2 & 33 & 37 & & & 8 & 6 \\
\hline 372 & 2 & 1 & 2 & 19 & 45 & & & 4 & 7 \\
\hline 373 & 4 & 1 & 2 & 28 & 81 & & & 6 & 7 \\
\hline 374 & 4 & 2 & 2 & 49 & 68 & & & 9 & 9 \\
\hline 375 & 1 & 1 & 2 & 41 & 54 & & & 6 & 8 \\
\hline 376 & 4 & 2 & 2 & 35 & 49 & & & 6 & 7 \\
\hline 377 & 1 & 1 & 2 & 45 & 63 & & & 6 & 9 \\
\hline 378 & 4 & 1 & 2 & 32 & 63 & & & 7 & 7 \\
\hline 379 & 3 & 1 & 2 & 31 & 67 & & & 7 & 8 \\
\hline 380 & 4 & 1 & 2 & 26 & 63 & & & 5 & 6 \\
\hline 381 & 4 & 2 & 2 & 38 & 61 & & & 6 & 6 \\
\hline 382 & 4 & 1 & 2 & 39 & 84 & & & 7 & 6 \\
\hline 383 & 4 & 2 & 2 & 34 & 47 & & & & \\
\hline 384 & 4 & 1 & 2 & 33 & 67 & & & 9 & 7 \\
\hline 385 & 4 & 1 & 2 & 33 & 53 & & & 7 & 5 \\
\hline 386 & 4 & 2 & 2 & 39 & 89 & & & 7 & 6 \\
\hline 387 & 4 & 2 & 2 & 44 & 58 & & & 8 & 8 \\
\hline 388 & 4 & 1 & 2 & 39 & 68 & & & 7 & 7 \\
\hline 389 & 4 & 2 & 2 & 32 & 43 & & & 2 & 7 \\
\hline 390 & 2 & 2 & 2 & 31 & 47 & & & 6 & 8 \\
\hline 391 & 3 & 1 & 2 & 50 & 60 & & & 7 & 7 \\
\hline 392 & 4 & 1 & 2 & 30 & 85 & & & 6 & 6 \\
\hline 393 & 4 & 1 & 2 & 32 & 81 & & & 6 & 6 \\
\hline 394 & 4 & 1 & 2 & 46 & 68 & & & 7 & 8 \\
\hline 395 & 3 & 1 & 2 & 33 & 59 & & & 5 & 5 \\
\hline 396 & 2 & 1 & 2 & 29 & 53 & & & 7 & 6 \\
\hline 397 & 4 & 1 & 2 & 19 & 31 & & & 5 & 5 \\
\hline 398 & 4 & 2 & 2 & 44 & 80 & & & 8 & 9 \\
\hline 399 & 2 & 2 & 2 & 39 & 81 & & & 6 & 8 \\
\hline
\end{tabular}


Table 7

Biology / Computer Literacy Raw Data

\begin{tabular}{|c|c|c|c|c|c|c|c|c|c|}
\hline STU & & & & BIO & BIO & COMP & COMP & STA & STA \\
\hline NUM & BTH & SBX & TBA & PRE & POST & PRB & POST & RBA & MATE \\
\hline 400 & 4 & 1 & 2 & 49 & 80 & & & 9 & 8 \\
\hline 401 & 4 & 1 & 2 & 36 & 55 & & & 5 & 6 \\
\hline 402 & 4 & 2 & 2 & 59 & 77 & & & 8 & 6 \\
\hline 403 & 4 & 2 & 2 & 35 & 45 & & & 9 & 7 \\
\hline 404 & 4 & 1 & 2 & 42 & 63 & & & 6 & 8 \\
\hline 405 & 4 & 2 & 2 & 48 & 63 & & & 8 & 8 \\
\hline 406 & 4 & 2 & 2 & 48 & 63 & & & 8 & 8 \\
\hline 407 & 4 & 2 & 2 & 46 & 34 & & & 8 & 6 \\
\hline 408 & 4 & 2 & 2 & 43 & 62 & & & 6 & 8 \\
\hline 409 & 4 & 2 & 2 & 32 & 66 & & & 7 & 8 \\
\hline 410 & 4 & 1 & 2 & 34 & 68 & & & 6 & 6 \\
\hline 411 & 4 & 1 & 2 & 36 & 75 & & & & \\
\hline 412 & 4 & 2 & 2 & 35 & 41 & & & 6 & 6 \\
\hline 413 & 3 & 2 & 2 & 49 & 70 & & & 7 & 7 \\
\hline 414 & 3 & 2 & 2 & 27 & 89 & & & 5 & 5 \\
\hline 415 & 4 & 1 & 2 & 32 & 85 & & & 5 & 5 \\
\hline 416 & 4 & 1 & 2 & 41 & 59 & & & 6 & 5 \\
\hline 417 & 4 & 1 & 2 & 40 & 55 & & & 6 & 5 \\
\hline 418 & 4 & 2 & 2 & 46 & 68 & & & 8 & 7 \\
\hline 419 & 4 & 2 & 2 & 40 & 54 & & & 6 & 6 \\
\hline 420 & 4 & 2 & 2 & 40 & 56 & & & 6 & 5 \\
\hline 421 & 3 & 1 & 2 & 47 & 51 & & & 8 & 6 \\
\hline 422 & 4 & 2 & 2 & 37 & 52 & & & & \\
\hline 423 & 3 & 2 & 2 & 35 & 60 & & & 7 & 6 \\
\hline 424 & 3 & 2 & 2 & 2 & 23 & & & & \\
\hline 425 & 4 & 1 & 2 & 35 & 52 & & & 8 & 6 \\
\hline 426 & 4 & 1 & 2 & 25 & 47 & & & 6 & 5 \\
\hline 427 & 4 & 2 & 2 & 31 & 46 & & & 6 & 9 \\
\hline 428 & 4 & 2 & 2 & 47 & 61 & & & 6 & 9 \\
\hline 429 & 3 & 1 & 2 & 49 & 76 & & & & \\
\hline 430 & 4 & 2 & 2 & 40 & 66 & & & 8 & 7 \\
\hline 431 & 2 & 2 & 2 & 29 & 46 & & & 7 & 7 \\
\hline 432 & 4 & 2 & 2 & 34 & 8 & & & 5 & 8 \\
\hline 433 & 4 & 1 & 2 & 30 & 91 & & & 6 & 6 \\
\hline 434 & 4 & 1 & 2 & 40 & 83 & & & 8 & 8 \\
\hline 435 & 4 & 1 & 2 & 44 & 61 & & & & \\
\hline 436 & 4 & 2 & 2 & 37 & 47 & & & 6 & 8 \\
\hline 437 & 4 & 2 & 2 & 32 & 78 & & & 9 & 8 \\
\hline 438 & 2 & 1 & 2 & 37 & 79 & & & 7 & 5 \\
\hline 439 & 4 & 2 & 2 & 25 & 42 & & & 6 & 6 \\
\hline
\end{tabular}


. 

作, 